Geração de redes vasculares sintéticas tridimensionais utilizando sistemas de Lindenmayer estocásticos e parametrizados

\author{
Miguel Ángel Galarreta Valverde
}

DisSERTAÇÃO APRESENTADA

AO

Instituto DE MATEMÁticA e EstatísticA

DA

UNIVERSIDADE DE SÃO PAULO

PARA

OBTENÇÃO DO TÍTULO

$\mathrm{DE}$

Mestre EM CiÊnCIAS

Programa: Ciência da Computação

Orientador: Prof. Dr. Marcel Parolin Jackowski

Durante o desenvolvimento deste trabalho o autor recebeu auxílio financeiro da CAPES

São Paulo, novembro de 2012 


\title{
Geração de redes vasculares sintéticas tridimensionais utilizando sistemas de Lindenmayer estocásticos e parametrizados
}

\author{
Esta tese/dissertação contém as correções e alterações \\ sugeridas pela Comissão Julgadora durante a defesa \\ realizada por Miguel Ángel Galarreta Valverde em 09/11/2012. \\ O original encontra-se disponível no Instituto de \\ Matemática e Estatística da Universidade de São Paulo.
}

Comissão Julgadora:

- Prof. Dr. Marcel Parolin Jackowski (orientador) - IME-USP

- Prof. Dr. Ronaldo Fumio Hashimoto - IME-USP

- Prof. Dr. Marco Antonio Gutierrez - INCOR 


\section{Agradecimentos}

Este trabalho não teria sido possível sem a ajuda e colaboração de inúmeras pessoas, Meus mais profundos agradecimentos a os meus pais Miguel e Felicitas, pelo apojo em cada uma das etapas da minha vida, pelo carinho e educação que me deram, e por ser um exemplo de família. A minha irmã Sheyla por alimentar o meu espirito da competição e acreditar em mim. A minha namorada Mariela, por ser o meu sustento emocional, que apesar dos muitos quilômetros de distancia é minha companhia em tudo momento, por seu amor, paciência e compreensão.

Agradeço profundamente ao professor Marcel Jackowski, por aceitar ser o meu orientador por seus conselhos, comentários e sua paciência. Agradeço a os professores Ronaldo Fumio Hashimoto, Marco Antonio Gutierrez e Roberto Hirata por todas as recomendações e correções dadas na qualificação e na defesa do mestrado.

Agradeço a Maysa por suas opiniões, comentários e correções. A David por sua paciência e correções, e a todos os amigos que em algum momento me ajudaram com revisões: Geiser, Jesus, Jihan, Luis, Rosario e William.

Agradeço aos amigos e companheiros do laboratório de visão: Amanda, Daniel, David, Edwin, Evelyn, Frank, Gesiele, Jihan, Jorge, Leandro, Leissi, Lucy, Luis, Renato, Rosario, Silvia, Talita e William. Aos amigos do IME-USP: Alfonso, Alvaro, Anderson, Antonio, Boris, Carlos, Edith, Erika, Fabio, Felipe, Geiser, Juan, Mijail, Pablo, Rafael, Toshi, Renzo , Jesus, pelos bons momentos que passamos juntos.

Aos meus amigos Edu e Reynaldo, com os quais comecei essa aventura do mestrado, por sua amizade e companhia nos bons e maus momentos. Finalmente quero agradecer a todos aqueles não nomeados, mas que brindaram seu inestimável apoio e sua presença o meu reconhecimento e agradecimento. 


\section{Resumo}

\section{GALARRETA-VALVERDE, MIGUEL A. Geração de redes vasculares sintéticas tridimensi-}

onais utilizando sistemas de Lindenmayer estocásticos e parametrizados. 2012.81 f. Dissertação (Mestrado) - Instituto de Matemática e Estatística, Universidade de São Paulo, São Paulo, 2012.

As imagens de angiografia por ressonância magnética (angio-RM) ou por tomografia computadorizada (angio-TC) permitem uma análise minuciosa das redes vasculares. A segmentação de redes vasculares a partir de tais imagens é uma das tarefas iniciais no diagnóstico de doenças vasculares como estenoses ou aneurismas. Porém, a grande diversidade de arquiteturas dos vasos dificulta a validação dos algoritmos de segmentação. Assim, a construção de redes vasculares sintéticas realistas permitem validar novas metodologias de segmentação de vasos. Este trabalho descreve uma metodologia de geração de redes vasculares sintéticas em três dimensões utilizando sistemas de Lindenmayer (L-systems) estocásticos. Para atingir esse objetivo, foram implementados um analisador léxico, um analisador sintático e um gerador de L-systems para a criação de vasos sintéticos baseado em gramáticas. A parametrização destas gramáticas possibilita a simulação de características naturais de vasos reais como o ângulo de bifurcação, comprimento, diâmetro médio e possibilita a simulação de anomalias vasculares. As expressões resultantes são utilizadas para criar imagens angiográficas sintéticas que simulam a distribuição de intensidades dos vasos em imagens angio-RM e angio-TC reais. As redes vasculares sintéticas podem também ser delimitadas por superfícies 3D arbitrárias de forma similar à geometria de órgãos. A flexibilidade de parametrização e natureza estocástica desta metodologia faz com que ela se torne uma ferramenta ideal para a validação de algoritmos de segmentação de vasos em imagens angiográficas.

Palavras-chave: redes vasculares sintéticas, angiografia, sistema de Lindenmayer estocástico. 


\section{Abstract}

GALARRETA-VALVERDE, MIGUEL A. Three-dimensional synthetic blood vessels generation using stochastic Lindenmayer systems. 2012. 81 f. Dissertação (Mestrado) - Instituto de Matemática e Estatística,Universidade de São Paulo, São Paulo, 2012.

Magnetic resonance angiography (MRA) or computed tomography angiography (CTA) images allow for a thorough analysis of the blood vessels. Vessel segmentation from MRA or CTA is thus the primary task in the diagnosis of vascular diseases such as stenosis and aneurysms. The wide architectural variability of the blood vessels, however, hinders the validation of vascular segmentation methods. The construction of synthetic realistic vascular architecture trees will aid in the validation of new vessel segmentation methodologies. This thesis describes a three-dimensional synthetic blood vessel generation methodology that employs stochastic Lindenmayer systems (L-systems). For this purpose, we implemented a parser and a generator of L-systems to create grammars that represent blood vessel architectures. The parameterization of the grammar allows one to simulate natural features of real vessels such as bifurcation angle, average length and diameter, and also accounts for vascular anomalies. The resulting expressions are used to create synthetic angiographic images that mimic real vessel intensity distributions in MRA and CTA. Blood vessel growth can also be delimited by arbitrary 3D surfaces that may represent organ geometries. The flexibility in the parameterization and stochastic nature of this methodology makes it an ideal tool for the validation of blood vessel segmentation algorithms from angiographic images.

Keywords: L-system, stochastic L-system, synthetic blood vessels, vasculature. 


\section{Sumário}

$\begin{array}{ll}\text { Lista de Abreviaturas } & \text { ix }\end{array}$

Lista de Figuras $\quad$ xi

1 Introdução 1

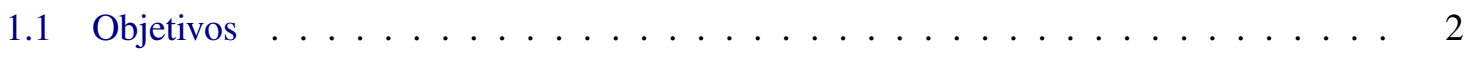

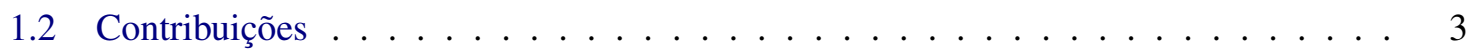

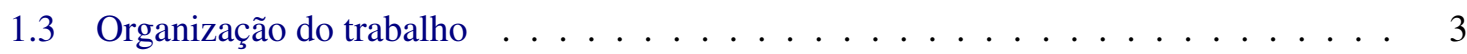

2 Conceitos 5

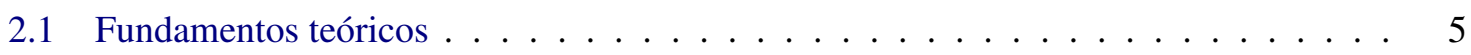

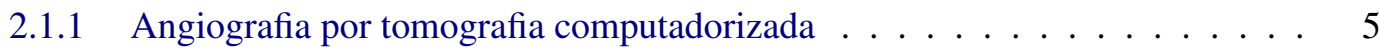

2.1.2 Angiografia por ressonância magnética . . . . . . . . . . . . . . 6

2.1.3 Rede vascular sintética . . . . . . . . . . . . . . . . . . 6

2.1.4 Criação de redes vasculares sintéticas . . . . . . . . . . . . . . . . . 7

2.1.5 Ramificação de redes vasculares . . . . . . . . . . . . . . . . 7

2.1.6 Esqueleto de redes vasculares . . . . . . . . . . . . . . . . . 8

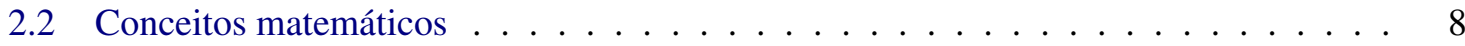

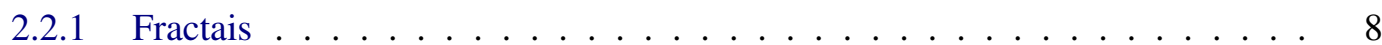

2.2.2 Conceitos básicos de autômatos . . . . . . . . . . . . . . 8

2.2.3 Sistema de Lindenmayer (L-systems) _ . . . . . . . . . . . . . . . . . . 9

2.3 Produção de cadeias a partir dos L-systems . . . . . . . . . . . . . . . . 12

2.3.1 Analisador léxico . . . . . . . . . . . . . . . . . . . . . . . . . 12

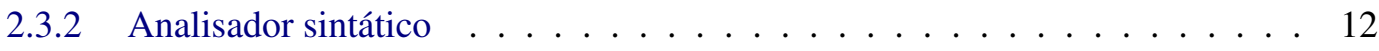

3 Metodologia 13

3.1 Definição da gramática e parâmetros . . . . . . . . . . . . . . . . . . . 13

3.1.1 Variáveis iniciais . . . . . . . . . . . . . . . . . . . . . . . 14

$3.1 .2 \quad \mathrm{O}$ alfabeto . . . . . . . . . . . . . . . . . . . . 15

3.1 .3 Definição da gramática . . . . . . . . . . . . . . . . . . . . . 16

3.1 .4 Formato do arquivo de entrada . . . . . . . . . . . . . . . . . 17

3.2 Geração de cadeias . . . . . . . . . . . . . . . . . . . . . . . . . . . . 19

3.2.1 Produção da cadeia final . . . . . . . . . . . . . . . . . . . . . . . . . . 19 
3.2.2 Cálculo das palavras reservadas . . . . . . . . . . . . . . . 24

3.3 Geração da rede vascular . . . . . . . . . . . . . . . . . . . 25

3.3.1 Instruções e seus parâmetros . . . . . . . . . . . . . . 25

3.4 Discretização . . . . . . . . . . . . . . . . . . . . . . . 28

3.4.1 Definição dos parâmetros . . . . . . . . . . . . . . 29

3.4 .2 Normalização dos pontos da RV . . . . . . . . . . . . . . . . . . 29

3.4 .3 Obtenção do esqueleto da RV . . . . . . . . . . . . . . . 29

3.4 .4 Adição de volume . . . . . . . . . . . . . . . . . . 30

3.5 Complexidade computacional ..................... 33

4 Resultados $\quad 35$

4.1 Resultados da geração de cadeias . . . . . . . . . . . . . . . . . . . . 35

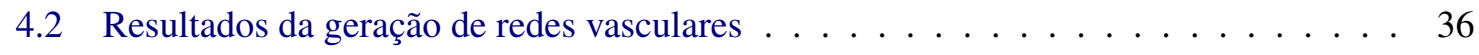

4.2.1 Controle de restrições . . . . . . . . . . . . . . . . . . 37

4.3 Resultados da discretização . . . . . . . . . . . . . . . . . . . . . 4 41

4.3.1 Exemplos do banco de imagens sintéticas criadas . . . . . . . . . . . 45

5 Conclusões $\quad 49$

5.1 Limitações e pesquisas futuras . . . . . . . . . . . . . . . . . . . 49

$\begin{array}{llr}\text { A Tokens e definições do analisador sintático } & 51\end{array}$

A.1 Relação de tokens . . . . . . . . . . . . . . . . . . . . . . 51

A.2 Definições do analisador sintático . . . . . . . . . . . . . . . . . 52

B Algoritmos desenvolvidos $\quad 55$

B.1 Classe libGenerator ..................... . . 55

$\begin{array}{llr}\text { C Dados adicionais } & \mathbf{5 7}\end{array}$

C.1 Código intermediário gerado . . . . . . . . . . . . . . . . . . . 57

C.2 Arquivos, gramáticas e valores de entrada utilizados . . . . . . . . . . . . . . . 58

C.2.1 Arquivo de entrada para geração de vasos no fígado . . . . . . . . . . . 58

C.2.2 Arquivo de entrada para geração de vasos na perna . . . . . . . . . . . . 59

$\begin{array}{lr}\text { D Publicações } & 61\end{array}$

$\begin{array}{ll}\text { Referências Bibliográficas } & 63\end{array}$

$\begin{array}{lr}\text { Índice Remissivo } & 67\end{array}$ 


\title{
Lista de Abreviaturas
}

\author{
Angio-RM Angiografia por Ressonância Magnética \\ Angio-TC Angiografia por Tomografia Computadorizada \\ RM Ressonância Magnética \\ RV Rede Vascular \\ TC Tomografia Computadorizada \\ MIP Projeção de Intensidade Máxima
}




\section{Lista de Figuras}

2.1 Exemplos de imagens de angiografia por TC mostrando os pulmões e o coração. . . . 5

2.2 Exemplos de imagens de angiografia por RM . . . . . . . . . . . . . . 6

2.3 Parâmetros de bifurcação . . . . . . . . . . . . . . . . . . . 8

2.4 Três iterações da curva de Koch. . . . . . . . . . . . . . . . . . . . . . . . . . 10

3.1 Esquema representativo da metodologia . . . . . . . . . . . . . . . . . . . . . . . . 14

3.2 Esquema representativo dos resultados obtidos em cada uma das etapas de geração das RVs. . . . . . . . . . . . . . . . . . . . . . . . . . . . 15

3.3 Resultado da execução de uma gramática simples. . . . . . . . . . . . . . . . . . 17

3.4 Exemplo do conteúdo de um arquivo de entrada . . . . . . . . . . . . . . . . . . 20

3.5 Telas do editor básico de arquivos de entrada. . . . . . . . . . . . . . . . 21

3.6 Estrutura do gerador de cadeias. . . . . . . . . . . . . . . . . . . . . 22

3.7 Árvore de análise sintática obtida a partir de uma regra . . . . . . . . . . . . . . . 23

3.8 Etapas no controle da geração de um novo ponto considerando restrições. . . . . . . . 27

3.9 Fluxo da discretização. . . . . . . . . . . . . . . . . . . . . . . . 28

3.10 Captura de tela do formulário de discretização. . . . . . . . . . . . . . . . . . 30

3.11 Sequência de geração do esqueleto no caso que o segmento possuir sub-segmentos. . 31

3.12 Gráfico da função Gaussiana para um raio igual a 3 . . . . . . . . . . . . . . . . . 32

3.13 Gráfico da função sigmoides . . . . . . . . . . . . . . . . . . . 32

3.14 Esqueleto e imagem com volume por distribuição gaussiana . . . . . . . . . . . . 33

4.1 Desenho dos segmentos gerados a partir de três gramáticas na sua terceira iteração. . 37

4.2 Desenho dos segmentos gerados para a execução de duas gramáticas na sua sexta iteração. . . . . . . . . . . . . . . . . . . . . . . . . . . 37

4.3 Desenho dos segmentos de uma RV vista de ângulos distintos, gerada a partir da execução da terceira gramática mostrada na Tabela 4.3 na sua sexta iteração. . . . . . . 38

4.4 Superfície sintética formada por dois cilindros. . . . . . . . . . . . . . . . . . . . 39

4.5 RV sintética gerada dentro de um contexto limitado por cilindros. . . . . . . . . . . . 39

4.6 RV sintética gerada dentro de uma superfície obtida a partir da segmentação de um

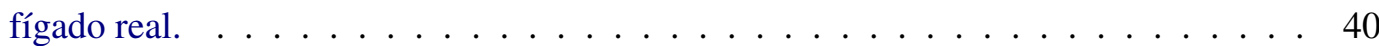

4.7 RV sintética gerada dentro de um espaço limitado por duas superfícies, uma da segmentação dos músculos da perna e outra do fêmur. . . . . . . . . . . . . . . . . . . 41 
4.8 Projeção MIP de uma RV sintética gerada dentro de uma superfície obtida a partir de uma segmentação de um fígado real. . . . . . . . . . . . . . . . . . . . . 42

4.9 RV sintética gerada dentro de um espaço limitado por duas superfícies, uma da segmentação dos músculos da perna e outra do fêmur . . . . . . . . . . . . . . . . . . 43

4.10 Comparação de duas RVs criadas com e sem interpolações. . . . . . . . . . . . . . . 44

4.11 Forma de um segmento gerado pela gramática: $F \rightarrow f(x)+(\theta) f(x)-(\theta) f(x)-$

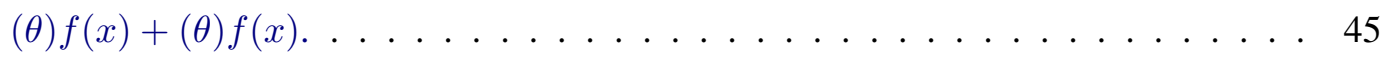




\section{Capítulo 1}

\section{Introdução}

As imagens de angiografia por ressonância magnética (angio-RM) ou por tomografia computadorizada (angio-TC) permitem uma análise minuciosa das redes vasculares (RV). No entanto, devido à sua natureza tridimensional e ao grande volume de tais imagens, são necessárias ferramentas automatizadas que auxiliem o radiologista no diagnóstico de possíveis anomalias ou patologias do sistema circulatório, as quais vem aumentando nos últimos anos em países desenvolvidos e em desenvolvimento [Chagas et al., 2009].

A delineação de redes vasculares é a tarefa inicial em muitas aplicações práticas como o diagnóstico de doenças vasculares (estenoses ou malformações). Os algoritmos de segmentação de redes vasculares são componentes-chave dos sistemas de diagnóstico radiológico automatizado [Cemil Kirbas, 2003]. Porém, a inexistência de um método de segmentação que seja eficaz para todas as modalidades de imagens angiográficas torna-se um problema para a análise vascular.

Uma vez que as trajetórias dos vasos e seus diâmetros são extraídos das imagens, é necessário que tais informações sejam analisadas. Dados como o número médio de bifurcações por segmento, diâmetro médio dos segmentos, nível de ramificação, entre outros servirão como uma base de conhecimento que será gerada a partir da extração das trajetórias e diâmetros das imagens angiográficas. Tais informações serão utilizadas no auxílio ao diagnóstico de problemas vasculares e possibilitarão a comparação entre quadros anteriores e posteriores a tratamentos e intervenções.

A grande variabilidade das redes vasculares em sistemas orgânicos complica ainda mais a sua extração e quantificação a partir de imagens angiográficas. Como consequência, estes algoritmos necessitam de validação. Para fazer a validação dessas técnicas teríamos que ter uma forma de comparar os resultados obtidos com os valores conhecidos. Para realizar essa tarefa poderíamos utilizar imagens phantom, que são imagens obtidas pelos processos normais de tomografia computadorizada (TC) ou ressonância magnética (RM), mas utilizando modelos físicos que imitam as características do corpo humano. Entretanto, esse método necessita de modelos sofisticados e às vezes caros e tem a desvantagem de possuírem uma estrutura fixa. Outro método para se obter imagens sintéticas de redes vasculares é gerá-las matematicamente, o qual oferece a vantagem de custo, tempo e a flexibilidade de modificar a rede vascular com diferentes configurações e até possibilitando adicionar anomalias na rede vascular.

Além dessa grande vantagem, o fato de ter uma rede vascular sintética poderia até facilitar a 
simulação de cirurgias, reduzindo assim os riscos dos procedimentos invasivos [Liu et al., 2010].

Desde o começo do século XX, o comportamento das ramificações em RV é motivo de estudo. No trabalho de Murray [1926] é descrito o comportamento das bifurcações de RV, dizendo que é possível utilizar estudos como base para a obtenção de parâmetros e entendimento da estrutura de uma RV. Zamir [1976] faz uma abordagem sobre a estrutura de RV e como se comportam as bifurcações para ocupar o maior espaço possível com a finalidade de otimizar ao máximo a distribuição de sangue no corpo. Posteriormente, foram realizadas muitas pesquisas comparando o comportamento de algumas estruturas da natureza incluindo as redes vasculares com o comportamento de fractais [Campbell e Abhyankar, 1978; Mandelbrot e Aizenman, 1979]. Essas pesquisas foram aprofundadas no campo da anatomia de modo que uma rede vascular compartilhe características em cada uma das suas bifurcações. Zamir [1999] propõe utilizar fractais no modelamento de RV sintéticas. Posteriormente, o Zamir [2001] melhorou essa ideia e sugeriu utilizar sistemas de Lindenmayer ( $L$ systems), os quais estão baseados em regras. Ele também elaborou algumas gramáticas e adicionou algumas variáveis aleatórias para a geração de RV sintéticas. No entanto, até esse momento, as redes vasculares sintéticas geradas eram só em duas dimensões e não utilizavam variáveis estocásticas ou distribuição de probabilidades nas escolhas de valores aleatórios.

Liu et al. [2010] introduziu a ideia de utilizar sistemas de Lindenmayer estocásticos para a geração de redes vasculares em duas dimensões e apresentou também parâmetros variáveis. No entanto, não utilizou distribuições estocásticas no seu trabalho mas utilizou valores aleatórios dentro de intervalos definidos. Além disso, não utilizou regras estocásticas para a geração das cadeias.

Apesar dos trabalhos anteriores terem sido feitos para RV em duas dimensões, o comportamento dos sistemas de Lindenmayer em três dimensões já é estudado em simulações de ramificações de plantas e flores [Jacob, 1995; Kókai et al., 1999a; Qi et al., 2011].

Nossa metodologia pretende aprimorar as metodologias anteriores utilizando os sistemas de Lindenmayer paramétricos e estocásticos para gerar redes vasculares sintéticas em três dimensões, parametrizando também o número de divisões que uma bifurcação pode ter.

Adicionalmente, foi desenvolvido um aplicativo de visualização e implementado um algoritmo de discretização da RV baseado no algoritmo de Bresenham [Bresenham et al., 1986] e de interpolação utilizando B-Splines cúbicas [Piegl, 1989] para gerar imagens similares às imagens geradas por angio-RM ou angio-TC. Assim, as imagens sintéticas que este trabalho permite criar, faz desta metodologia uma ferramenta ideal para a validação de algoritmos de segmentação de vasos em imagens angiográficas. Não obstante, a metodologia descrita possibilitará a simulação de cirurgias e pesquisas sobre anomalias em vasos.

\subsection{Objetivos}

O objetivo principal dessa dissertação é criar uma metodologia de geração de redes vasculares sintéticas em três dimensões utilizando $L$-systems estocásticos, que possam ser utilizadas como ferramentas para a avaliação de algoritmos de segmentação de redes vasculares a partir de imagens de angio-RM e angio-TC.

Como objetivos específicos dessa dissertação estão: 
1. Elaboração de uma metodologia de geração de redes vasculares sintéticas realistas.

2. Adaptação dos modelos de geração existentes em 2D para 3D.

3. Restrição do crescimento dos ramos dentro de espaços limitados por superfícies.

4. Geração de imagens sintéticas baseadas nas redes vasculares sintéticas geradas.

5. Geração de arquivos que assistam à validação de algoritmos de segmentação (esqueleto das $\mathrm{RVs})$.

6. Simulação de anormalidades como aneurismas e estenoses nos vasos sintéticos gerados.

\subsection{Contribuições}

As principais contribuições deste trabalho são as seguintes:

1. Permitir a geração de redes vasculares sintéticas realistas, nas quais se tenta respeitar as dimensões, estrutura, geometria e demais características próprias de uma RV real.

2. Melhora dos métodos atuais de geração de vasos sintéticos para a criação em três dimensões.

3. Desenvolvimento de um método de controle de crescimento para respeitar superfícies que restringem o crescimento.

4. Possibilitar a criação de uma base de dados de redes vasculares sintéticas para poder ser utilizado por outros pesquisadores para a avaliação dos seus próprios algoritmos, métodos ou aplicativos.

5. Propiciar avanços de estudos sobre anomalias e envelhecimento de RV e auxiliar em cirurgias virtuais.

\subsection{Organização do trabalho}

No Capítulo 2, apresentamos os conceitos básicos de L-systems, bases matemáticas e técnicas para o cálculo de bifurcações e comprimentos de segmentos de RV, necessárias para o entendimento da metodologia proposta.

No Capítulo 3 apresentam-se a metodologia desenvolvida, desde a definição do alfabeto e a gramática, geração e criação das redes vasculares sintéticas, até o método de criação das suas imagens.

No Capítulo 4 mostram-se resultados experimentais do método proposto, etapa por etapa, começando desde a produção de gramáticas até a geração das imagens finais.

No Capítulo 5 discutimos algumas conclusões obtidas neste trabalho, analisando as vantagens e desvantagens do método proposto para a geração de RV sintéticas. Finalmente, sugerimos algumas pesquisas futuras como continuação do trabalho. 



\section{Capítulo 2}

\section{Conceitos}

\subsection{Fundamentos teóricos}

\subsubsection{Angiografia por tomografia computadorizada}

A angiografia por tomografia computadorizada é uma técnica de imageamento que utiliza radiação ionizante durante o processo de emissão de energia. Essa técnica consiste na emissão de uma série de raios-X, radiação essa que os tecidos absorvem e refletem de forma diferente. Os ossos, em particular, a absorvem muito, tornando-se muito destacados neste tipo de imagem. A imagem é reconstruída a partir das projeções desses raios em cortes tomográficos. As estruturas internas do corpo são visualizadas a partir de uma série de cortes transversais que são posteriormente montados pelo computador para formar uma imagem 3D. As imagens de angiografia por tomografia usualmente são adquiridas ministrando ao paciente um contraste endovenoso que realça o fluxo de sangue deixandoo radio-opaco, já que o sangue, por si só, não resulta em uma atenuação do sinal [Suetens, 2009]. Dois exemplos de angio-TC são mostrados na Figura 2.1.

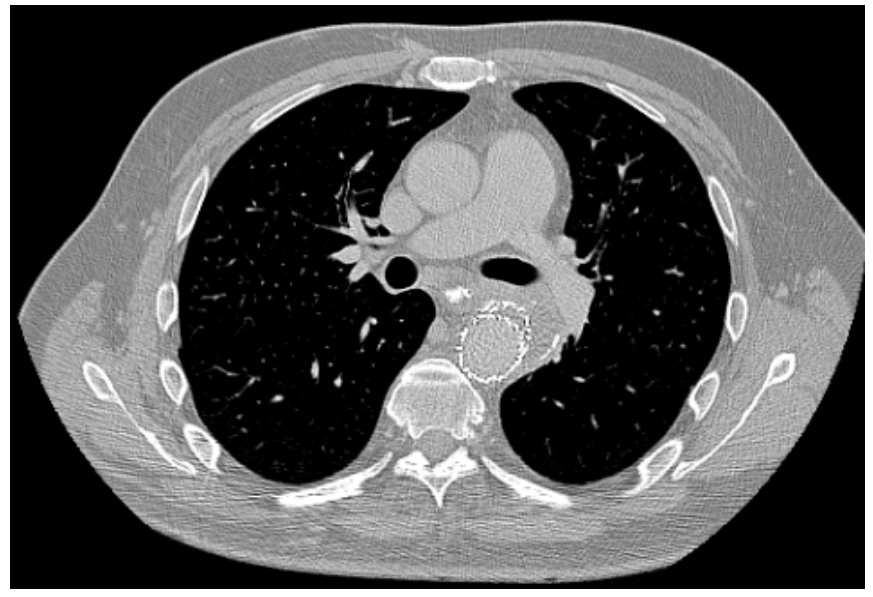

(a)

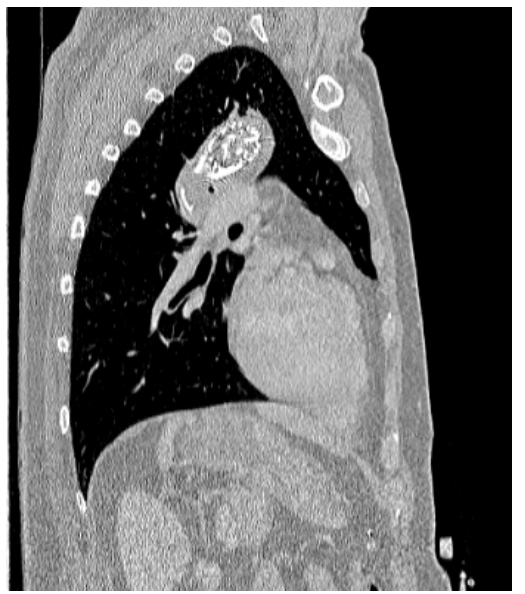

(b)

Figura 2.1: Exemplos de imagens de angiografia por TC mostrando os pulmões e o coração, a) Corte axial, b) Corte sagital. 


\subsubsection{Angiografia por ressonância magnética}

Angiografia por ressonância magnética é uma técnica de imageamento que não utiliza radiação ionizante. Inicialmente foi inventada como uma técnica de espectrografia e mais tarde implementada como técnica de aquisição de imagens. Esta técnica consiste na emissão e recebimento de ondas de rádio em um campo magnético que orienta átomos de hidrogênio. Durante a fase de recebimento de energia, os núcleos de hidrogênio ficam instáveis e, após essa fase, passam a emitir energia em que sua intensidade vai diferir de acordo com o tempo de recebimento de energia e com o tipo de tecido em que esses núcleos estão presentes. Assim como na tomografia computadorizada, a imagem é normalmente dividida em tomos que formam uma imagem 3D. A angio-RM pode ser adquirida de três formas: contraste de fase, time-of-flight ou contraste endovenoso [Suetens, 2009]. Um exemplo de angio-RM de visões diferentes e sua projeção são mostrados na Figura 2.2.
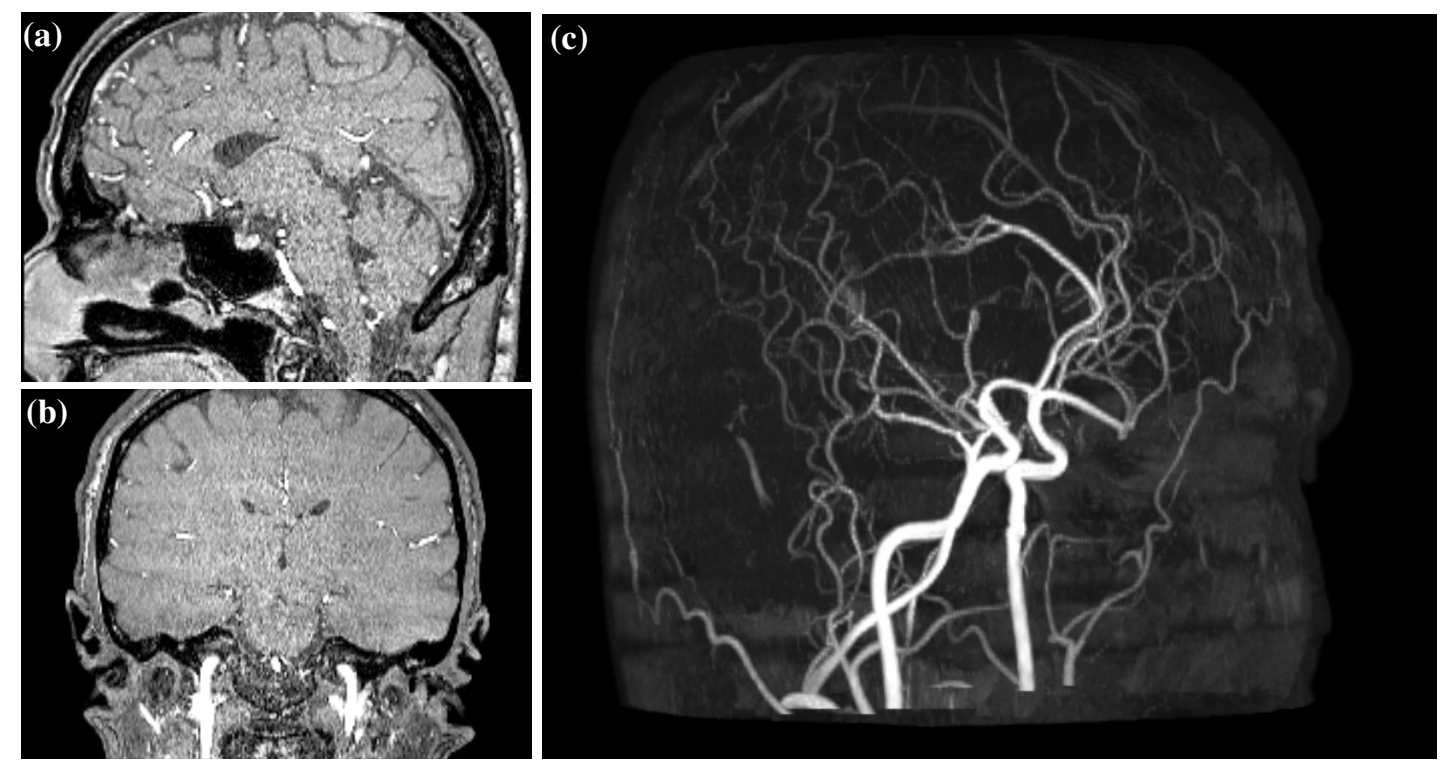

Figura 2.2: Exemplos de imagens de angiografia por RM da cabeça. a) Corte sagital. b) Corte coronal. c) Projeção de máxima intensidade.

\subsubsection{Rede vascular sintética}

É uma rede vascular (RV) gerada artificialmente, de modo que suas caraterísticas (diâmetro, comprimento e posição) são conhecidas a priori. Uma rede vascular sintética ideal é aquela com características mais próximas das caraterísticas das RVs do corpo humano.

A unidade básica estrutural de uma RV é o segmento de rede vascular, o qual pode estar formado por sub-segmentos unidos em forma sequencial. Os pontos em que três ou mais segmentos são conectados são conhecidos como ramificações. 


\subsubsection{Criação de redes vasculares sintéticas}

A criação de redes vasculares sintéticas tem sido estudada usando diferentes abordagens, mas os principais métodos para sua geração são os baseados em L-systems e os baseados em crescimento iterativo [Hamarneh e Jassi, 2010].

Os métodos baseados em L-systems estão definidos de acordo com uma gramática que controla a criação de ramificações e torção dos segmentos, enquanto que os baseados em crescimento iterativo seguem modelos fisiológicos [Szczerba e Székely, 2002].

Apesar dos modelos fisiológicos apresentarem bons resultados, é preciso fazer um estudo individual do comportamento de cada um dos fatores requeridos. Além disso, os L-systems oferecem uma maior flexibilidade, obtendo comportamentos diferentes mudando apenas a gramática.

\subsubsection{Ramificação de redes vasculares}

Uma RV consiste inicialmente de um segmento de RV que, após um certo comprimento $(l)$, divide-se em novas ramificações e cada uma das novas ramificações comporta-se de forma igual, cada um dos segmentos depois da bifurcação tem um ângulo de inclinação com respeito ao segmento principal, num ambiente de duas dimensões a inclinação será delimitada por um ângulo para cada um dos segmentos filhos $\theta_{1}$ e $\theta_{2}$. Esses ângulos serão depois utilizados para fazer rotações num mesmo plano dentro de um espaço tridimensional.

Para cada um dos novos segmentos, o diâmetro da RV principal $\left(d_{0}\right)$ tem que ter a mesma capacidade de fluxo sanguíneo $(Q)$ que a soma de fluxos dos novos segmentos, isso cria uma relação entre $d_{0}$ e os diâmetros das suas ramificações $\left(d_{1}\right.$ e $\left.d_{2}\right)$ (esses parâmetros são mostrados na Figura 2.3). Assim, existe uma relação entre os fluxos sanguíneos, como a mostrada na equação seguinte:

$$
Q_{0}(t)=Q_{1}(t)+Q_{2}(t),
$$

em que $Q_{i}(t)$ é o fluxo sanguíneo num tempo $t$ no segmento $i$. Além disso, o fluxo é proporcional à soma das potências dos diâmetros. Desta forma, em uma bifurcação para 2 segmentos temos:

$$
d_{0}{ }^{k}=d_{1}{ }^{k}+d_{2}{ }^{k} .
$$

O parâmetro k é conhecido como expoente de bifurcação. No trabalho de Zamir [2001], é sugerido o valor $k=3$.

Outro parâmetro importante é a taxa de assimetria dos diâmetros $(\alpha)$ ou seja:

$$
\alpha=\frac{d_{2}}{d_{1}}
$$

Esses valores serão de utilidade para realizar os cálculos de novas bifurcações no capítulo da metodologia. 


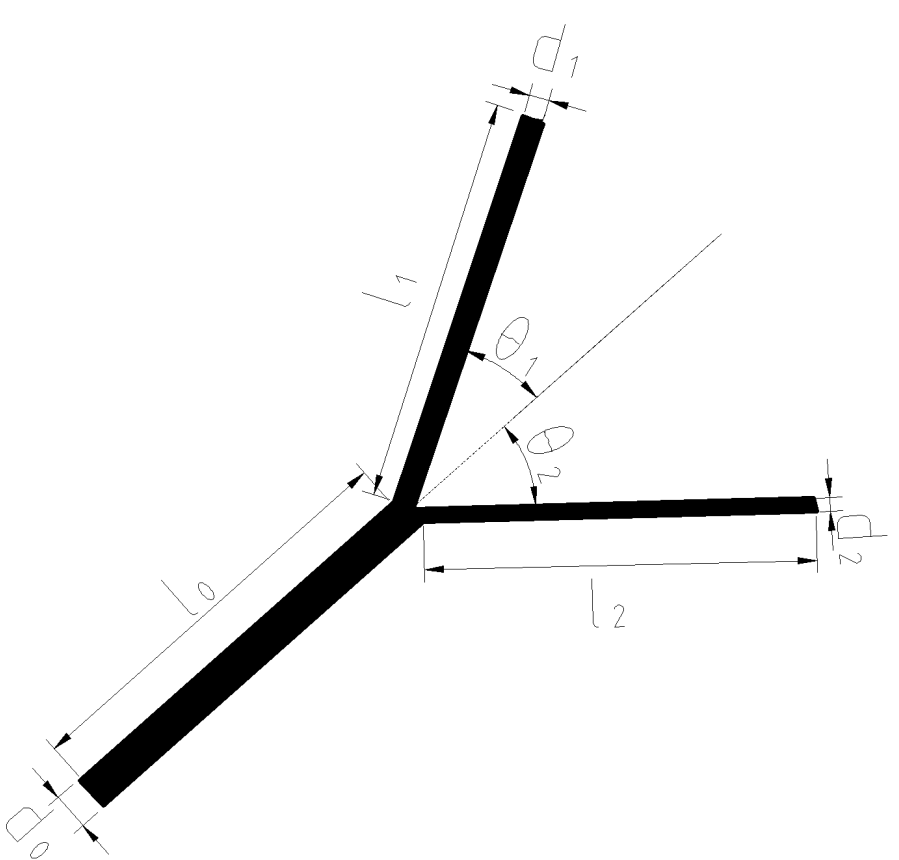

Figura 2.3: Parâmetros de bifurcação: diâmetros $\left(d_{0}, d_{1}, d_{2}\right)$, comprimentos $\left(l_{0}, l_{1}, l_{2}\right)$ e ângulos de bifurcação $\left(\theta_{1}, \theta_{2}\right)$.

\subsubsection{Esqueleto de redes vasculares}

Um esqueleto de rede vascular ou centro de linha é formado pelo centro de cada um dos segmentos que conforma a RV.

\subsection{Conceitos matemáticos}

\subsubsection{Fractais}

O termo fractal foi criado pelo matemático francês B. B. Mandelbrot durante a década de 1970. O termo que deriva do latim, significa "partir". Um fractal é um objeto geométrico autossimilar que pode ser dividido em partes, cada uma delas semelhante à original. A maioria dos fractais pode ser descrita recursivamente [Vinoy et al., 2003].

Existe uma grande variedade de fractais, dentre os quais destacamos os sistemas de Lindenmayer (L-systems) que são estudados neste trabalho. O comportamento desses sistemas está fortemente relacionado aos autômatos e às linguagens formais.

\subsubsection{Conceitos básicos de autômatos}

Um al fabeto $\Sigma$ é um conjunto de elementos abstratos chamados letras ou símbolos. Uma palavra num alfabeto $\Sigma$ é um texto finito de zero ou mais letras de $\Sigma$, em que uma mesma letra pode aparecer múltiplas vezes [Rozenberg, 1980].

Uma gramática é uma quádrupla ordenada $G=(\Sigma, P, S, \Delta)$, em que $\Sigma$ e $\Delta$ são alfabetos e $\Delta \subsetneq \Sigma, S$ é a letra inicial e $P$ é um conjunto finito de pares $(w, u)$, em que $w$ e $u$ são palavras 
contidas no alfabeto. Esses elementos de $P$ são conhecidos como regras de reescrita ou produções e escrita $w \rightarrow u$ [Hopcroft et al., 1979; Linz, 2011].

\subsubsection{Sistema de Lindenmayer (L-systems)}

Os sistemas de Lindenmayer ou L-systems foram introduzidos em 1968 por Aristid Lindenmayer, quem construiu um formalismo para o desenvolvimento de organismos multicelulares, chamado Lsystems [Lindenmayer, 1968].

Formalmente um L-system é uma tupla $(\Sigma ; \omega ; P)$ em que $\Sigma$ é um alfabeto, $\omega$ é um elemento não vazio de $\Sigma$ chamado axioma que representará o elemento inicial e $P$ é o conjunto de funções ou regras definidas em $\Sigma$ [Rozenberg, 1980].

Existem diferentes tipos de L-System: os determinísticos, os não determinísticos, os livres de contexto e os sensíveis ao contexto, os quais podem ter parâmetros ou não.

\section{L-system determinístico livre de contexto (DOL-System)}

Um DOL-system é um dos L-systems mais simples, é dito determinístico porque sempre terá o mesmo resultado para uma mesma gramática. Formalmente é definido como: seja $\Sigma$ um alfabeto, $\Sigma^{+}$o conjunto de elementos não vazios de $\Sigma$ e $\Sigma^{*}$ o conjunto das combinações dos elementos de $\Sigma$. Um DOL-System é uma terna ordenada $G=(\Sigma ; \omega ; P)$, em que: $\Sigma=s_{1}, s_{2}, \ldots, s_{n}$ é o alfabeto do sistema, $\omega \in \Sigma^{+}$é um elemento não vazio chamado axioma, $P \subset \Sigma \times \Sigma^{*}$ é o conjunto finito de produções. Uma produção $(a, \chi) \in P$ é escrita como $a \rightarrow \chi$, em que $a$ é chamado predecessor e $\chi$ é o sucessor [Kókai et al., 1999b; Prezemyslaw e Lindenmayer, 1996].

Como um exemplo de um L-System básico temos:

$$
\begin{aligned}
\Sigma & =\mathrm{a}, \mathrm{b} \\
\omega & =\mathrm{a} \\
P & =\{\mathrm{a} \rightarrow \mathrm{ab}, \mathrm{b} \rightarrow \mathrm{a}\}
\end{aligned}
$$

Com a aplicação das definições anteriores, obtemos a seguinte sequência de derivação:

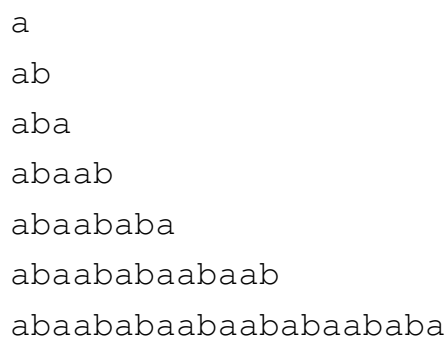

Uma sequência como a anterior pode representar um gráfico em que determinado símbolo significa uma rotação, translação, desenho de linha ou alguma outra operação.

Um exemplo clássico de muita importância para o adequado entendimento do comportamento de um L-system são as Curvas de Koch. 


\section{Curvas de Koch}

Originalmente introduzidas pelo matemático suíço Helge von Koch em 1904, essa geometria é importante porque pode levar a várias outras generalizações.

A construção geométrica da curva de Koch comum é simples. Começa com uma linha reta, chamada de inicializador. Essa é particionada em três partes iguais e o segmento do meio é trocado por outros dois, os quais formam um triângulo equilátero com a linha reta inicial. Trata-se da primeira iteração e a reta inicial é chamada gerador. O processo é reutilizado para novas iterações. Na sequência cada segmento de linha reta é substituído pelo gerador [Von Koch, 1993]. Essa construção geométrica é mostrada na Figura 2.4.

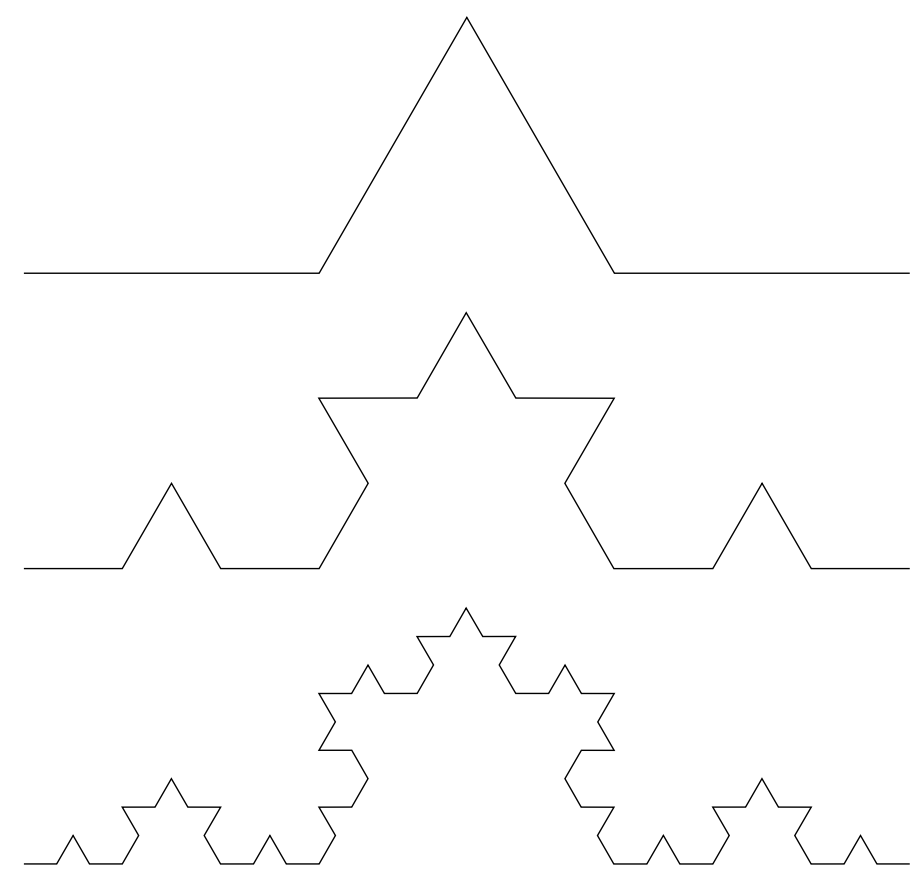

Figura 2.4: Três iterações da curva de Koch.

A gramática para a geração da curva de Koch é:

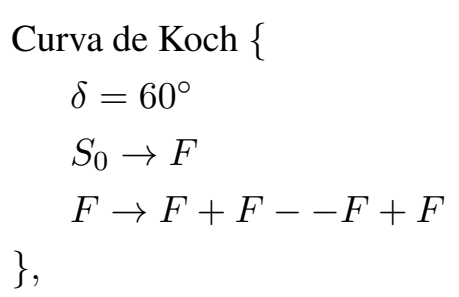

em que $S_{0}$ é o axioma, e o alfabeto $\Sigma=\{F,+,-\}$. "F" é avançar em linha reta, “+” e "_" são rotacionar à direita e à esquerda em um certo grau definido por $\delta$.

\section{DOL-system paramétrico}

Existem certas limitações para um DOL-system no que diz respeito a parametrização de instruções. Por exemplo: se a instrução $f$ significa avançar, então só com essa informação, não é possível 
saber qual é o comprimento desse avanço e no caso das rotações não é possível definir o seu ângulo de forma variável. Com a finalidade de suprir essa deficiência, Lindenmayer propôs que alguns símbolos de $\Sigma$ poderiam ser associados a parâmetros numéricos [Lindenmayer, 1974].

Nesse projeto, os parâmetros serão agrupados por parênteses e separados por vírgulas.

Os nomes das regras são chamados elementos não terminais e os elementos de $P$ que não são operadores são chamados terminais.

Um exemplo de uma regra de um DOL-System paramétrico é:

$$
A \rightarrow+(10) f(5)
$$

em que $A$ é o nome da regra e "+" e " $f$ " são dois símbolos de $\Sigma$. Nesta regra, o símbolo + recebe o número 10 como parâmetro e o símbolo $f$ recebe o número 5 . Nesse caso, os parâmetro dados a $f$ e + parecem não ter relevância, mas se associamos a cada uma das letras uma função específica, os parâmetros cobram muita relevância. Assim, neste projeto, utilizamos o símbolo $f$ para representar a função avançar e "+" para rotacionar, como mostrado no Capítulo 3. Logo, a regra $A$ mostrada anteriormente fará uma rotação de 10 graus e depois avançará 5 unidades.

\section{L-system estocásticos}

A teoria dos L-systems estocásticos é uma extensão que permite estabelecer um conjunto de regras e restrições não-determinísticas. Assim, cada uma das regras pode ter uma probabilidade $p$ associada à sua execução. Por exemplo: “ $A: p \rightarrow \chi$ ”. A probabilidade de $p$ é usualmente descrita por: $P(A \rightarrow \chi)$. Isso permite obter resultados na sequência de derivações provavelmente distintos em tempos de execução distintos [Elena e Manuela, 2006; McCormack et al., 1993].

Uma gramática estocástica é correta se, para cada uma das regras $A \rightarrow \chi_{j}$, temos:

$$
\sum_{j} P\left(A \rightarrow \chi_{j}\right)=1 .
$$

Um exemplo da representação de dois possíveis estados é mostrado nas seguintes regras:

$$
\begin{aligned}
& a: 0.7 \rightarrow b \\
& a: 0.3 \rightarrow c
\end{aligned}
$$

Em que $a, b$ e $c$ são símbolos quaisquer. De acordo com essas regras, a probabilidade de $a$ se transformar em $b$ é de $70 \%$ e de se transformar em $c$ é de $30 \%$.

Por exemplo, utilizando a seguinte gramática:

$$
\begin{aligned}
& \omega=a \\
& a: 0.7 \rightarrow a b \\
& a: 0.3 \rightarrow b
\end{aligned}
$$

As possíveis cadeias resultantes dessa gramática em uma primeira iteração são: $a b$ ou $b$, enquanto que para uma segunda iteração a cadeia produzida pode ser: $a b b, b b$ ou $b$. 


\subsection{Produção de cadeias a partir dos L-systems}

Com a finalidade de produzir cadeias resultantes de L-systems, são usados usualmente algoritmos recursivos. Nossa abordagem usa um analisador léxico e sintático para gerar um código intermediário para montar cadeias resultantes para um determinado número de iterações, a partir de gramáticas de L-system.

\subsubsection{Analisador léxico}

A tarefa de um analisador léxico (lexer) é produzir uma sequência de símbolos chamados símbolos léxicos ou tokens a partir de uma cadeia de texto inicial [Xiao e Xu, 2011]. Cada um desses tokens possui regras definidas como expressões regulares, as quais permitem definir se uma cadeia de texto pertence ou não a um tipo de token [Friedl, 2006].

Por exemplo, para verificar se um texto é ou não é um número decimal, pode ser utilizada a seguinte expressão regular: “[0-9] + ( [ [0-9]+) ?”, a qual significa, que um número decimal é formado por um ou mais dígitos seguidos possivelmente por um ponto decimal e, no caso de ter decimais, por um ou mais dígitos depois do ponto.

A finalidade de separar a cadeia em tokens é que eles serão utilizados depois pelo analisador sintático.

\subsubsection{Analisador sintático}

O analisador sintático recebe como entrada os tokens gerados pelo analisador léxico para obter a estrutura do texto inicial [Xiao e Xu, 2011]. Essa estrutura é obtida utilizando regras gramaticais internas do analisador sintático e nossa abordagem será depois utilizada para analisar a gramática do L-system e gerar as funções intermediárias.

Nesse projeto, foi desenvolvido um analisador sintático descendente [Aho et al., 1998], ou seja, é construída a árvore de análise sintática começando pela raiz e terminando nas folhas, e é analisado o valor de entrada caractere por caractere da esquerda para a direita. Dessa forma, podemos gerar uma árvore de análise sintática da gramática dada como entrada e obter sua estrutura. 


\section{Capítulo 3}

\section{Metodologia}

Neste capítulo, será detalhada a metodologia proposta que utiliza $L$-systems estocásticos parametrizados para gerar uma RV sintética com sua respectiva imagem, a qual simula as intensidades e o formato das imagens de angiografia reais.

Começamos a detalhar a metodologia mostrando a Figura 3.1 que representa os principais processos e fluxos. Nossa metodologia inicia-se pela definição de variáveis globais como: posição, diâmetro, direção inicial, razão diâmetro-comprimento e pela gramática que determina o comportamento de geração da rede vascular.

Esta gramática dada como entrada é executada respeitando os parâmetros estabelecidos anteriormente, com a finalidade de obter uma cadeia de texto que represente uma sequência de instruções que têm que ser seguidas para criar a rede vascular.

Uma rede vascular é então criada seguindo as instruções geradas na etapa anterior, mas levando em consideração o limite espacial para o crescimento da RV. Nessa etapa, são geradas sequências de segmentos definidos por pontos com seus respectivos diâmetros.

Finalmente, na etapa de discretização, são inseridos pontos adicionais utilizando os pontos criados na etapa anterior como pontos de controle para uma função de B-Splines. Todos os pontos são posteriormente unidos por uma adaptação do algoritmo de Bresenham em 3D com a finalidade de obter o esqueleto da RV criada. Por fim, é adicionado volume ao esqueleto, criando assim imagens sintéticas que simulam imagens resultantes das técnicas angiográficas conhecidas.

O diagrama de fluxo dos resultados obtidos em cada uma das etapas é mostrado na Figura 3.2.

\subsection{Definição da gramática e parâmetros}

As técnicas de geração baseadas em $L$-systems necessitam de uma gramática inicial, portanto precisam também de uma definição formal do alfabeto. Também precisamos de uma certa aleatoriedade para o processo de geração com a finalidade de obter um nível razoável de realismo. Será necessário também o estabelecimento de variáveis que definam um estado inicial.

Os $L$-systems parametrizados foram escolhidos, já que o comportamento das RVs variam entre os diferentes órgãos dependendo da natureza dos tecidos. O L-system parametrizado proporciona uma maior flexibilidade na geração das RVs, já que é possível passar informação adicional à próxima 


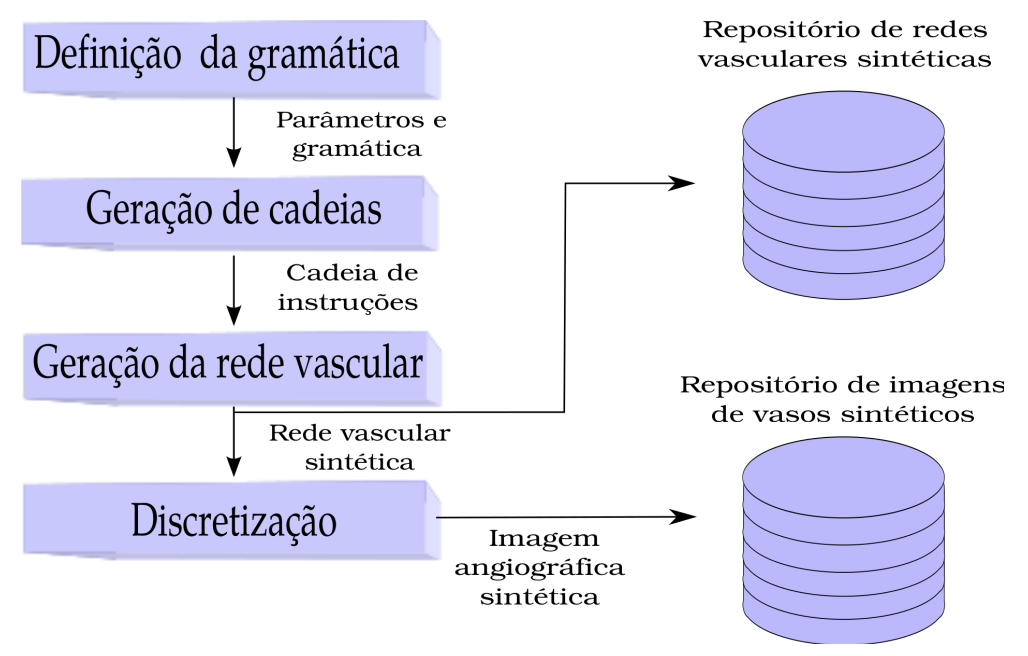

Figura 3.1: Esquema representativo da metodologia. Os blocos representam processos, os fuxos representam dados e os cilindros representam repositórios de dados.

iteração de geração. Por exemplo, podemos passar como parâmetro um diâmetro maior numa regra para gerar um segmento e, assim, simular aneurismas.

\subsubsection{Variáveis iniciais}

Serão levadas em conta as seguintes variáveis iniciais:

Posição inicial: A posição inicial será definida como um ponto num campo cartesiano tridimensional $P=(x, y, z)$.

Direção: É um vetor unitário $\vec{V}_{\text {direção }}=(\hat{i}, \hat{j}, \hat{k})$ que indica a direção do segmento de RV seguinte.

Direção perpendicular: Indica uma direção perpendicular à direção inicial e é representado por um vetor unitário $\vec{V}_{\text {perpendicular }}=(\hat{i}, \hat{j}, \hat{k})$. O fato de termos definido dois vetores de direção permite fazer rotações nas 3 dimensões.

Diâmetro inicial: É o diâmetro do primeiro segmento de RV, trata-se de um valor real.

Razão diâmetro-comprimento: Corresponde à proporção entre o diâmetro de um segmento e seu comprimento; é um valor real.

Sigma: É o valor sigma utilizado nas funções implementadas que utilizam distribuições Gaussianas.

Restrições: As restrições são formadas por superfícies que limitam o crescimento da RV. Uma das formas mais naturais de representar uma superfície é utilizando arquivos . $\mathrm{vtk}^{1}$ que representem uma superfície.

\footnotetext{
${ }^{1}$ Mais informações com relação aos arquivos . vtk podem ser encontradas em Schroeder et al. [2003]
} 


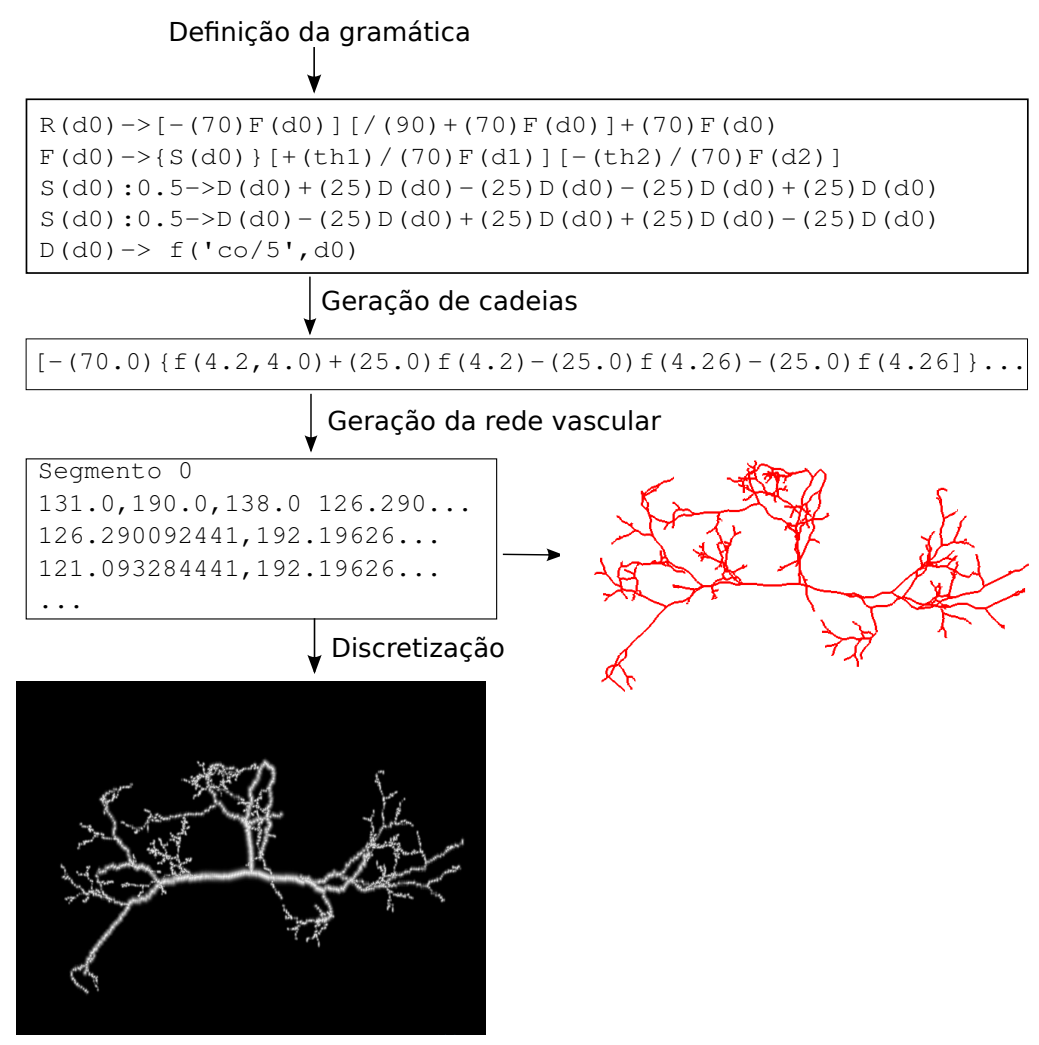

Figura 3.2: Esquema representativo dos resultados obtidos em cada uma das etapas de geração das RVs.

\subsubsection{O alfabeto}

O alfabeto é o conjunto de todos os símbolos válidos dentro de uma gramática. Neste projeto, o alfabeto é formado por elementos terminais e não-terminais.

Elementos não-terminais: São elementos usados como nomes das regras gramaticais; são representados por letras maiúsculas.

Elementos terminais: Conjunto formado por letras minúsculas, podendo ou não estar acompanhadas de parâmetros. Nesse projeto, definimos elementos não-terminais especiais que definem um comportamento específico. A descrição completa do comportamento desses símbolos e como serão processados encontra-se na Seção 3.3.1. Esses elementos são:

$f$ : Representa avançar em linha reta na direção do $\vec{V}_{\text {direção }}$ atual. Se $f$ não tem parâmetros, esses serão definidos por valores-padrão. A chamada completa ao símbolo $f$ é: $f$ (comprimento, diâmetro), comprimento e diâmetro são números reais que representam o comprimento e o diâmetro do segmento a ser criado pelo símbolo $f$.

+ Representa uma rotação do vetor de direção atual num ângulo $\alpha$ com respeito à direção perpendicular em sentido anti-horário.

- A funcionalidade é igual à do símbolo “+” mas em sentido horário. 
I Representa uma rotação do vetor da direção perpendicular num ângulo $\beta$ com respeito à direção atual em sentido horário. Se $\beta$ não for dado como parâmetro, é utilizado um ângulo de 70 graus.

* Representa uma rotação do vetor da direção perpendicular num ângulo $\beta$ com respeito à direção atual em sentido anti-horário. Se $\beta$ é dado como parâmetro, é utilizado um ângulo de 70 graus.

[ Salva o estado atual numa pilha. O estado atual é composto pelos valores de diâmetro, posição e vetores de direção.

] Retira o primeiro valor da pilha e coloca nas variáveis com os valores armazenados.

$\{$ Define o começo de um segmento de rede vascular. A partir desse símbolo serão criados sub-segmentos. Esse símbolo é utilizado para aplicar interpolação entre os pontos.

\} Fim de um segmento.

Palavras reservadas: Para utilizar parâmetros mais complexos calculados dinamicamente, foram estabelecidas algumas palavras reservadas que serão estudadas com maior profundidade na etapa de geração 3.2.

As palavras reservadas são: "theta1", "theta2", "comprimento", "diametro0", "diametro1", "diametro2".

Devido ao comprimento relativamente grande dessas palavras, foram também inclusas suas contrações como palavras reservadas. As contrações de cada palavra respectivamente são: "th1", "th2", "co", "d0", “d1", “d2”. Podendo ser utilizada qualquer uma das duas opções, por exemplo $f$ (comprimento) tem o mesmo efeito que $f(\mathrm{co})$.

Operações: É possível também utilizar como parâmetro uma sequência de operações que contenha palavras reservadas misturadas com números. Para isso, a operação terá que estar entre aspas simples (' '), por exemplo: f(' $2 *$ comprimento+3'). Essa sequência de operações será calculada com prioridade.

O analisador léxico e sintático proposto é capaz de aceitar qualquer outro elemento não terminal, ou seja, letra minúscula. Na etapa seguinte só serão considerados os elementos terminais descritos anteriormente, já que outro símbolo não teria um significado e não representaria instrução alguma.

\subsubsection{Definição da gramática}

Uma gramática é composta por um conjunto de elementos do alfabeto, agrupados em regras gramaticais, das quais a primeira regra é considerada como o axioma da gramática. Nessa metodologia, as regras gramaticais tem a seguinte forma:

Nome(parâmetros): probabilidade $\rightarrow$ sucessor

Em que o Nome está formado por uma letra maiúscula que representa a regra.

Os parâmetros são formados por uma sequência de números ou palavras reservadas separadas por vírgulas. Assim, um elemento terminal poderia ter parâmetros como, por exemplo, $f(5)$, que significa avançar 5 unidades. 
Neste trabalho, as regras também podem precisar de um parâmetro. Nesse caso, se uma regra fará o cálculo de bifurcações (obtenção de novos diâmetros e ângulos de rotação numa bifurcação), o parâmetro requerido é o diâmetro atual, chamado $d_{0}$, que terá que ser passado obrigatoriamente à regra. Por exemplo, uma regra com parâmetros é:

$F(d 0) \rightarrow f$ (comprimento). Essa regra utilizará $d_{0}$ para realizar o cálculo do "comprimento".

A probabilidade é definida como um número $x \in R \mid 0<=x<=1$, que uma regra pode ou não ter associada, e indica a frequência com que uma regra vai ser executada. Se uma regra é estocástica, é necessário que a soma das probabilidades das regras com o mesmo nome seja igual a 1.

Por exemplo, nas duas regras seguintes a probabilidade de execução é $40 \%$ para a primeira e $60 \%$ para a segunda:

$$
\begin{aligned}
& F: 0.4 \rightarrow f \\
& F: 0.6 \rightarrow f F
\end{aligned}
$$

O sucessor é uma sequência de símbolos terminais e não terminais, com ou sem parâmetros. Um exemplo de gramática simples:

$$
X \rightarrow f[+(45) X][-(45) X] .
$$

Na Figura 3.3 é mostrado o esqueleto resultante da gramática acima.

Neste ponto, é importante mencionar que cada órgão do corpo normalmente tem estrutura, composição e comportamento diferente um dos outros. Portanto, as redes vasculares de cada órgão tem que ter parâmetros de geração distintos e gramáticas específicas.

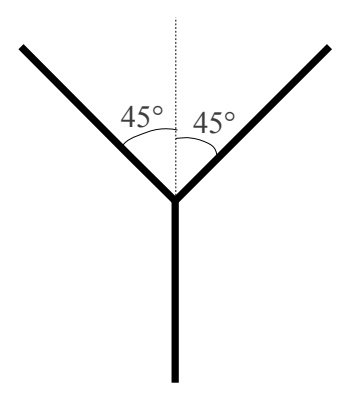

(a)

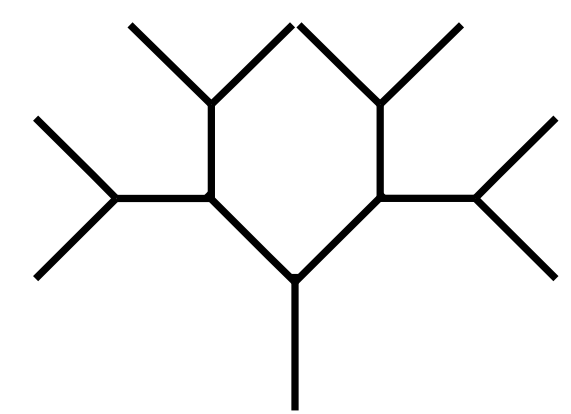

(b)

Figura 3.3: Resultado da execução da gramática $X \rightarrow f[+(45) X][-(45) X]$. a) Em sua primeira e b) na terceira iteração.

\subsubsection{Formato do arquivo de entrada}

A gramática e os valores das variáveis são embutidos dentro de um arquivo de texto que será dado como entrada para a geração da RV. 
O arquivo de entrada nesse projeto está dividido em quatro seções, em cada uma dessas seções, é possível definir valores para variáveis estabelecidas. Se algum dos valores não é definido, será utilizado um valor padrão.

As seções e as variáveis que podem ser definidas em cada uma são:

Parâmetros: as variáveis requeridas para os cálculos de bifurcação e crescimento, definem o comportamento do crescimento.

Proporção entre comprimento e diâmetro (propCD): É a razão que relaciona o comprimento e o diâmetro. Esta variável é criada devido ao fato de que um segmento na média tem um comprimento que depende do diâmetro, já que, por exemplo, um segmento longo tende a ter um diâmetro maior que um segmento curto. Assim, o valor ótimo do comprimento de um segmento é:

$$
C_{O p t}=d_{0} * \operatorname{prop} C D
$$

em que $d_{0}$ é o diâmetro inicial. O valor padrão de prop $C D$ é 10 .

Margem da proporção (margemCD): É a variância que pode ter o comprimento. Assim, o valor do comprimento de um segmento está no intervalo:

$$
\left[C_{O p t}-\operatorname{margemCD}, C_{O p t}+\right.\text { margemCD]. }
$$

Proporção entre valor ótimo e sigma (propOptSigma): Consideramos os valores de thet $a_{1}$, thet $a_{2}$ e o comprimento tal como mostrados na Seção 2.1.5 como valores ótimos. Logo, propOptSigma é a razão entre o valor ótimo $V_{o p t}$ e o valor do sigma utilizado nas distribuições estocásticas, ou seja:

$$
\text { propOptSigma }=V_{\text {opt }} / \sigma .
$$

Assim, quanto maior for esse valor, mais próximos serão os resultados dos valores ótimos.

Estocástico (estocs): Um valor Booleano (True ou False) que define o uso de distribuições, estocásticas ou não, para o cálculo de uma rede vascular.

Variáveis: As variáveis que definem a rede vascular, seu comprimento e direção.

Diâmetro (d0): É o diâmetro inicial de um segmento, esse diâmetro não é necessariamente igual ao diâmetro desse mesmo segmento na imagem final, já que, para a discretização, será aplicada uma escala aos pontos. Isso será visto na etapa de discretização na Seção 3.4. O valor padrão é 1 .

Direção (direcao): É o vetor de direção inicial. Seu valor padrão é $V_{\text {direção }}=[0,1,0]$

Direção perpendicular (direcaoPerpendicular): Vetor obrigatoriamente perpendicular à direção inicial. $\mathrm{O}$ valor padrão é $V_{\text {perpendicular }}=[0,0,1]$. 
Ponto inicial (pontoInicial): Ponto em coordenadas cartesianas que define a localização do ponto inicial. O valor padrão é pontoInicial $=[0,0,0]$.

Restrições: Superfícies que limitam o espaço onde pode ou não crescer a RV.

Pode crescer dentro de (pode): Uma sequência de endereços de arquivos . vtk que representam as superfícies que limitam o espaço onde é possível o crescimento de RVs. É vazia por padrão.

Não pode crescer dentro de (naoPode): Uma sequência de endereços de arquivos . vt k que representam as superfícies que limitam o espaço onde não é possível o crescimento de RVs. É vazia por padrão.

Pode crescer fora (valeFora): Um valor booleano que indica se é permitida a geração nos espaços não delimitados por nenhuma superfície. Se não foi definida nenhuma superfície de restrição, este valor é verdadeiro.

Gramática: É o conjunto de regras da gramática, as quais seguem as seguintes normas:

- Cada regra em uma linha diferente.

- O axioma é a primeira regra.

- O axioma não pode ser estocástico.

- As probabilidades das regras estocásticas com o mesmo nome tem que somar 1.

Devido à grande quantidade de parâmetros e à necessidade de criar arquivos de entrada com a formatação correta, como no exemplo mostrado na Figura 3.4, foi desenvolvido um aplicativo que recebe esses dados de maneira intuitiva e gera os arquivos de entrada requeridos, com algumas características adicionais como a capacidade de mostrar uma pré-visualização das superfícies, o que permite ter noção do diâmetro, comprimento do primeiro segmento, direção, ponto inicial e as superfícies de limitação. Uma imagem da tela de nosso gerador de arquivos de entrada é mostrada na Figura 3.5.

\subsection{Geração de cadeias}

Na etapa de geração, é utilizada a gramática para produzir uma cadeia final que representa todas as operações que tem que ser feitas para gerar os pontos que formam a RV com os seus respectivos diâmetros.

\subsubsection{Produção da cadeia final}

A produção da cadeia final começa com o axioma, que é a primeira regra de uma tal gramática. Utilizaremos como exemplo a seguinte gramática:

$$
\begin{aligned}
& A \rightarrow F \\
& F: 0.9 \rightarrow f[+(45) F][-(45) F] \\
& F: 0.1 \rightarrow f f
\end{aligned}
$$




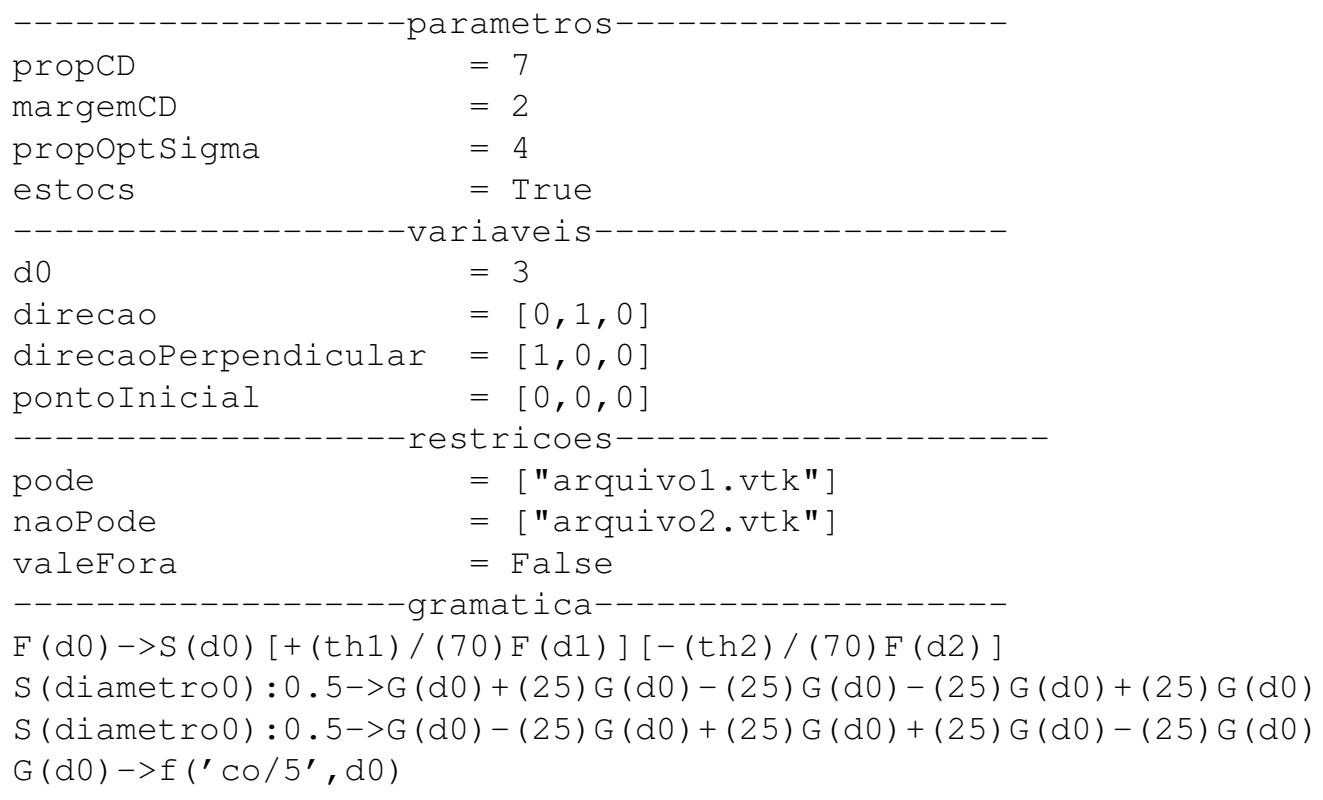

Figura 3.4: Exemplo do conteúdo de um arquivo de entrada

No exemplo, o axioma é $A$ por ser a primeira regra. Portanto a cadeia inicial será " $A$ ". O número de execuções $n$ é conhecido e vai diminuindo a cada iteração. Na iteração número 1 , é executada a regra $A$ e é produzida a cadeia: " $F$ ".

Na segunda iteração, é chamada a regra $F$. No entanto, existem duas regras chamadas $F$. A probabilidade da primeira regra ser executada é de $90 \%$ e da segunda $10 \%$. Assumindo que fosse executada a primeira, a cadeia na segunda iteração será: " $f[+(45) F][-(45) F]$ ”.

$\mathrm{Na}$ terceira iteração, precisamos chamar duas vezes a regra F. Se na primeira chamada, for executada a primeira definição de "F" e, na segunda chamada, a segunda regra, a cadeia será: " $f[+(45) f[+(45) F][-(45) F]][-(45) f f] "$.

A produção continua gerando cadeias enquanto houver pelo menos um elemento não-terminal e o número da iteração for menor ou igual a $n$. Para fazer essa produção automaticamente, elaboramos um analisador léxico e outro sintático, ambos construídos com PLY (Python Lex-Yacc) ${ }^{2}$, com a finalidade de gerar código em Python, em que cada regra gramatical será uma função em Python. Essas funções serão chamadas para gerar a cadeia final. A estrutura do gerador de cadeias é mostrada na Figura 3.6:

\section{Analisador léxico}

A tarefa de um analisador léxico é produzir uma sequência de tokens a partir de uma cadeia inicial [Xiao e Xu, 2011], os quais serão utilizados pelo analisador sintático.

Os tokens válidos gerados por nosso analisador em ordem de prioridade são:

- Qualquer uma das palavras reservadas descritas no alfabeto presente na Seção 3.1.2 é um token,

${ }^{2}$ PLY (Python Lex-Yacc) é uma implementação das ferramentas lex and yacc para Python. Seu site oficial é http: //www. dabeaz.com/ply/ [Beazley, 2009]. 


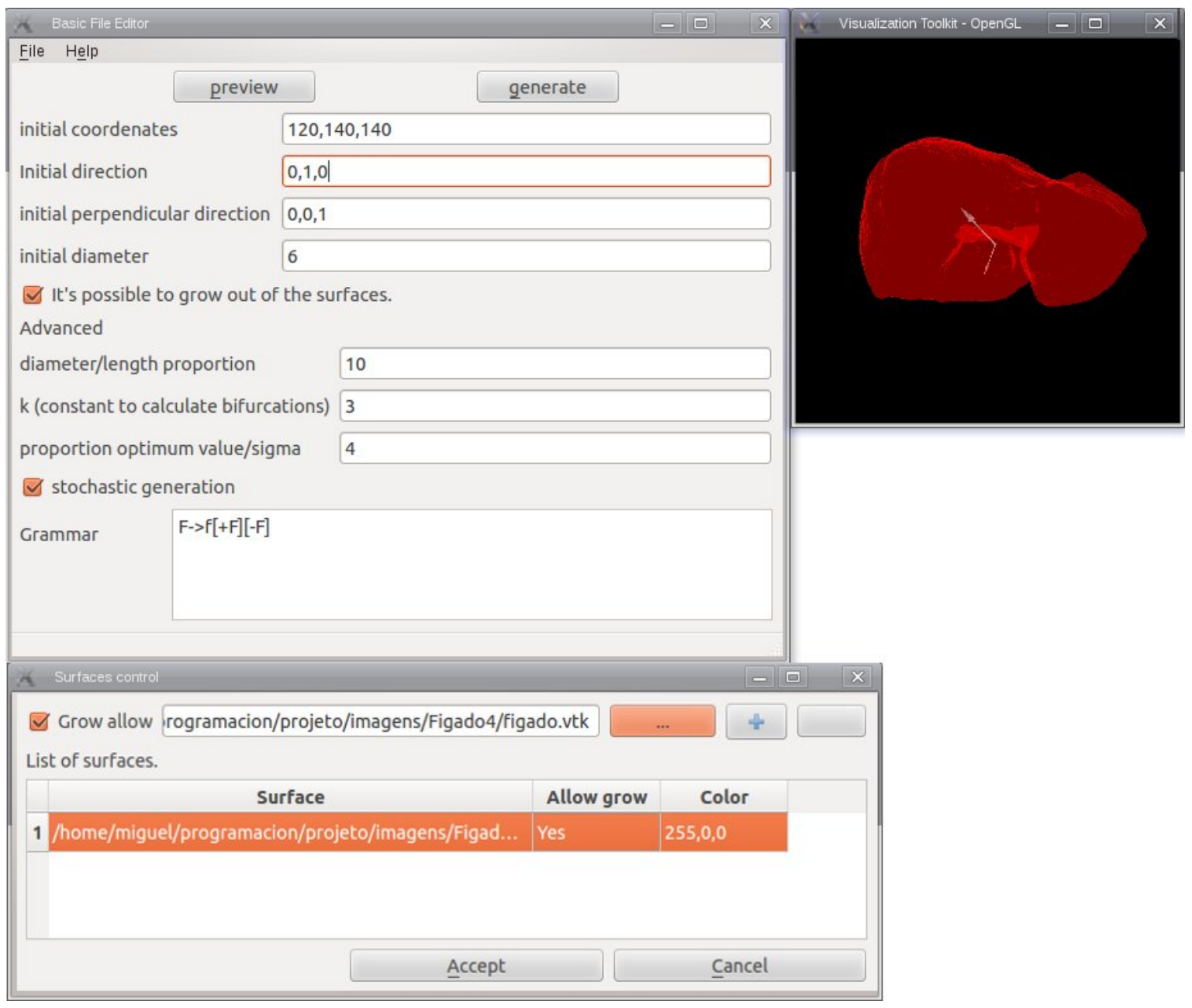

Figura 3.5: Telas do editor básico de arquivos de entrada.

cujo nome é a própria palavra reservada.

- NOME: Os nomes das regras serão retornados como token "NOME". Por exemplo, na regra "F->f" o nome é F.

- NUMERO: Qualquer número inteiro ou real.

- ASSIGN: O símbolo de atribuição de nossas regras gramaticais “->”.

- SIMBOLO: Símbolos não-terminais como, por exemplo, "F" ou "X".

- TERMINAL: Símbolos terminais como, por exemplo, "f" ou "x".

- ESPECIAL: Símbolos especiais como, por exemplo, “+”, “-”, “[”, “]”.

- OPER: Grupo de operações matemáticas, as quais têm que ser calculadas com prioridade. Por exemplo, “2+comprimento". Nesse caso, o símbolo “+” não é o símbolo da rotação, é a operação de soma.

- Quaisquer dos seguintes caracteres são considerados um token: “(”, “)”, “:” 


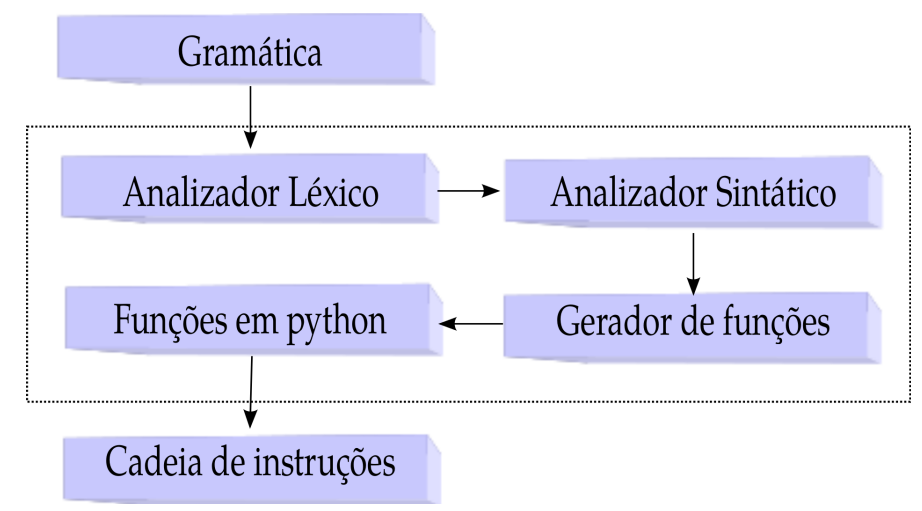

Figura 3.6: Estrutura do gerador de cadeias.

Neste analisador léxico, as linhas que começam com "\#” são consideradas como comentários, portanto, são descartadas junto com os espaços em branco.

\section{Analisador sintático}

Recebe como entrada os tokens gerados pelo analisador léxico, com a finalidade de obter a estrutura do texto inicial [Xiao e Xu, 2011]. O texto inicial neste caso é formado pelas regras gramaticais do $L$-system. Para refletir a estrutura hierárquica do L-system, uma árvore de análise sintática é construída respeitando as gramáticas internas do analisador sintático. A lista completa dessas gramáticas internas com suas definições está descrita no Apêndice A.

Neste trabalho, foi desenvolvido um analisador sintático descendente [Aho et al., 1998], ou seja, é construída a árvore de análise sintática começando pela raiz e terminando nas folhas e é analisado o valor de entrada da esquerda para a direita, caractere por caractere. Por exemplo, uma árvore de análise para a função $F(d 0): 0.5 \rightarrow f[+F] F$ tal como a geraria nosso analisador sintático é mostrada na Figura 3.7.

\section{Gerador de funções Python}

Após analisar a estrutura da gramática, é gerada uma função em Python para cada uma das regras gramaticais e uma adicional para cada regra estocástica.

Por exemplo, para a regra: “ $F(d 0)->f[+F(d 0)]-F(d 0)$ ” será gerado o seguinte código:

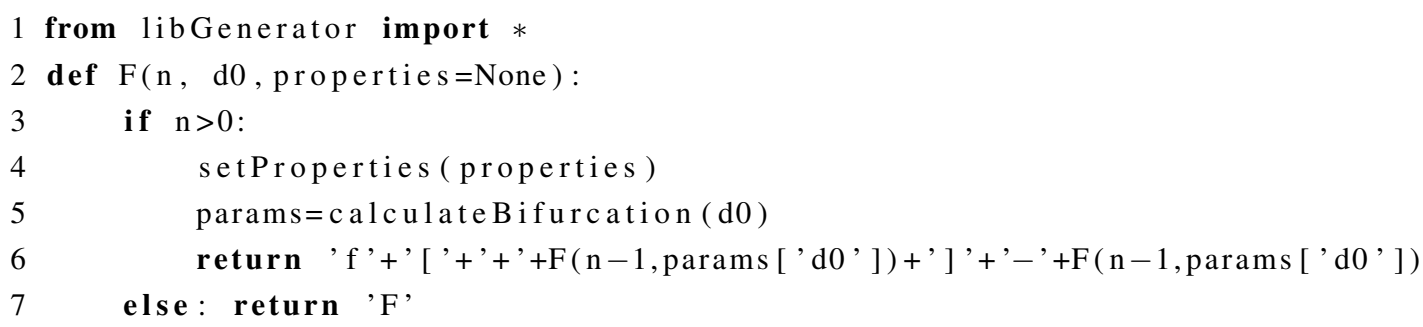

A função criada chamada " $F$ " retorna uma cadeia que representa a produção da regra $\mathrm{F}$ em $n$ iterações, de acordo com os parâmetros dados em properties. Se não são dados parâmetros, são usados valores padrão para esses parâmetros. 


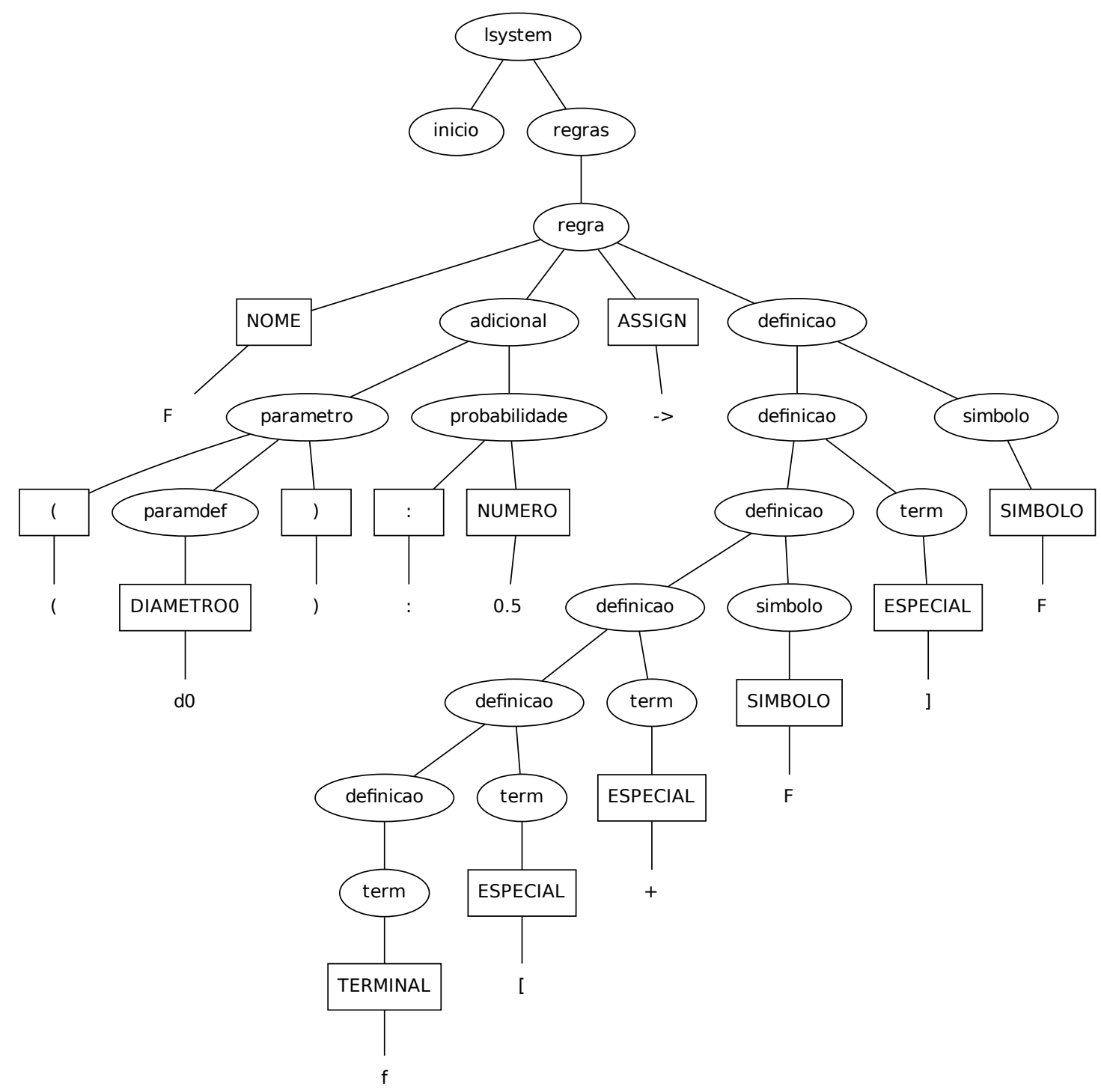

Figura 3.7: Árvore de análise sintática da expressão: “ $F(d 0): 0.5->f[+F] F$ ”, cada elipse representa um estado e cada quadrilátero corresponde a um token. 
O código-fonte da implementação das funções setPropriedades(properties) e calculateBifurcation $(d 0)$, utilizadas dentro desta função é descrito no Apêndice B. A função setProperties(properties) estabelece as variáveis gerais no arquivo de entrada e estabelece os valores padrão para as que não foram especificadas. Por exemplo: properties poderia ser:

1 properties $=\{$ "propCD" $: 8$, " estocs ": True $\}$

$\mathrm{Na}$ linha 5 do código anterior, é chamada a função calculateBifurcation(d0), a qual calcula os valores das palavras reservadas, de acordo com o descrito na Seção 3.2.2.

Essa função, para $n=1$ e um diâmetro inicial $d_{0}=1$ dará: " $f[+F(1)]-F(1)$ ".

Para $n=2:$ : $f[+\mathrm{f}[+F(1)]-F(1)]-f[+F(1)]-F(1)$ ”.

No caso das regras estocásticas, é criada uma função adicional que tem a seguinte forma:

1 def $F(n, d 0)$ :

$2 \quad r=$ random .random ()

3 if $r>=0.0$ and $r<0.3$ : return $F 1(n, d 0)$

4 if $r>=0.3$ and $r<1.0$ : return $F 2(n, d 0)$

F1 e F2 são as funções individuais de cada regra. Essa função foi gerada da seguinte gramática:

$$
\begin{aligned}
& F(d 0): 0.3->f \\
& F(d 0): 0.7->f f
\end{aligned}
$$

\subsubsection{Cálculo das palavras reservadas}

As palavras reservadas que poderiam ser utilizadas na definição das regras da gramática, são calculadas e substituídas pelos seus respectivos valores na cadeia final. Essas palavras reservadas representam os parâmetros tal como mostrados na Figura 2.3.

\section{Comprimento: comprimento(co)}

Na média, o comprimento $l$ de um segmento de rede vascular normal é $l=d_{0} * \operatorname{prop} C D$, em que $d_{0}$ é o diâmetro do segmento e prop $C D$ é a proporção entre o comprimento e o diâmetro. Devido ao fato de que o comprimento e o diâmetro estão relacionados, segmentos de RV com diâmetros pequenos tendem a possuir comprimentos pequenos [Zamir, 2001]. Assim, alguns dados sugerem um valor médio de 10 para a proporção comprimento-diâmetro (propCD) [Liu et al., 2010].

Para adicionar diferenças entre os comprimentos, foi criada a variável margem $C D$ com a qual o comprimento de um segmento está no intervalo: $[l-\operatorname{margem} C D, l+\operatorname{margem} C D]$.

\section{Ângulos de bifurcação: theta1 (th1) e theta2 (th2)}

Com a finalidade de obter ângulos de inclinação nas bifurcações, foram escolhidas as seguintes equações que imitam os ângulos de bifurcação no corpo humano [Liu et al., 2010; Zamir, 1988]:

$$
\begin{aligned}
& \cos \theta_{1}=\frac{\left(1+\alpha^{3}\right)^{4 / 3}+1-\alpha^{4}}{2\left(1+\alpha^{3}\right)^{2 / 3}} \\
& \cos \theta_{2}=\frac{\left(1+\alpha^{3}\right)^{4 / 3}+\alpha^{4}-1}{2 \alpha^{2}\left(1+\alpha^{3}\right)^{2 / 3}}
\end{aligned}
$$


Em que $\alpha$ é a taxa de assimetria dos diâmetros filhos como mostrado na Equação 2.3, Zamir [1988] propõe utilizar $\alpha=2.5$ ou $\alpha=3$ como variável principal para a definição dos ângulos de inclinação das ramificações da RV. Os ângulos de inclinação $\theta_{1}$ e $\theta_{2}$ são mostrados na Figura 2.3.

Uma boa forma de avaliar a escolha correta de ângulos, é levar em conta que a média de inclinação dos ângulos em alguns órgãos do corpo humano, como nas ramificações das artérias coronárias, tendem a ser $70^{\circ}$ [Murray, 1926; Zamir, 1988], ou seja: $\theta_{1}+\theta_{2} \simeq 70^{\circ}$.

\section{Diâmetros: diametro0 (d0), diâmetro1 (d1), diametro2 (d2)}

Embora estejamos utilizando a Equação 3.1 para o cálculo das bifurcações, essa equação depende da escolha dos diâmetros dos segmentos filhos, já que $\alpha$ depende dos diâmetros. A escolha do primeiro diâmetro (diametro1) é feita utilizando uma distribuição gaussiana $N(\mu, \sigma)$, em que a média $(\mu)$ é igual ao diâmetro ótimo $\left(d_{\text {opt }}\right)$, ou seja, quando a RV é dividida em duas redes vasculares de igual diâmetro. $\mathrm{O}$ desvio padrão $\sigma$ dependerá do valor da variável propOptSigma, que pode ser estabelecida como uma variável no arquivo de entrada, tal como descrito na Seção 3.1.4.

Depois de ter feito a escolha do diametro1, o segundo diâmetro diametro2 é calculado utilizando a Equação 2.2.

\subsection{Geração da rede vascular}

Até este ponto de nossa metodologia, temos uma cadeia que representa exatamente as ações que devem ser executadas para gerar a RV sintética. No entanto, essas instruções ainda não respeitam os limites de espaço em que é permitido o crescimento da RV. A tarefa de geração é a execução dessas instruções levando em consideração superfícies-limite, para que ao final tenhamos um conjunto de pontos com seus respectivos diâmetros, os quais representam a RV sintética.

A cadeia dada como entrada nessa etapa é formada por ações representadas por tokens que são processados de forma sequencial. Entenda-se por token uma instrução com seus respectivos parâmetros. Por exemplo, a seguinte instrução é um token: " $f(10,3)$ ". O significado de cada um dos parâmetros dependerá da instrução. Nesse caso, significa: avançar 10 unidades com um diâmetro igual a 3 .

\subsubsection{Instruções e seus parâmetros}

Os parâmetros utilizados para a execução da cadeia gerada são oferecidos no arquivo de entrada inicial. Assim, são definidos os valores das variáveis: $P_{\text {atual }}$ como o ponto inicial, $V_{\text {direção }}$ (vetor de direção) como a direção inicial, $V_{\text {perpendicular }}$ como a direção perpendicular, diâmetro como o diâmetro inicial. Além dessas variáveis, é inicializada uma pilha que pode armazenar todos os valores das variáveis num determinado instante, a qual chamaremos simplesmente pilha.

Essas variáveis serão utilizadas para o cálculo das instruções como descrito a seguir. 


\section{Avançar (f)}

A instrução de avançar com todos os possíveis parâmetros é: $f$ (comprimento, diâmetro). Caso o diâmetro não tenha sido passado como parâmetro, será utilizado o diâmetro atual. No caso de o comprimento não for passado como parâmetro, será calculado da mesma forma que a palavra reservada "comprimento" conforme a Seção 3.2.2. Assim, se não existir nenhuma superfície de restrição o ponto final $\left(P_{f}\right)$ será:

$$
P_{f}=P_{\text {atual }}+V_{\text {direção }} * \text { comprimento. }
$$

Caso o crescimento esteja limitado por superfícies, precisamos de saber se um ponto encontra-se dentro ou fora das restrições.

Cálculo de se um ponto está dentro das restrições: Para identificar se um ponto $P_{0}=\left(x_{0}, y_{0}, z_{0}\right)$ está dentro ou fora de uma superfície de restrição foi definido um algoritmo próprio, já que algoritmos como o convex hull só admitem superfícies convexas e existem muitos órgãos com pequenas concavidades.

Em nosso método é necessário analisar o espaço ao redor de um ponto. Para isso, é definida uma esfera unitária onde o centro é o ponto $P_{0}$. Essa esfera é subdividida em seções latitudinais e longitudinais. Para cada um dos pontos $P_{i}=\left(x_{i}, y_{i}, z_{i}\right)$ é calculado um vetor unitário $\vec{v}=$ $\left|P_{i}-P_{0}\right|$, a direção desse vetor necessariamente aponta para uma das seções da esfera, sendo esta marcada como visitada. Os seguintes pontos são analisados da mesma forma.

O cálculo termina quando todas as seções são visitadas ou quando todos os pontos foram analisados. No caso em que todas as seções tenham sido visitadas, o ponto é considerado dentro dessa superfície de restrição.

Esse cálculo é utilizado na criação de novos pontos. Assim, para a criação de um novo ponto na RV serão seguidos os seguintes passos:

1. Calcular o ponto final $P_{f}$.

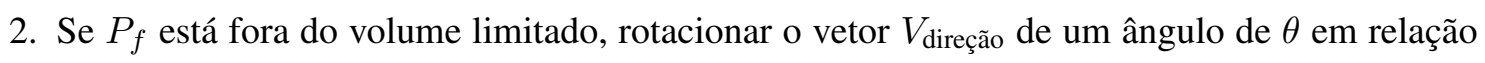
ao vetor $V_{\text {perpendicular }}$ e criar uma órbita circular ao redor do primeiro vetor circular.

3. Testar $n$ pontos dentro da órbita atual. Se não for encontrado um ponto interno, voltar ao passo anterior e criar outra órbita.

4. O primeiro ponto encontrado que pertença a um espaço de possível criação é considerado o ponto final do segmento.

Para melhor o entendimento dessa sequência, esta é mostrada graficamente na Figura 3.8.

Uma vez criado o ponto final e, portanto, definido o segmento atual, esses valores são escritos no arquivo de saída desta etapa. Assim, o valor do ponto final se converte no "ponto atual" e os valores de direção, direção perpendicular e diâmetro são atualizados.

Devido ao fato de que a instrução $f$ tem a capacidade de estabelecer o diâmetro atual, podemos utilizar a instrução para simular anomalias. 


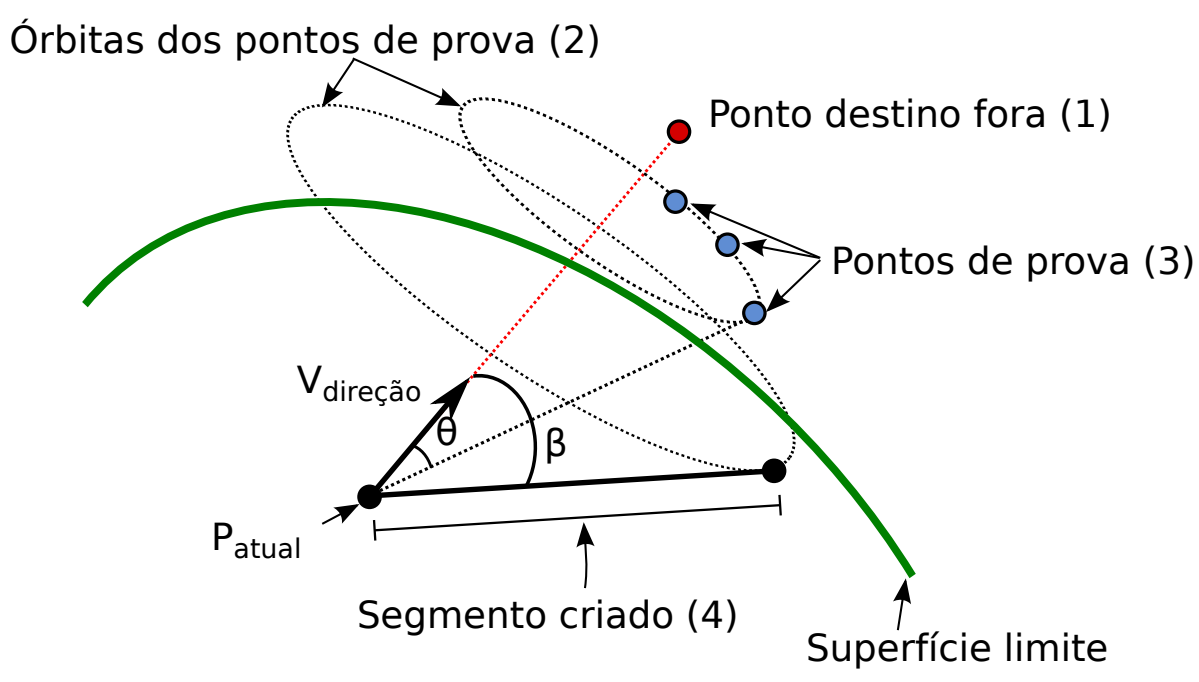

Figura 3.8: Etapas no controle da geração de um novo ponto considerando restrições.

\section{Simulação de anomalias}

Para simular anomalias como aneurismas e estenoses dentro das RVs, utilizamos a instrução de avançar para modificar o diâmetro atual por um comprimento dado e depois o diâmetro original é restaurado. A seguir, são mostradas duas regras de exemplo, uma cria um segmento com estenose e a outra com aneurisma.

Estenose $E(d 0) \rightarrow f(1, d 0) f\left(1,{ }^{\prime} d 0 / 2^{\prime}\right) f(1, d 0)$, nesse caso o segmento atual avança uma unidade com o diâmetro inicial $(d 0)$, depois avança com um diâmetro igual a $d 0 / 2$. Esse é o setor da estenose. E finalmente restaura o seu diâmetro original avançando mais uma unidade.

Aneurisma A regra: $A(d 0) \rightarrow f(1, d 0) f\left(1,{ }^{\prime} d 0 * 2^{\prime}\right) f(1, d 0)$, gera um segmento avançando uma unidade com o diâmetro inicial $(d 0)$, depois avança uma unidade com um diâmetro igual a $d 0 * 2$, esse é o setor da aneurisma, a qual têm o dobro do diâmetro. Finalmente, restaura o seu diâmetro original, avançando mais uma unidade.

\section{Rotações do vetor de direção (+, -)}

O símbolo "+" representa rotações no sentido anti-horário do vetor $V_{\text {direção }}$ no eixo do vetor $V_{\text {perpendicular }}$, enquanto "-” é a rotação no sentido horário.

A operação de rotação aceita um parâmetro $\theta$ que é o ângulo de rotação. Por exemplo: $+(30)$ significa a rotação de 30 graus sexagesimais no sentido horário. Se o valor de $\theta$ não for dado, será utilizado o ângulo $\theta_{1}$ calculado como descrito na Equação 3.1.

Para simular os ângulos numa bifurcação, é recomendável utilizar uma rotação de thet $a_{1}$ graus no sentido horário e outra de $t$ het $a_{2}$ no sentido anti-horário.

\section{Rotações do vetor de direção perpendicular $(/, *)$}

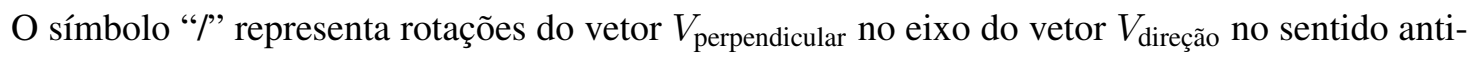
horário, enquanto “*” realiza a rotação no sentido horário. 
Essas rotações com todos os parâmetros são $/(\theta)$ e $*(\theta)$, em que $\theta$ é o ângulo de rotação. Se o valor de $\theta$ não é dado, será usado um ângulo de rotação ótimo. Nesse caso, é usado $\theta=70^{\circ}$.

\section{Empilhar e desempilhar ([, ])}

O símbolos "[" e "]" não precisam de parâmetros e servem para empilhar e desempilhar o estado atual na pilha.

Os dados que compõem o estado atual e que são empilhados na pilha são: $V_{\text {perpendicular }}, V_{\text {direção, }}$ diâmetro, $P_{\text {atual. }}$. Se for chamada a instrução and tese desempilhar, essas variáveis são sobrescritas.

\subsection{Discretização}

Uma vez que temos todos os dados da rede vascular, é necessário prover volume à RV e representála como uma imagem tridimensional. As imagens médicas mais utilizadas na angiografia são as imagens de RM e de TC, e os formatos de imagens médicas mais conhecidos são DICOM, Nifti e Analyze [Polzehl e Tabelow, 2007]. No entanto, todos esses tipos precisam de informações adicionais, como nome do paciente e modos de adquisição das imagens. Foi escolhido o formato . raw que só armazena as imagens como uma sequência de bytes, e um arquivo de cabeçalho adicional . mhd, que contém algumas informações da imagem raw como comprimento e espaçamento.

A geração das imagens é feita nas etapas seguintes (Figura 3.9):

- Definição dos parâmetros para a geração da imagem resultante.

- Normalização dos pontos da rede vascular sintética gerada nas etapas anteriores.

- Geração do esqueleto.

- Adição de volume.

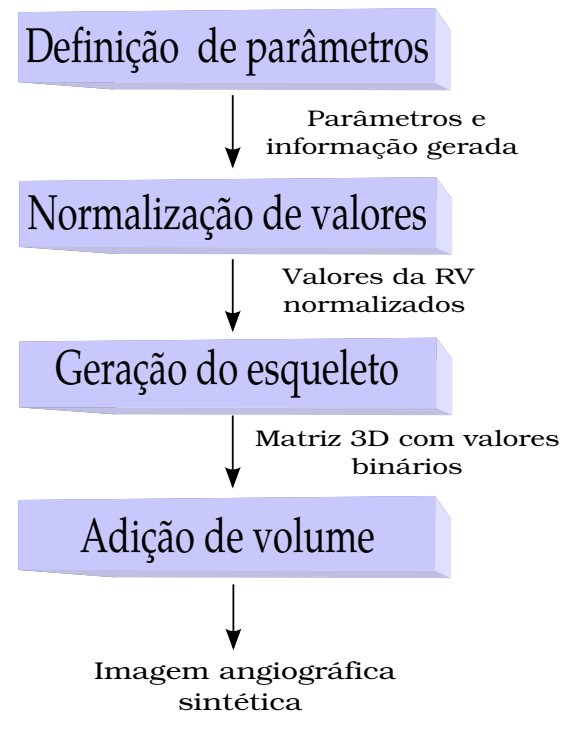

Figura 3.9: Fluxo da discretização. 


\subsubsection{Definição dos parâmetros}

Os parâmetros para a geração das imagens finais tem que ser estabelecidos no começo da discretização. Os parâmetros requeridos são:

Tamanho da imagem: O tamanho da imagem é formado por 3 valores inteiros, os quais representam o tamanho em $x, y$ e $z$.

Espaçamento da imagem: $O$ espaçamento na imagem é formado por 3 valores reais: $E_{x}, E_{y}$ e $E_{z}$. O valor padrão é 1 para cada um.

Porcentagem de ruído: O valor da porcentagem de ruído que será utilizada encontra-se no intervalo $[0,1]$.

Iterações de interpolação: O valor padrão é 3. Quanto maior for o valor, maior será a quantidade de pontos interpolados.

Tipo de imagem: Imagem de vasos com volume ou imagem de esqueleto da RV.

Mudança da escala da imagem: A imagem sofrerá uma mudança de escala para ocupar o maior espaço possível nos três eixos.

Uma captura de tela do formulário implementado pode ser vista na Figura 3.10.

\subsubsection{Normalização dos pontos da RV}

Os pontos criados na etapa de geração da RV são números reais, podendo possuir coordenadas negativas. Portanto, é importante fazer uma normalização para o espaço dos inteiros, e alterar a escala dos pontos para ocupar o espaço designado dentro dos limites da imagem final, por meio da definição de uma função de normalização para qualquer ponto da RV gerada.

Seja $P_{1}(x, y, z)$ um ponto qualquer da RV gerada. Se a área na qual se encontra a rede vascular está delimitada pelos pontos $A_{0}$ e $A_{1}$ e o tamanho da matriz final é $(\Delta X, \Delta Y, \Delta Z)$, então o ponto normalizado $P_{2}$ será dado por:

$$
P_{2}=\left(\left\lfloor\frac{P_{1_{x}}-A_{0_{x}}}{A_{1_{x}}-A_{0_{x}}} \Delta X\right\rfloor,\left\lfloor\frac{P_{1_{y}}-A_{0_{y}}}{A_{1_{y}}-A_{0_{y}}} \Delta Y\right\rfloor,\left\lfloor\frac{P_{1_{z}}-A_{0_{z}}}{A_{1_{z}}-A_{0_{z}}} \Delta Z\right\rfloor\right) .
$$

\subsubsection{Obtenção do esqueleto da RV}

O esqueleto da RV é uma imagem na qual só é mostrado o centro de linha dos segmentos da RV. Isso é principalmente útil para a avaliação de algoritmos de segmentação de RV, que podem comparar se os centros dos segmentos encontrados pelo método casam com o esqueleto da imagem original.

Em nossa metodologia, a imagem gerada é uma imagem binária, na qual o esqueleto é representado pela intensidade máxima $\left(I_{m} a x\right)$, e o resto da imagem é representado por uma intensidade igual a zero.

$\mathrm{O}$ arquivo criado na etapa de geração contém todos os segmentos e sub-segmentos da rede vascular, os quais são representados com pontos e os seus respectivos diâmetros. Graças à normalização, 


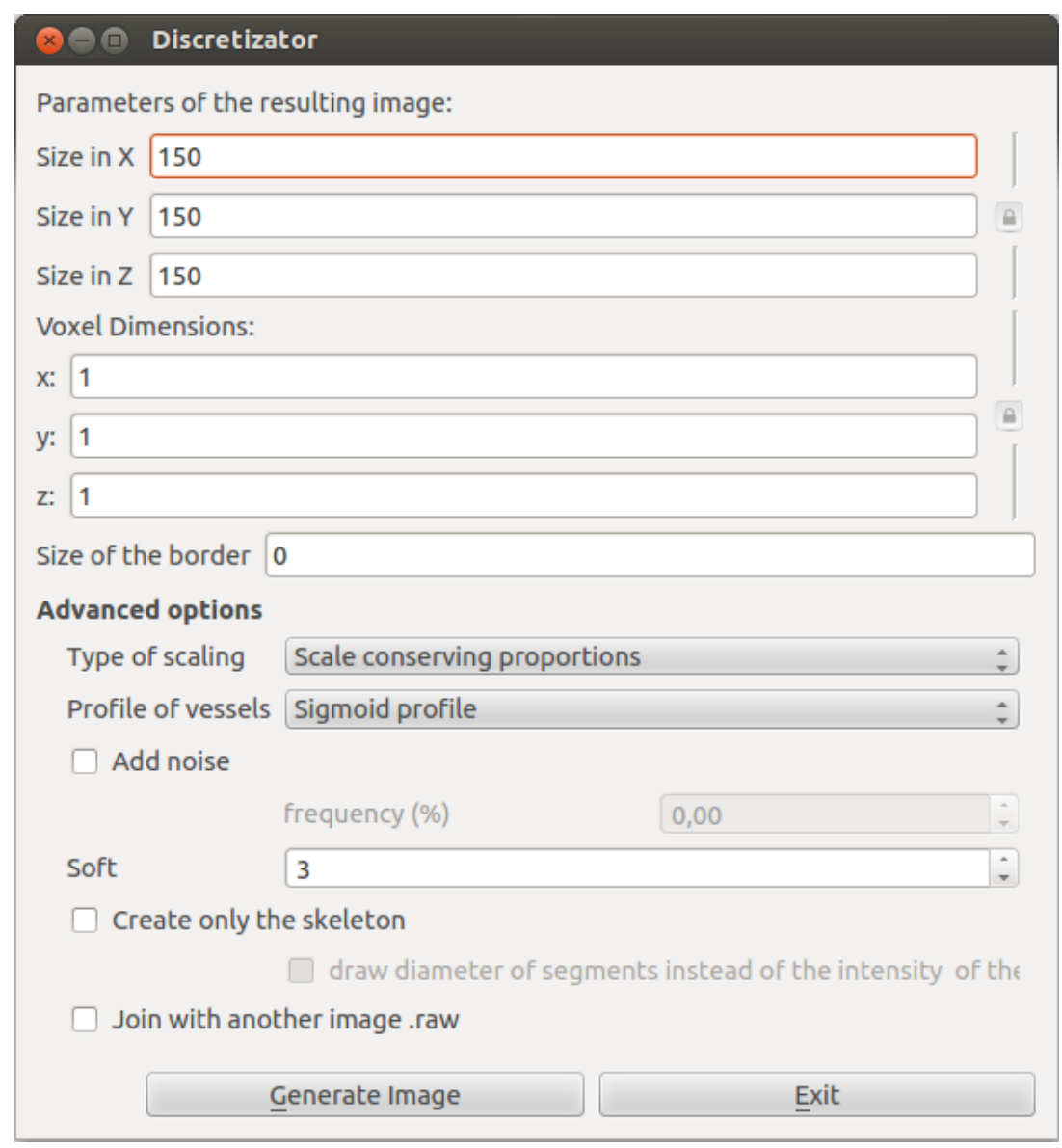

Figura 3.10: Captura de tela do formulário de discretização.

podemos converter esses pontos descritos em pontos dentro da imagem. Neste momento, precisamos de algum método para juntar esses pontos que poderiam estar separados, de tal forma que descreva o trajeto pelo qual passa a RV. Para isso, existem duas abordagens:

- Se um segmento da RV não tiver sub-segmentos, os dois pontos limites do segmento podem ser conectados simplesmente por segmentos de reta. Para esse fim foi escolhido o algoritmo de Bresenham criado inicialmente para duas dimensões [Bresenham et al., 1986], mas modificado para três dimensões utilizando como base o algoritmo desenvolvido por Heckbert [1994].

- Caso o segmento seja formado por sub-segmentos, os pontos limite de cada sub-segmento servirão como pontos de controle para uma spline do tipo B-Spline que será utilizada para calcular $n$ pontos intermediários, dependendo do número de iterações $i$ escolhido nos parâmetros. De forma geral, são gerados $n=2^{i}-1$ pontos intermediários para cada um dos sub-segmentos. A sequência de geração para este caso é mostrada na Figura 3.11.

\subsubsection{Adição de volume}

Os perfis de segmentos de RV em imagens de angiografia real, dependendo da modalidade de aquisição, tendem a ter um perfil do tipo gaussiano [Zana e Klein, 2001] ou um perfil baseado em 
1)

A

A
-

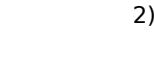

B

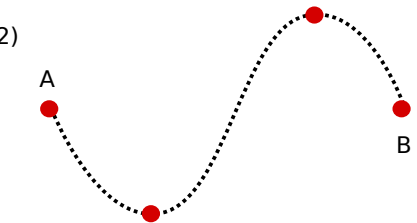

3)

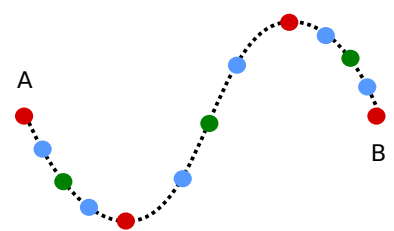

4)

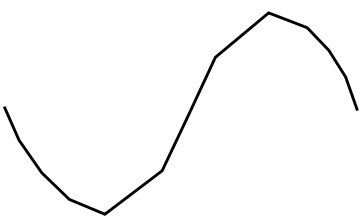

.... Função spline.

- Esqueleto final.

Pontos de controle.

P. criados na primeira interpolação.

- P. criados na segunda interpolação.

Figura 3.11: Sequência de geração do esqueleto no caso que o segmento possuir subsegmentos. 1) Pontos iniciais do segmento (pontos de controle). 2) Traçado da função de interpolação. 3) Criação de pontos interpolados. 4) Segmento traçado entre os pontos.

funções sigmoides [Kirbas e Quek, 2003].

Para a obtenção de imagens com perfis similares aos perfis obtidos nas imagens de angiografia reais, é preciso adicionar informação volumétrica aos vasos gerados. Para isso, é feita uma convolução de uma esfera com intensidades distribuídas de acordo com a função Gaussiana ou sigmoide escolhida.

\section{Função Gaussiana}

$\mathrm{Na}$ função Gaussiana, a intensidade dada a um pixel separado do centro do segmento de uma distância $d$ é:

$$
I_{p}=e^{\frac{-d^{2}}{2 \sigma^{2}}}
$$

em que o $\sigma$ escolhido por ter melhores resultados experimentais é $\sigma=$ raio/2. Um gráfico dessa função Gaussiana com raio $=3$ é mostrada na Figura 3.12.

\section{Função sigmoide}

Uma função sigmoide como mostrada na Figura 3.13a é definida como:

$$
P(x)=\frac{1}{1+e^{-x}}
$$

A função sigmoide é crescente no eixo $x$. No entanto, nós precisamos de uma função decrescente, para que no centro de cada segmento de RV, a intensidade seja máxima. Além disso, como a função sigmoide tem valores diferentes de zero e um, no intervalo $[-6,6]$ do eixo $x$, podemos normalizar a equação para ter esses valores no intervalo de $[0,1]$ no eixo $x$, tal como mostrado na seguinte equação 


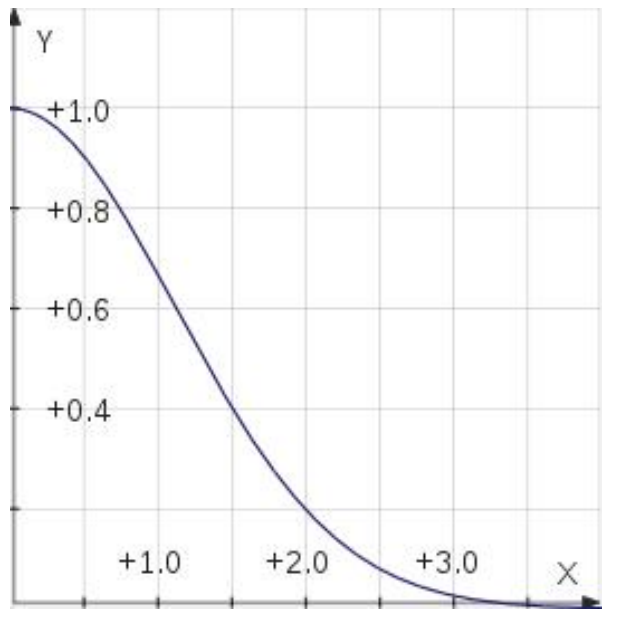

Figura 3.12: Gráfico da função Gaussiana para um raio igual a 3

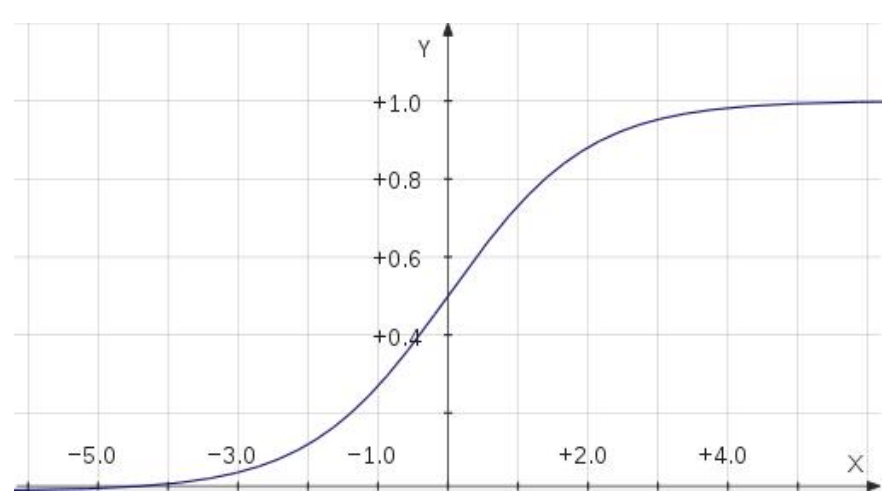

(a)

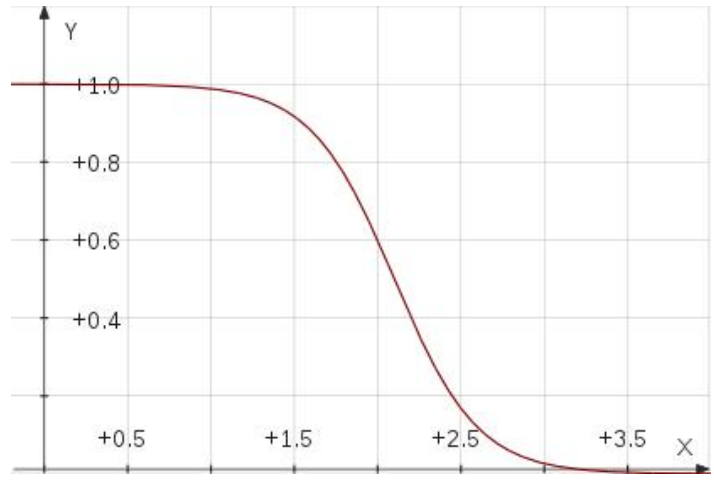

(b)

Figura 3.13: a) Gráfico da função sigmoide. b) Gráfico da função sigmoide para um raio igual a 3 .

que desenvolvemos:

$$
P(x)=\frac{1}{1+e^{12(x-0.5)}} .
$$

De forma geral, temos que a distribuição de intensidades de um voxel que está separado do centro do segmento a uma distância $d$ é dada por:

$$
P(d)=\frac{1}{1+e^{\gamma(d-\beta)}},
$$

em que a constante $\gamma$ controla a inclinação e $\beta$ é o ponto central no eixo $x$ da função, no qual a curva têm valor 0.5 .

Experimentalmente, obtivemos uma curva semelhante às curvas de perfil em imagens reais, com valores de: $\gamma=12 /$ raio e $\beta=0.7 *$ raio, em que raio é o raio do segmento atual.

Um gráfico da função sigmoide para o raio igual a 3 é mostrado na Figura 3.13b. 


\section{Aplicação da distribuição no esqueleto}

As intensidades da esfera criada são normalizadas com a finalidade de obter uma intensidade máxima ( $\left.y_{\max }\right)$ no centro. Um ponto, cuja distância ao centro seja maior que o raio do segmento atual, recebe uma intensidade 0 . A fórmula de normalização é:

$$
y^{\prime}=\frac{y_{\max }^{\prime}-y_{\min }^{\prime}}{y_{\max }} * y
$$

em que $y_{\max }^{\prime}$ e $y_{\min }^{\prime}$ são as intensidades máximas e mínimas desejadas, $y$ é a intensidade inicial e $y^{\prime}$ a intensidade normalizada.

Uma nova esfera é calculada para cada um dos segmentos e, para cada um dos pontos do seu esqueleto, é passada a esfera.

Caso o segmento tenha sido formado por sub-segmentos e interpolados por uma spline, a cada sub-segmento resultante da interpolação é associado um diâmetro que também é interpolado. Na Figura 3.14 é mostrada uma imagem após adicionar volume a um esqueleto de RV com o método descrito.

Finalmente, a intensidade de cada pixel da imagem é escrita como uma sequência de bytes num arquivo com extensão . raw e as informações da imagem num cabeçalho em formato . mhd.

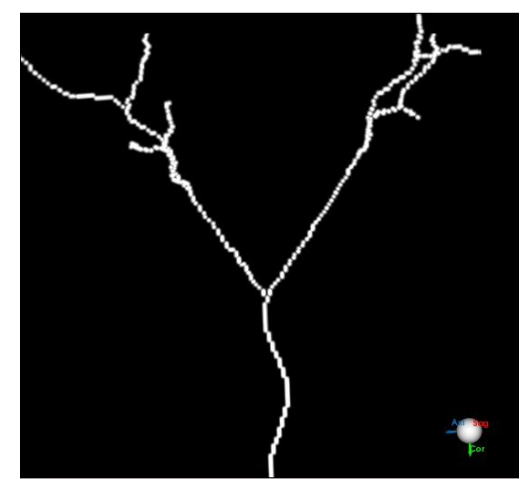

(a)

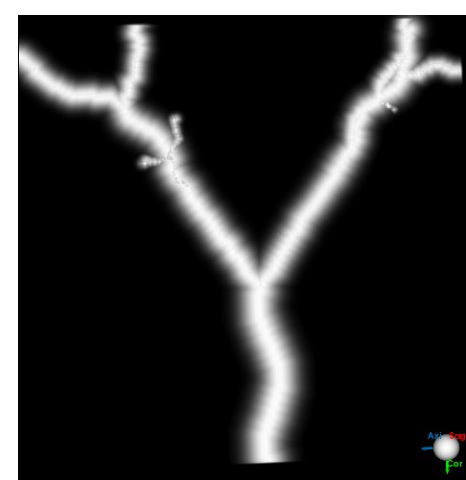

(b)

Figura 3.14: a) Imagem do esqueleto de uma RV. b) Imagem da RV com adição de volume por distribuição gaussiana.

\subsection{Complexidade computacional}

A complexidade computacional da metodologia depende muito da gramática dada como entrada, já que uma regra poderia ou não ser recursiva ou uma regra até poderia terminar na primeira execução sem importar o número de iterações. No entanto, é possível calcular o tempo computacional em cada uma das sub-etapas (sem considerar a geração da cadeia, pelo problema explicado anteriormente).

Uma vez que temos a cadeia gerada pela gramática, a execução de cada uma das seguintes instruções tem ordem $O(1)$ : rotacionar $(+,-, /, *)$; salvar e recuperar o estado $([$ e $]$ ); e avançar $(f)$ quando o crescimento não tiver restrições. 
Se o crescimento for restrito, a complexidade da instrução $f$ dependerá do número de órbitas $(N)$, do número de pontos por órbita a ser testados $(P)$ e da complexidade de saber se um ponto está dentro ou fora das superfícies limites $O$ (ForaOuDentro $)$. Assim a complexidade é de ordem $O(N * P * O($ ForaOuDentro $))$. 


\section{Capítulo 4}

\section{Resultados}

Neste capítulo são apresentados diferentes resultados experimentais obtidos da implementação da metodologia descrita no Capítulo 3. Nessa implementação, foram utilizadas as linguagens de programação: Python ${ }^{1}$, para a geração das redes vasculares sintéticas e geração de imagens finais, e $\mathrm{C}++$, para gerar um aplicativo utilizado para visualizar um desenho preliminar dos dados antes da discretização. Durante o desenvolvimento, foram utilizadas também as seguintes bibliotecas: $\mathbf{Q t}^{2}$, $\mathrm{VTK}^{3}, \mathrm{PLY}^{4}, \mathrm{SciPy}^{5}$ e $\mathrm{PIL}^{6}$.

Os resultados mostrados no seguinte capítulo foram produzidos utilizando um computador com 16 núcleos de processador Intel $2.4 \mathrm{GHz}$ com 20 GB de memória RAM sob o sistema operacional Ubuntu/GNU-Linux.

O objetivo principal desses experimentos é avaliar a viabilidade da metodologia, avaliar a funcionalidade do algoritmo de geração das redes vasculares sintéticas criadas, assim como mostrar a flexibilidade e a capacidade da metodologia para criar uma grande diversidade de RV sintéticas.

São mostrados alguns resultados obtidos a partir da implementação da nossa metodologia.

\subsection{Resultados da geração de cadeias}

Nas Tabelas 4.1, 4.2 e 4.3 são mostradas algumas cadeias resultantes depois da i-ésima iteração de uma dada gramática. Por motivos de espaço, os valores numéricos nessas tabelas foram arredondados para dois dígitos.

Como foi explicado na metodologia, para a produção dessas cadeias são geradas inicialmente funções em Python para cada uma das regras, assim, os códigos-fonte gerados a partir das gramáticas

\footnotetext{
${ }^{1}$ Python é uma linguagem de programação interpretada, imperativa e orientada a objetos (http: / / www . python . org).

${ }^{2}$ Qt é um framework multiplataforma para desenvolvimento de interfaces gráficas em C++ (http: //qt. nokia. $\mathrm{com} /$ ).

${ }^{3}$ O VTK (Visualization ToolKit) é um software de código aberto, para computação gráfica 3D, processamento de imagem e visualização (http: / /www. vtk. org/).

${ }^{4}$ PLY (Python Lex-Yacc) é uma implementação das ferramentas Lex and Yacc para Python (http: / / www . dabeaz . $\mathrm{com} / \mathrm{ply} /$ )[Beazley, 2009].

${ }^{5}$ SciPy é um software de código aberto para matemática, ciência e engenharia (http: / / www . scipy . org).

${ }^{6}$ PIL(Python Image Library) é uma biblioteca do Python que adiciona suporte à abertura e gravação de muitos formatos de imagens (http://www. pythonware.com/products/pil/).
} 


\begin{tabular}{|c|c|}
\hline Iteração & $\begin{array}{c}\text { Resultados da gramática: } \\
\mathrm{F} \rightarrow \mathrm{f}[+\mathrm{F}]-\mathrm{F}\end{array}$ \\
\hline \hline 1 & $\mathrm{f}[+\mathrm{F}]-\mathrm{F}$ \\
\hline 2 & $\mathrm{f}[+\mathrm{f}[+\mathrm{F}]-\mathrm{F}]-\mathrm{f}[+\mathrm{F}]-\mathrm{F}$ \\
\hline 3 & $\mathrm{f}[+\mathrm{f}[+\mathrm{f}[+\mathrm{F}]-\mathrm{F}]-\mathrm{f}[+\mathrm{F}]-\mathrm{F}]-\mathrm{f}[+\mathrm{f}[+\mathrm{F}]-\mathrm{F}]-\mathrm{f}[+\mathrm{F}]-\mathrm{F}$ \\
\hline
\end{tabular}

Tabela 4.1: Resultados de execuções de uma gramática simples em 3 diferentes iterações.

\begin{tabular}{|c|l|}
\hline & Resultados da gramática: \\
Iter. & $\mathrm{F}(\mathrm{d} 0) \rightarrow \mathrm{f}(\mathrm{d} 0)[+(\mathrm{th} 1) \mathrm{F}(\mathrm{d} 1)]-(t h 2) \mathrm{F}(\mathrm{d} 2)$ \\
\hline \hline 1 & $\mathrm{f}[+(43.47) \mathrm{F}][-(31.58) \mathrm{F}]$ \\
\hline 2 & $\mathrm{f}[+(53.57) \mathrm{f}[+(39.98) \mathrm{F}][-(34.98) \mathrm{F}]][-(22.24) \mathrm{f}[+(65.38) \mathrm{F}][-(12.39) \mathrm{F}]]$ \\
\hline 3 & $\begin{array}{l}\mathrm{f}[+(37.46) \mathrm{f}[+(38.94) \mathrm{f}[+(18.5) \mathrm{F}][-(57.87) \mathrm{F}]][-(36.0) \mathrm{f}[+(37.47) \mathrm{F}][-(37.47) \mathrm{F}]]][- \\
(37.47) \mathrm{f}[+(37.47) \mathrm{f}[+(40.32) \mathrm{F}][-(34.64) \mathrm{F}]][-(37.47) \mathrm{f}[+(55.6) \mathrm{F}][-(20.46) \mathrm{F}]]]\end{array}$ \\
\hline
\end{tabular}

Tabela 4.2: Resultados de execuções de uma gramática com parâmetros em 3 diferentes iterações.

\begin{tabular}{|c|l|}
\hline \multirow{3}{*}{ Iter. } & Resultados da gramática: \\
& $\mathrm{F}(\mathrm{d} 0) \rightarrow \mathrm{S}(\mathrm{d} 0)[+(\mathrm{th} 1) /(70) \mathrm{F}(\mathrm{d} 1)][-(\mathrm{th} 2) /(70) \mathrm{F}(\mathrm{d} 2)]$ \\
& $\mathrm{S}(\mathrm{d} 0): 0.5 \rightarrow \mathrm{D}(\mathrm{d} 0)+(25) \mathrm{D}(\mathrm{d} 0)-(25) \mathrm{D}(\mathrm{d} 0)-(25) \mathrm{D}(\mathrm{d} 0)+(25) \mathrm{D}(\mathrm{d} 0)$ \\
& $\mathrm{S}(\mathrm{d} 0): 0.5 \rightarrow \mathrm{D}(\mathrm{d} 0)-(25) \mathrm{D}(\mathrm{d} 0)+(25) \mathrm{D}(\mathrm{d} 0)+(25) \mathrm{D}(\mathrm{d} 0)-(25) \mathrm{D}(\mathrm{d} 0)$ \\
& $\mathrm{D}(\mathrm{d} 0) \rightarrow \mathrm{f}\left({ }^{c} \mathrm{co} / 5,, \mathrm{~d} 0\right)$ \\
\hline \hline 1 & $\mathrm{~S}[+(40.06) /(70.0) \mathrm{F}][-(34.9) /(70.0) \mathrm{F}]$ \\
\hline 2 & $\mathrm{D}-(25.0) \mathrm{D}+(25.0) \mathrm{D}+(25.0) \mathrm{D}-(25.0) \mathrm{D}[+(34.09) /(70.0) \mathrm{S}[+(13.19) /(70.0) \mathrm{F}][-$ \\
& $(64.35) /(70.0) \mathrm{F}]][-(40.89) /(70.0) \mathrm{S}[+(37.47) /(70.0) \mathrm{F}][-(37.47) /(70.0) \mathrm{F}]]$ \\
\hline 3 & $\mathrm{f}(1.50,1.0)-(25.0) \mathrm{f}(1.48,1.0)+(25.0) \mathrm{f}(1.52,1.0)+(25.0) \mathrm{f}(1.52,1.0)-$ \\
& $(25.0) \mathrm{f}(1.59,1.0)[+(24.19) /(70.0) \mathrm{D}+(25.0) \mathrm{D}-(25.0) \mathrm{D}-(25.0) \mathrm{D}$ \\
& $+(25.0) \mathrm{D}[+(10.84) /(70.0) \mathrm{S}[+(32.08) /(70.0) \mathrm{F}][-(42.95) /(70.0) \mathrm{F}]][-$ \\
& $(67.42) /(70.0) \mathrm{S}[+(31.45) /(70.0) \mathrm{F}][-(43.60) /(70.0) \mathrm{F}]]][-(51.4) /(70.0) \mathrm{D}-$ \\
& $(25.0) \mathrm{D}+(25.0) \mathrm{D}+(25.0) \mathrm{D}-(25.0) \mathrm{D}[+(40.21) /(70.0) \mathrm{S}[+(37.46) /(70.0) \mathrm{F}][-$ \\
& $(37.46) /(70.0) \mathrm{F}]][-(34.74) /(70.0) \mathrm{S}[+(40.82) /(70.0) \mathrm{F}][-(34.15) /(70.0) \mathrm{F}]]]$
\end{tabular}

Tabela 4.3: Resultados de execuções de uma gramática estocástica e com parâmetros em 3 diferentes iterações. Nesse caso, a regra $S$ é uma regra estocástica e $D$ é uma regra não estocástica que cria um sub-segmento.

mostradas são mostrados no Apêndice C.

\subsection{Resultados da geração de redes vasculares}

Como foi visto no Capítulo 3, nessa etapa é gerado um conjunto de pontos com seus respectivos diâmetros. Os segmentos que unem esses pontos foram desenhados para poder percebê-los num espaço cartesiano. $\mathrm{O}$ desenho dos segmentos gerados na terceira iteração pelas gramáticas mostradas nas Tabelas 4.1, 4.2 e 4.3 são mostrados na Figura 4.1.

As duas primeiras gramáticas formam imagens em duas dimensões, enquanto que a terceira gera uma RV em três dimensões. No entanto, para o terceiro caso o número de iterações é muito pequeno 


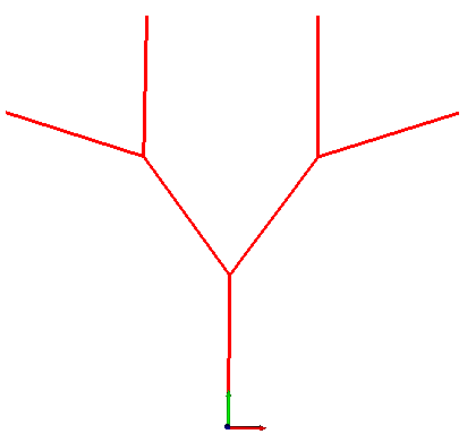

(a)

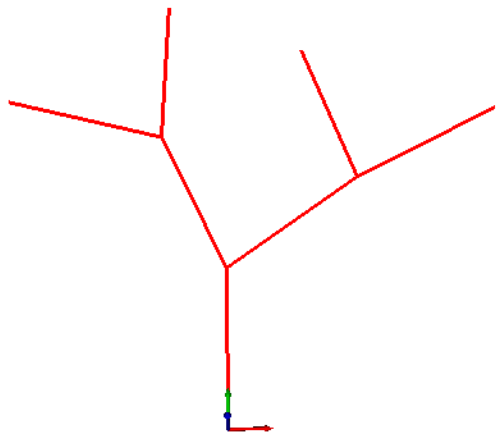

(b)

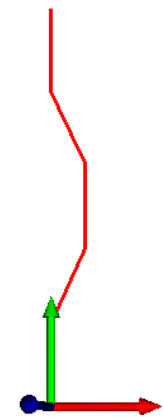

(c)

Figura 4.1: Desenho dos segmentos gerados a partir da execução das três gramáticas mostradas na Seção 4.1 na sua terceira iteração.

como para conseguir produzir uma bifurcação e é gerado apenas um segmento torto. É por isso que para uma melhor apreciação do comportamento dessas gramáticas são mostradas as gerações das mesmas gramáticas mas com 6 iterações. Na Figura 4.2 é mostrado o resultado das duas primeiras gramáticas e na Figura 4.3 é mostrado o resultado da geração da terceira gramática vista a partir de três ângulos diferentes.

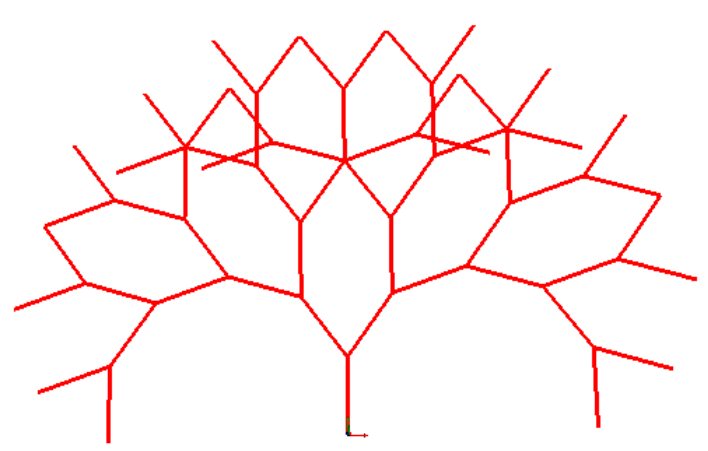

(a)

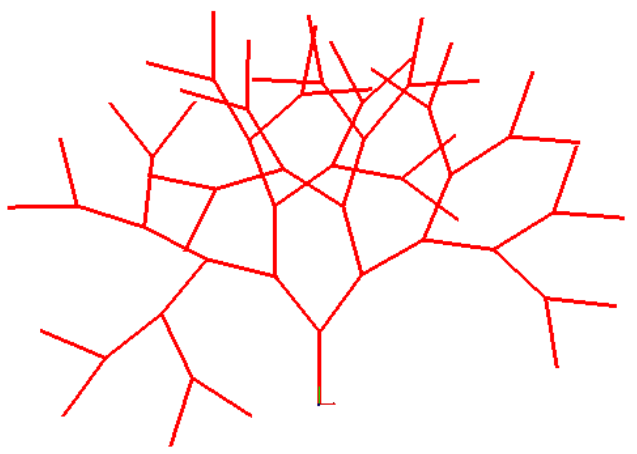

(b)

Figura 4.2: Desenho dos segmentos gerados para a execução das duas primeiras gramáticas mostradas na Seção 4.1 na sua sexta iteração.

\subsubsection{Controle de restrições}

Na produção de uma RV sintética, esta pode ter uma superfície que restringe o seu crescimento. Esse comportamento pode ser apreciado nas RVs sintéticas que apresentamos nessa seção, entre a quais mostramos imagens de três RVs sintéticas geradas; uma usando restrições sintéticas e duas outras geradas em superfícies obtidas a partir de segmentações de imagens reais.

Uma restrição sintética formada por duas superfícies em forma de cilindros, uma dentro da outra, é mostrada na Figura 4.4. Utilizando a mesma gramática que gerou a RV sintética da Figura 4.3 e com os mesmos parâmetros, foi gerada uma RV com 6 iterações no espaço entre os dois cilindros, 


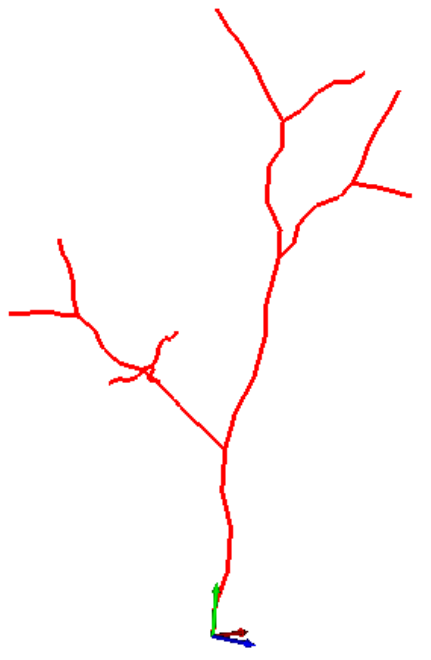

(a) Vista lateral.

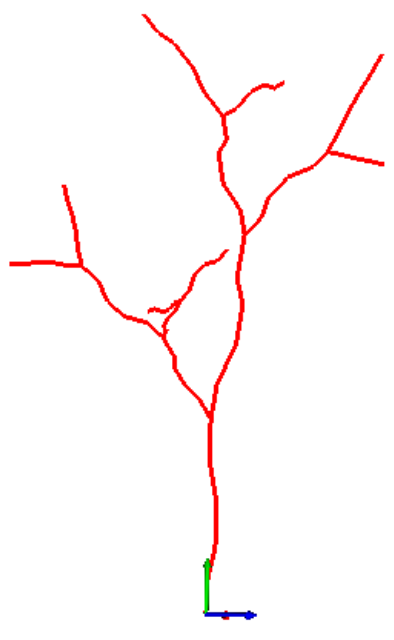

(b) Vista lateral.

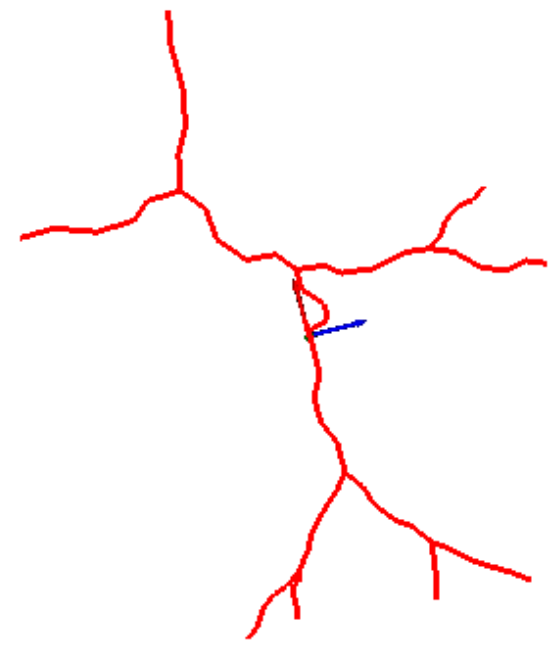

(c) Vista de cima.

Figura 4.3: Desenho dos segmentos de uma RV vista de ângulos distintos, gerada a partir da execução da terceira gramática mostrada na Tabela 4.3 na sua sexta iteração. 
não sendo possível o crescimento dentro do cilindro menor. O resultado dessa geração pode ser visto na Figura 4.5. O ponto inicial da RV foi escolhido intencionalmente para conseguir que ela chegue à superfície limite e possa ser apreciada a rotação que ela faz.

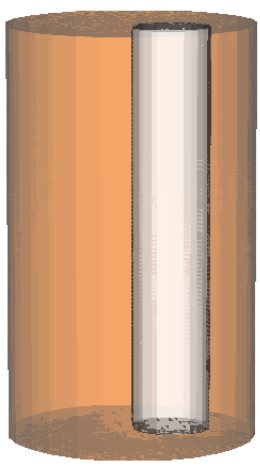

(a)

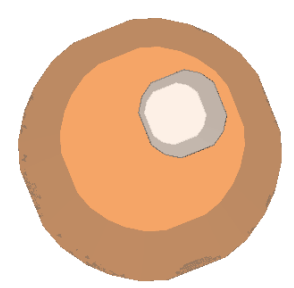

(b)

Figura 4.4: Superfície sintética formada por dois cilindros. a) Visão lateral. b) Visão superior.

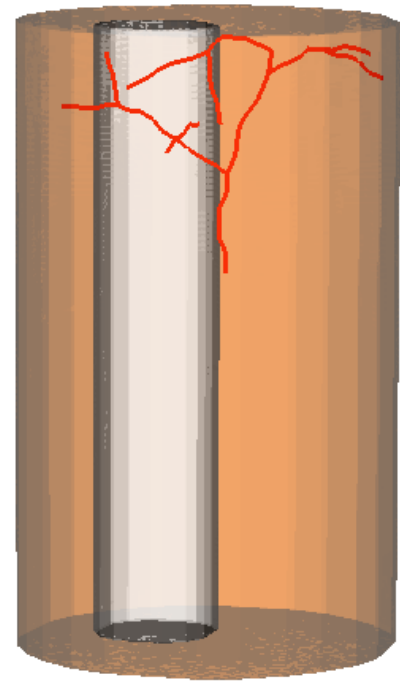

(a)

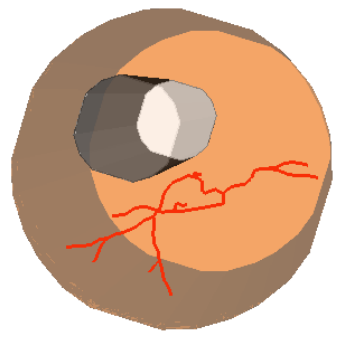

(b)

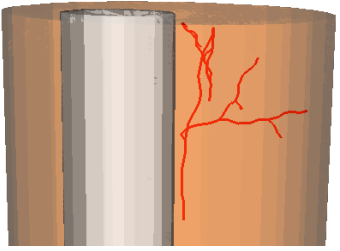

(c)

Figura 4.5: $R V$ sintética gerada dentro de um contexto limitado por cilindros.

A diferença entre utilizar restrições e ter uma geração sem elas é notória ao visualizar as duas RVs geradas com as mesmas propriedades mas só restringindo o espaço de crescimento. Para poder testar o comportamento dentro de espaços realistas, foram realizados dois testes. Em um deles utilizamos uma superfície gerada a partir da segmentação de um fígado real [Heimann et al., 2009]. Essa superfície, que pode ser encontrada em http: / /www. vision.ime.usp.br/ miguelgalarreta/ mestrado/figado.vtk, é formada por 221998 pontos. Na Figura 4.6, é mostrada uma RV sintética gerada em 10 iterações dentro dessa superfície. Nesse caso, foi utilizada a gramática mostrada no Apêndice C.2.1. Essa gramática começa com uma bifurcação com três segmentos filhos apenas na primeira bifurcação, as bifurcações seguintes têm dois segmentos filhos. 


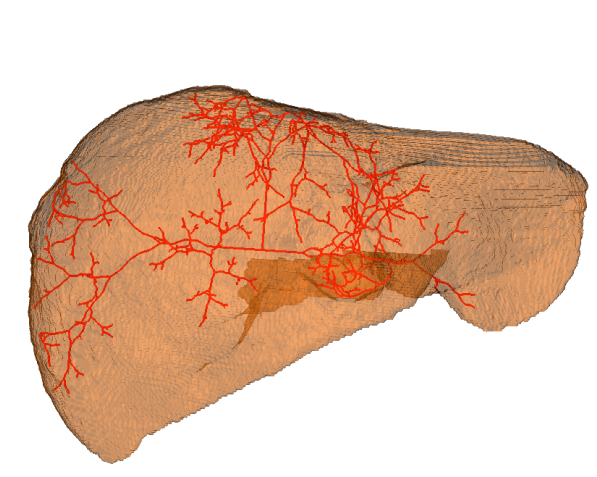

(a)

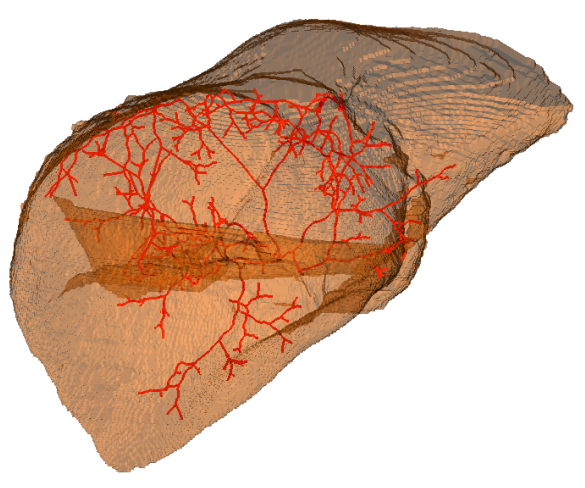

(b)

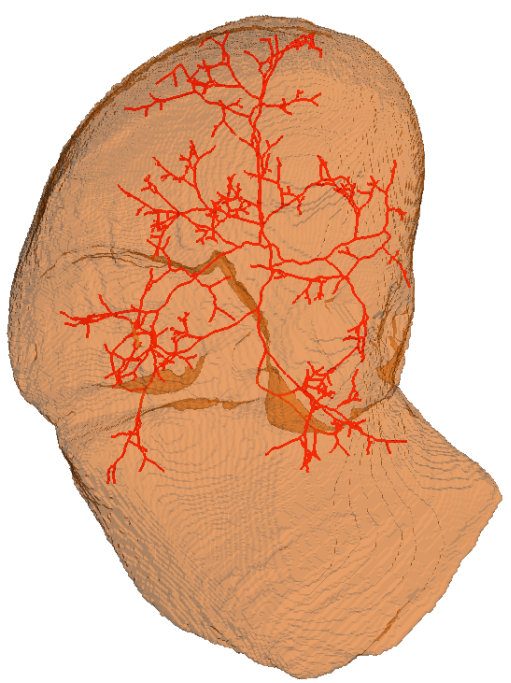

(c)

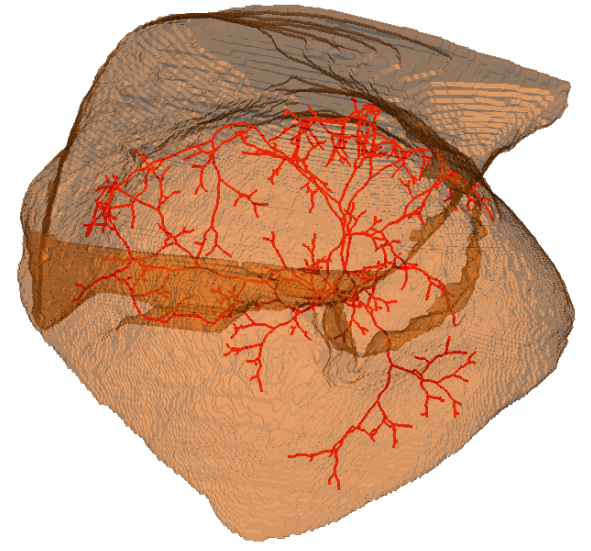

(d)

Figura 4.6: $R V$ sintética gerada dentro de uma superfície obtida a partir da segmentação de um fígado real, visto a partir de diferentes direções. 


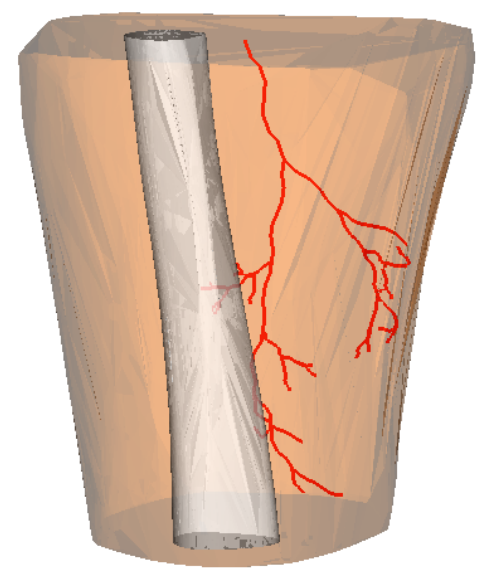

(a)

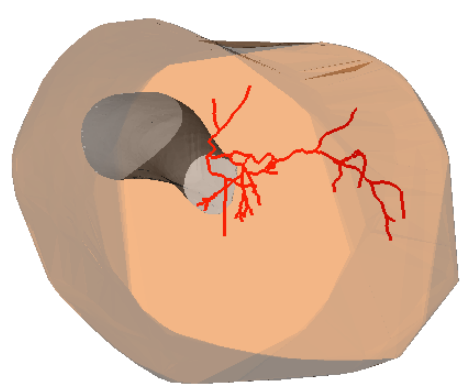

(b)

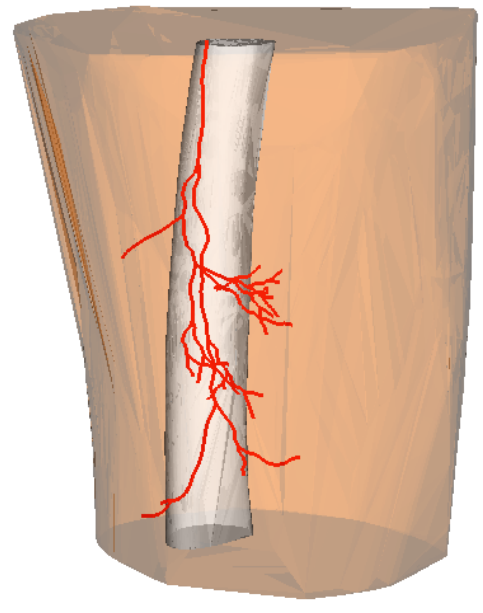

(c)

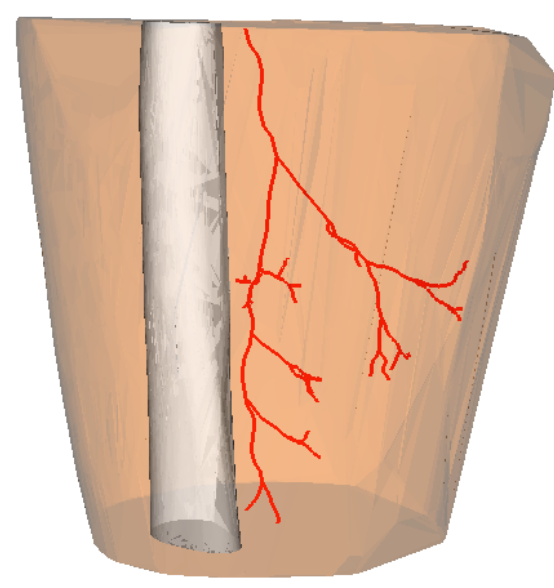

(d)

Figura 4.7: $R V$ sintética gerada dentro de um espaço limitado por duas superfícies, uma da segmentação dos músculos da perna e outra do fêmur. a), b), c) e d) são vistas obtidas a partir de diferentes direções.

Uma segunda RV sintética foi gerada dentro de um espaço limitado por duas superfícies, uma obtida a partir da segmentação da região muscular da perna e a outra da segmentação do fêmur. Ambas as superfícies foram obtidas de uma mesma imagem de angio-TC. O desenho dos segmentos que conformam a RV gerada, junto às superfícies que o limitam, é mostrada na Figura 4.7. Para a sua produção foi utilizado o arquivo de entrada mostrado no Apêndice C.2.2.

\subsection{Resultados da discretização}

Uma vez que tenhamos criado os pontos e os diâmetros que representam a RV, esta é discretizada para obter a imagem sintética final.

Uma projeção MIP da RV sintética que foi mostrada na Figura 4.6, sendo esta última gerada dentro de um espaço limitado pelo fígado, é mostrada na Figura 4.8. Nesse caso, a imagem da RV 
foi criada utilizando perfis de intensidade do tipo sigmoide.

A partir da RV gerada na perna, que foi mostrada anteriormente na Figura 4.7, geramos sua discretização e a mostramos na Figura 4.9. Nesse caso também utilizamos sigmoides para a simulação do perfil. Essa imagem foi gerada mantendo o comprimento e o espaçamento da imagem original, para assim poder mostrá-la junto às superfícies.

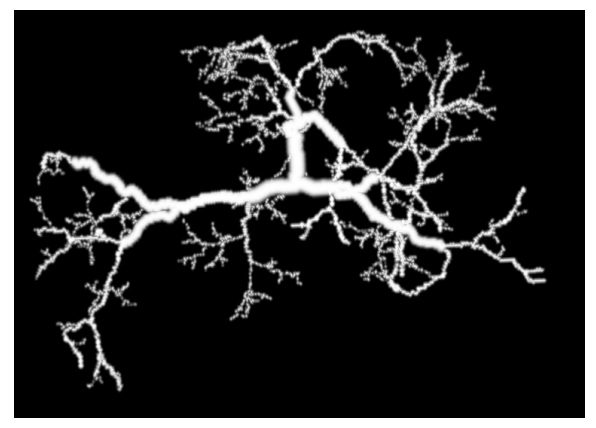

(a)

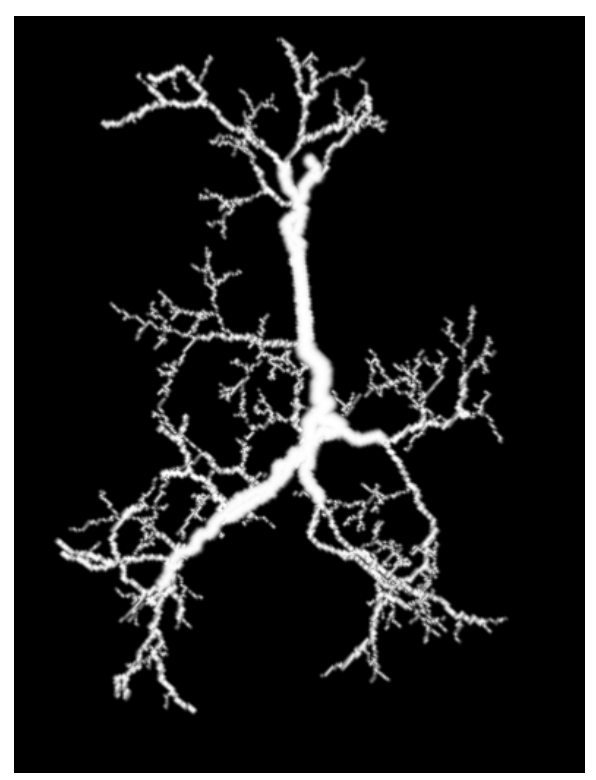

(b)

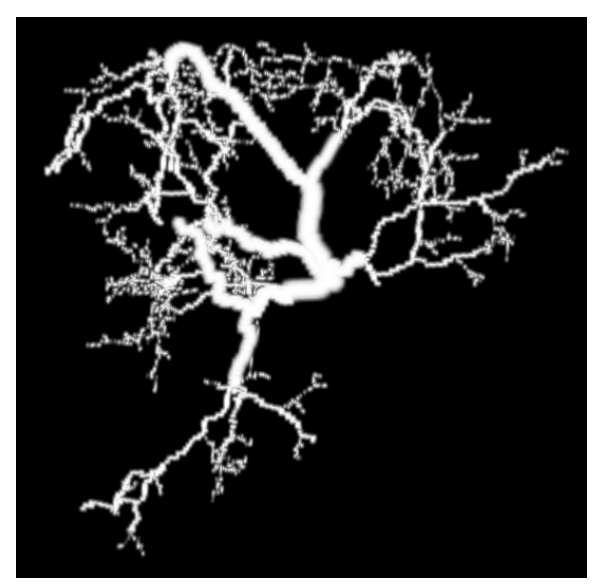

(c)

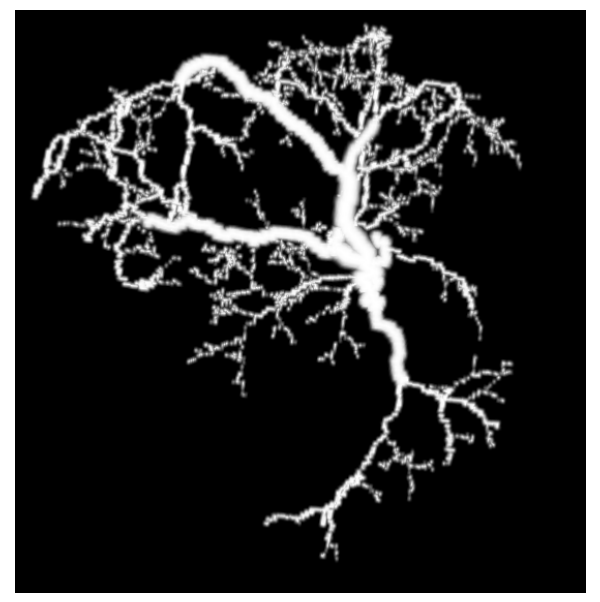

(d)

Figura 4.8: Projeção MIP de uma RV sintética gerada dentro de uma superfície obtida a partir de uma segmentação de um fígado real, vista a partir de diferentes direções.

\section{Interpolação dos pontos na discretização}

Para poder enxergar o efeito gerado pela interpolação de pontos dentro dos segmentos, mostramos na Figura 4.10 uma comparação entre uma imagem gerada com interpolação, vista nas Figuras 4.10b e 4.10e, e outra sem interpolação, mostrada nas Figuras 4.10a e 4.10d. As duas RVs são criadas utilizando as gramáticas seguintes:

Com interpolação:

$$
\begin{aligned}
& F(d 0) \rightarrow S(d 0)[+(t h 1) /(70) F(d 1)][-(t h 2) /(70) F(d 2)] \\
& S(d 0) \rightarrow f\left({ }^{\prime} c o / 5^{\prime}, d 0\right)+(39.4) f\left({ }^{\prime} c o / 5^{\prime}\right)-(39.4) f\left({ }^{\prime} c o / 5^{\prime}\right)-(39.4) f\left({ }^{\prime} c o / 5^{\prime}\right)+(39.4) f\left({ }^{\prime} c o / 5^{\prime}\right)
\end{aligned}
$$




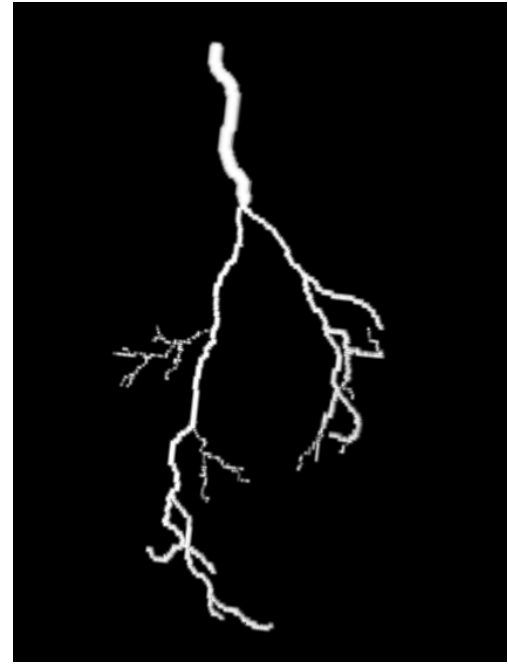

(a)

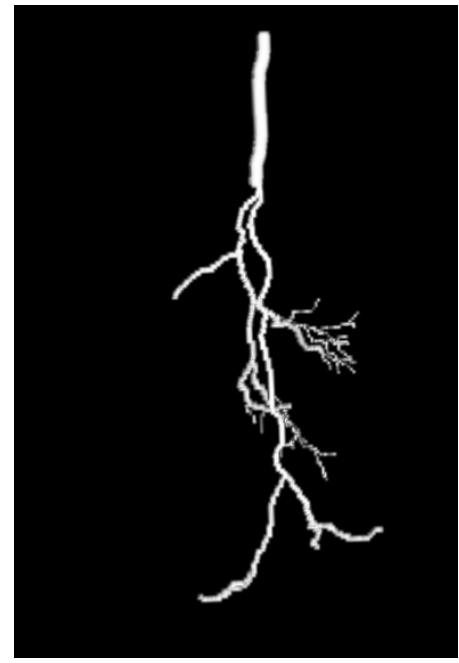

(c)

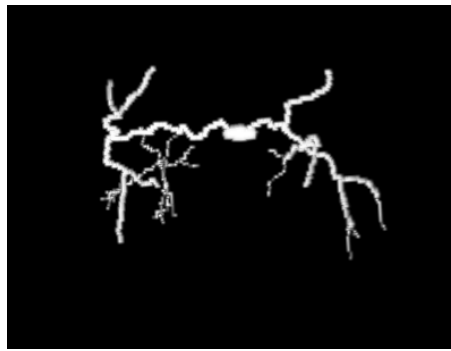

(b)

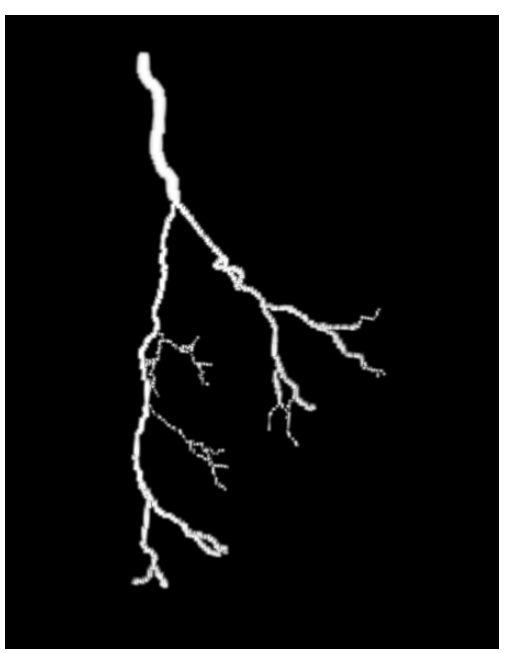

(d)

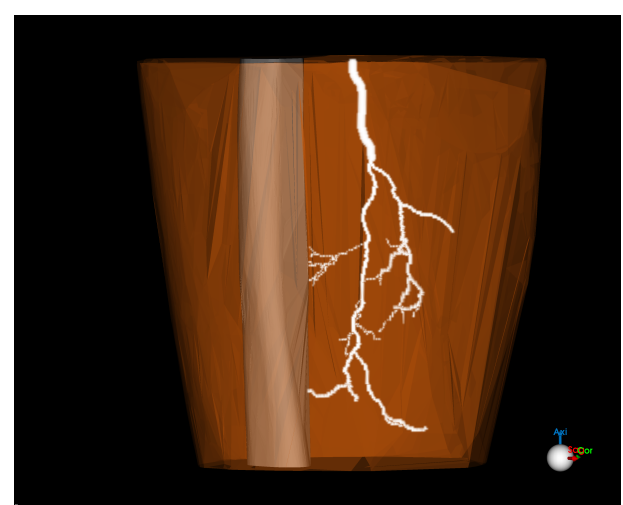

(e)

Figura 4.9: $R V$ sintética gerada dentro de um espaço limitado por duas superfícies, uma da segmentação dos músculos da perna e outra do fêmur. a), b), c), e d) mostram MIPs desde diferentes ângulos. e) uma MIP junto com as superfícies que a limitam. 


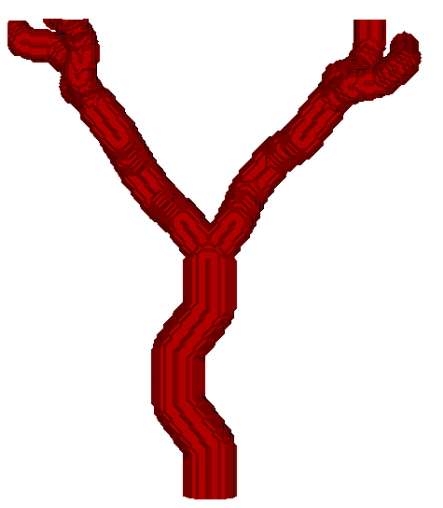

(a)

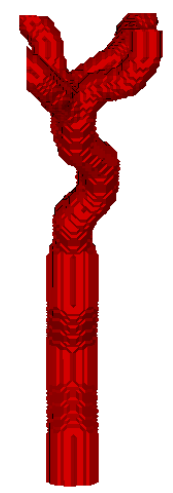

(d)

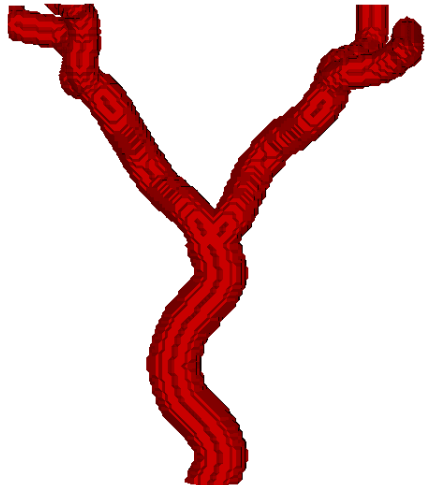

(b)

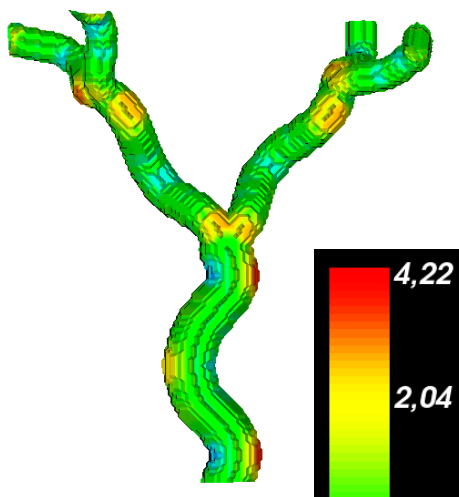

(c)

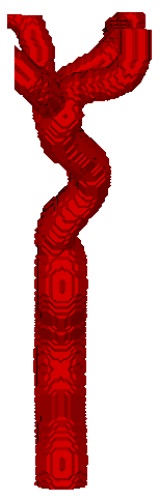

(e)

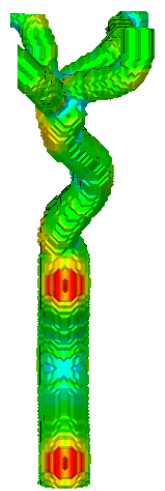

(f)

Figura 4.10: Comparação de duas RVs criadas com e sem interpolações. a) e d) RV sem interpolação. b) e e) $R V$ com interpolação. c) ef) Diferença entre as duas superfícies. g) Escala de diferenças em voxels.

Sem interpolação:

$F(d 0) \rightarrow S(d 0)[+(t h 1) /(70) F(d 1)][-(t h 2) /(70) F(d 2)]$

$S(d 0) \rightarrow f\left({ }^{\prime} c o / 5^{\prime}, d 0\right)+(39.4) f\left({ }^{\prime} c o / 5^{\prime}\right)-(39.4) f\left({ }^{\prime} c o / 5^{\prime}\right)-(39.4) f\left({ }^{\prime} c o / 5^{\prime}\right)+(39.4) f\left({ }^{\prime} c o / 5^{\prime}\right)$

Essas gramáticas foram executadas em 4 iterações e com todos os parâmetros padrão, exceto o parmsEstocs, que define se a rede será estocástica ou não. Esse parâmetro foi configurado como falso para garantir a geração das duas RVs com as mesmas características.

As imagens mostradas são o resultado da segmentação das imagens volumétricas geradas, enquanto que as Figuras 4.10c e 4.10f mostram a diferença da superfície sem interpolação $(x)$, com a superfície com interpolação $(y)$. A cor vermelha na superfície de diferenças é formada pelos pontos presentes em $y$ mas não em $x$, e a cor azul são os pontos presentes em $x$ mas não em $y$. A escala de diferenças, a qual indica quantos voxels precisam ser adicionados ou removidos a uma superfície para casar com outra, é mostrada na Figura $4.10 \mathrm{~g}$.

\section{Avaliação da Tortuosidade}

$\mathrm{Na}$ literatura, para poder comparar a tortuosidade dos segmentos dos vasos reais são utilizadas algumas métricas dentre as quais destaca-se o fator de distância (FD). 
O FD é uma abordagem utilizada frequentemente para avaliar tortuosidade vascular. É calculado como a razão entre o comprimento ao longo do segmento considerando as curvas e a distância entre o ponto inicial e o ponto final do segmento [Bullitt et al., 2003; Wood et al., 2006] ${ }^{7}$. Para um segmento formado pelos pontos $S_{0}, S_{1}, \ldots, S_{n}$, a equação para o cálculo do $F D$ é:

$$
F D=\frac{\sum_{i=0}^{n-1}\left|S_{i+1}-S_{i}\right|}{\left|S_{n}-S_{0}\right|}
$$

Assim o FD produz um valor adimensional que é de aproximadamente $1.1 \pm 0.1$ para artérias basilares normais [Bullitt et al., 2003], enquanto que para a artéria femoral é $0.683 * 10^{-3} \pm 0.9 *$ $10^{-3}$ [Wood et al., 2006].

A flexibilidade do $L$-system permite criar regras gramaticais que gerem segmentos com uma tortuosidade desejada, por meio de rotações de ângulos calculados manualmente. Assim, um segmento com $F D=1.1$ pode ser gerado por 5 sub-segmentos como o mostrado na regra seguinte:

$$
F(d 0) \rightarrow f\left({ }^{\prime} c o / 5 '\right)+(39.4) f\left({ }^{\prime} c o / 5^{\prime}\right)-(39.4) f\left({ }^{\prime} c o / 5 '\right)-(39.4) f\left({ }^{\prime} c o / 5^{\prime}\right)-(39.4) f\left({ }^{\circ} c o / 5 '\right)+
$$
(39.4) $f\left({ }^{\prime} c o / 5\right.$ ') .

Nessa regra, o ângulo 39.4 foi escolhido para satisfazer uma tortuosidade igual a 1.1. O comprimento total do segmento é ' $c o$ '. A forma do segmento gerado é mostrada na Figura 4.11, em que $x=c o / 5$ e $\theta=39.4$.

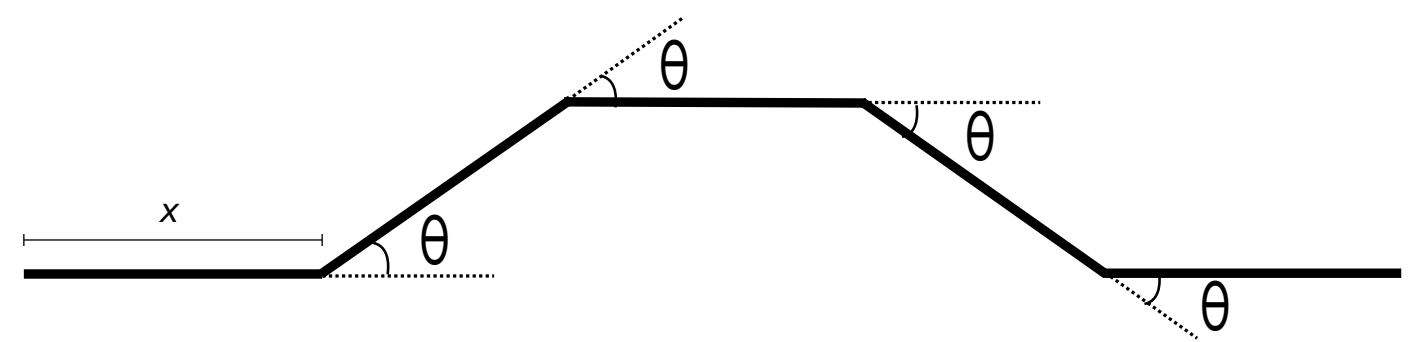

Figura 4.11: Forma de um segmento gerado pela gramática: $F \rightarrow f(x)+(\theta) f(x)-(\theta) f(x)-$ $(\theta) f(x)+(\theta) f(x)$.

\subsubsection{Exemplos do banco de imagens sintéticas criadas}

Foram criadas 50 redes vasculares sintéticas, as quais podem ser obtidas livremente no site: http://www.vision.ime.usp.br/ miguelgalarreta/mestrado/RVsinteticas.

Com a finalidade de mostrar a diversidade de RVs que nossa metodologia possibilita gerar, são mostradas visualizações volumétricas de algumas RVs geradas com suas respetivas gramáticas.

A RV seguinte tem um diâmetro muito maior em comparação à media de RVs reais. Isso é devido à proporção entre o comprimento e o diâmetro do segmento $(\operatorname{prop} C D)$ é muito pequena. Esse tipo de imagem pode ser de muita utilidade para fazer validações iniciais de algoritmos de segmentação.

\footnotetext{
${ }^{7}$ [Wood et al., 2006] considera o FD como a razão menos um, enquanto que no estudo feito por [Bullitt et al., 2003] o 1 não é subtraído.
} 


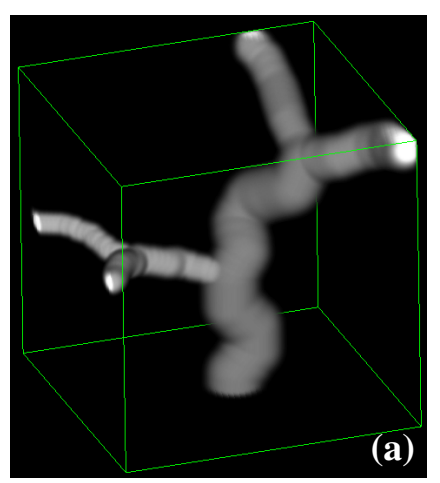

Variáveis modificadas: $\operatorname{prop} C D=3 ; \operatorname{margem} C D=2$.

Iterações: 4

Gramática:

$\mathrm{F}(\mathrm{d} 0) \rightarrow \mathrm{S}(\mathrm{d} 0)[+(\mathrm{th} 1) /(70) \mathrm{F}(\mathrm{d} 1)][-(\mathrm{th} 2) /(70) \mathrm{F}(\mathrm{d} 2)]$

$S(d 0): 0.5 \rightarrow G(d 0)-(25) G(d 0)+(25) G(d 0)+(25) G(d 0)-(25) G(d 0)$

$S(d 0): 0.5 \rightarrow G(d 0)+(25) G(d 0)-(25) G(d 0)-(25) G(d 0)+(25) G(d 0)$

$\mathrm{G}(\mathrm{d} 0) \rightarrow \mathrm{f}\left({ }^{\prime} \mathrm{CO} / 5^{\prime}, \mathrm{d} 0\right)$

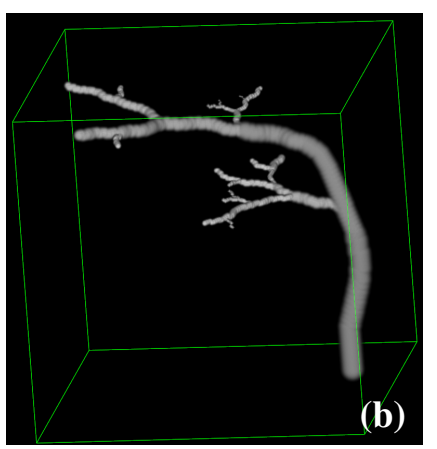

Variáveis modificadas: $\operatorname{prop} C D=5 ;$ margem $C D=2$.

Iterações: 8.

Gramática:

$\mathrm{I}(\mathrm{d} 0) \rightarrow \mathrm{f}\left({ }^{\prime} \mathrm{Co} / 3^{\prime}, \mathrm{d} 0\right)+(25)[\mathrm{R}(\mathrm{d} 0)]$

$\mathrm{R}(\mathrm{d} 0) \rightarrow \mathrm{f}\left({ }^{\prime} \mathrm{Co} / \mathrm{3}^{\prime}\right) \mathrm{D}(\mathrm{d} 0) \mathrm{D}(\mathrm{d} 0) \mathrm{D}(\mathrm{d} 0)[\mathrm{B}(\mathrm{d} 1)] \mathrm{f}\left({ }^{\prime} \mathrm{Co} / 2^{\prime}, \mathrm{d} 2\right) \mathrm{B}(\mathrm{d} 2)$

$\mathrm{B}(\mathrm{d} 0) \rightarrow \mathrm{D}(\mathrm{d} 0) \mathrm{D}(\mathrm{d} 0) \mathrm{D}(\mathrm{d} 0) /(90) \mathrm{A}(\mathrm{d} 0)$

$\mathrm{D}(\mathrm{d} 0) \rightarrow \mathrm{f}\left({ }^{\prime} \mathrm{CO} / 7^{\prime}, \mathrm{d} 0\right)-(18)$

$\mathrm{A}(\mathrm{d} 0) \rightarrow \mathrm{S}(\mathrm{d} 0)[+(\mathrm{th} 1) \mathrm{A}(\mathrm{d} 1)][-(\mathrm{th} 2) \mathrm{A}(\mathrm{d} 2)]$

$S(d 0): 0.5 \rightarrow G(d 0)-(25) G(d 0)+(25) G(d 0)+(25) G(d 0)-(25) G(d 0)$

$S(d 0): 0.5 \rightarrow G(d 0)+(25) G(d 0)-(25) G(d 0)-(25) G(d 0)+(25) G(d 0)$

$\mathrm{G}(\mathrm{d} 0) \rightarrow \mathrm{f}\left({ }^{\prime} \mathrm{CO} / 5^{\prime}, \mathrm{d} 0\right)$

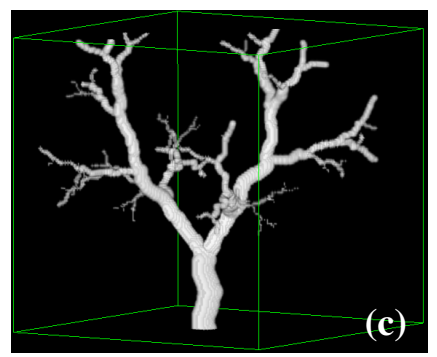

Variáveis modificadas: $\operatorname{prop} C D=5 ;$ margem $C D=2$.

Iterações: 9.

Gramática:

$\mathrm{F}(\mathrm{d} 0) \rightarrow\{\mathrm{S}(\mathrm{d} 0)\}[+(\operatorname{th} 1) /(70) \mathrm{F}(\mathrm{d} 1)][-(\mathrm{th} 2) /(70) \mathrm{F}(\mathrm{d} 2)]$

$S(d 0): 0.5 \rightarrow D(d 0)+(25) D(d 0)-(25) D(d 0)-(25) D(d 0)+(25) D(d 0)$

$S(d 0): 0.5 \rightarrow D(d 0)-(25) D(d 0)+(25) D(d 0)+(25) D(d 0)-(25) D(d 0)$

$\mathrm{D}(\mathrm{d} 0) \rightarrow \mathrm{f}\left({ }^{\prime} \mathrm{CO} / 5^{\prime}, \mathrm{dO}\right)$

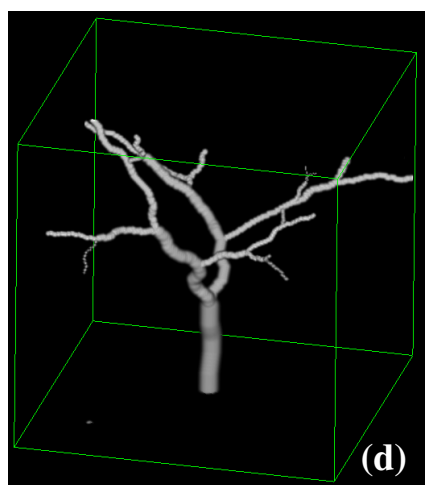

Variáveis modificadas: $\operatorname{prop} C D=8 ;$ margem $C D=4$.

Iterações: 6 .

Gramática:

$F(d 0) \rightarrow\{S(d 0)\}[+(t h 1) /(70) F(d 1)][-(t h 2) /(70) F(d 2)]$

$S(d 0): 0.5 \rightarrow D(d 0)+(25) D(d 0)-(25) D(d 0)-(25) D(d 0)+(25) D(d 0)$

$S(d 0): 0.5 \rightarrow D(d 0)-(25) D(d 0)+(25) D(d 0)+(25) D(d 0)-(25) D(d 0)$

$\mathrm{D}(\mathrm{d} 0) \rightarrow \mathrm{f}\left({ }^{\prime} \mathrm{CO} / 5^{\prime}, \mathrm{dO}\right)$ 


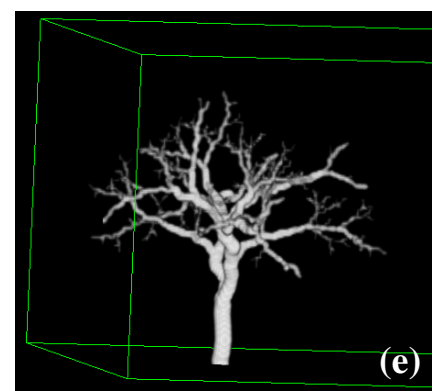

Variáveis modificadas: $\operatorname{prop} C D=7$.

Iterações: 11.

Gramática:

$\mathrm{F}(\mathrm{d} 0) \rightarrow\{\mathrm{S}(\mathrm{d} 0)\}[+(\operatorname{th} 1) /(70) \mathrm{F}(\mathrm{d} 1)][-(\mathrm{th} 2) /(70) \mathrm{F}(\mathrm{d} 2)]$

$S(d 0): 0.5 \rightarrow D(d 0)+(25) D(d 0)-(25) D(d 0)-(25) D(d 0)+(25) D(d 0)$

$S(d 0): 0.5 \rightarrow D(d 0)-(25) D(d 0)+(25) D(d 0)+(25) D(d 0)-(25) D(d 0)$

$\mathrm{D}(\mathrm{d} 0) \rightarrow \mathrm{f}\left({ }^{\prime} \mathrm{CO} / 5^{\prime}, \mathrm{d} 0\right)$

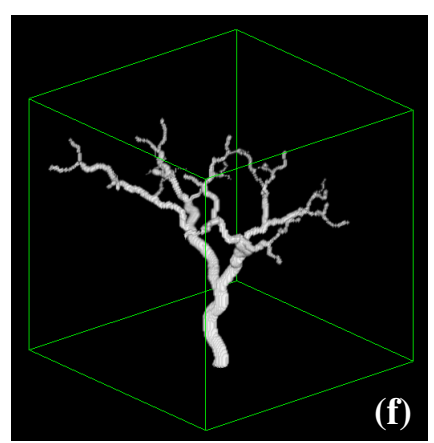

Variáveis modificadas: Todas as variáveis têm valores por padrão.

Iterações: 8.

Gramática:

$\mathrm{F}(\mathrm{d} 0) \rightarrow\{\mathrm{S}(\mathrm{d} 0)\}[+(\mathrm{th} 1) /(70) \mathrm{F}(\mathrm{d} 1)][-(\mathrm{th} 2) /(70) \mathrm{F}(\mathrm{d} 2)]$

$S(d 0): 0.5 \rightarrow D(d 0)+(39.4) D(d 0)-(39.4) D(d 0)-(39.4)$

$\mathrm{D}(\mathrm{d} 0)+(39.4) \mathrm{D}(\mathrm{d} 0)$

$S(d 0): 0.5 \rightarrow D(d 0)-(39.4) D(d 0)+(39.4) D(d 0)+(39.4)$ $\mathrm{D}(\mathrm{d} 0)-(39.4) \mathrm{D}(\mathrm{d} 0)$

$\mathrm{D}(\mathrm{d} 0) \rightarrow \mathrm{f}\left({ }^{\prime} \mathrm{CO} / 5^{\prime}, \mathrm{dO}\right)$

Descrição: Uma RV que simula a estrutura básica dos rins.

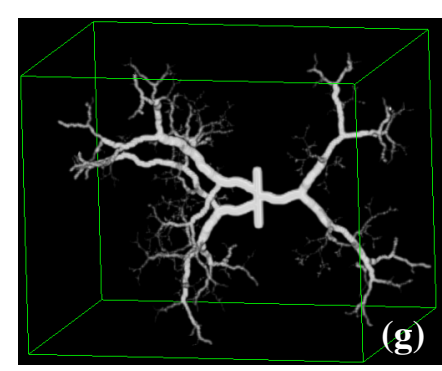

Variáveis modificadas: Todas as variáveis têm valores por padrão.

Iterações: 11.

Gramática:

$\mathrm{R}(\mathrm{d} 0) \rightarrow \mathrm{f}\left({ }^{\prime} \mathrm{Co} / 2^{\prime}, \mathrm{dO}\right)[+(100) \mathrm{F}(\mathrm{d} 0)] \mathrm{f}\left({ }^{\prime} \mathrm{Co} / 6^{\prime}\right)[-(86) \mathrm{F}(\mathrm{d} 0)]$ $\mathrm{f}\left({ }^{\prime} \mathrm{Co} / 6^{\prime}\right)[+(80) \mathrm{F}(\mathrm{do})] \mathrm{f}\left({ }^{\prime} \mathrm{co} / 2^{\prime}\right)$

$\mathrm{F}(\mathrm{d} 0) \rightarrow\{\mathrm{S}(\mathrm{d} 0)\}\left[+\left({ }^{\prime} \mathrm{th} 1+10^{\prime}\right) /(90) \mathrm{F}(\mathrm{d} 1)\right]$ $\left[-\left({ }^{\prime}\right.\right.$ th $\left.\left.2+10^{\prime}\right) /(90) \mathrm{F}(\mathrm{d} 2)\right]$

$S(d 0): 0.5 \rightarrow D(d 0)+(25) D(d 0)-(25) D(d 0)-(25) D(d 0)+(25) D(d 0)$

$S(d 0): 0.5 \rightarrow D(d 0)-(25) D(d 0)+(25) D(d 0)+(25) D(d 0)-(25) D(d 0)$

$\mathrm{D}(\mathrm{d} 0) \rightarrow \mathrm{f}\left({ }^{\prime} \mathrm{CO} / 5^{\prime}, \mathrm{d} 0\right)$

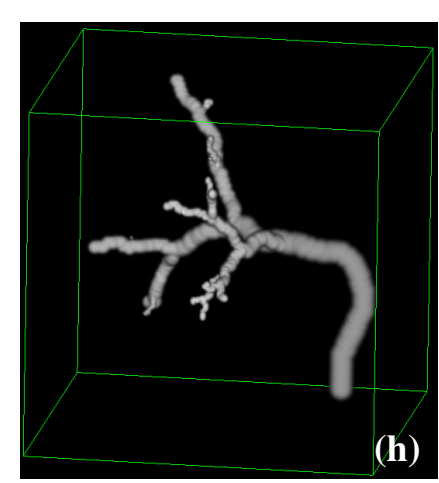

Variáveis modificadas: $\operatorname{prop} C D=4$; $\operatorname{margem} C D=2$.

Iterações: 7.

Gramática:

$I(\mathrm{~d} 0) \rightarrow \mathrm{f}\left({ }^{\prime} \mathrm{CO} / 3^{\prime}, \mathrm{d} 0\right)+(25)[\mathrm{R}(\mathrm{d} 0)]$

$\mathrm{R}(\mathrm{d} 0) \rightarrow \mathrm{f}\left({ }^{\prime} \mathrm{Co} / \mathrm{3}^{\prime}\right) \mathrm{D}(\mathrm{d} 0) \mathrm{D}(\mathrm{d} 0) \mathrm{D}(\mathrm{d} 0) \mathrm{D}(\mathrm{d} 0) \mathrm{D}(\mathrm{d} 0) \mathrm{D}(\mathrm{d} 0) /(90) \mathrm{A}(\mathrm{d} 0)$

$\mathrm{D}(\mathrm{d} 0) \rightarrow \mathrm{f}\left({ }^{\prime} \mathrm{CO} / 7^{\prime}, \mathrm{d} 0\right)-(18)$

$A(d 0) \rightarrow S(d 0)[+(t h 1) /(70) A(d 1)][-(t h 2) /(70) A(d 2)]$

$S(d 0): 0.5 \rightarrow D(d 0)+(25) D(d 0)-(25) D(d 0)-(25) D(d 0)+(25) D(d 0)$

$S(d 0): 0.5 \rightarrow D(d 0)-(25) D(d 0)+(25) D(d 0)+(25) D(d 0)-(25) D(d 0)$ $\mathrm{D}(\mathrm{d} 0) \rightarrow \mathrm{f}\left({ }^{\prime} \mathrm{CO} / 5^{\prime}, \mathrm{dO}\right)$

A RV seguinte contém aneurismas. Para criar esse efeito, a regra "D" contida na sua gramática 
têm $30 \%$ de probabilidade de simular a doença. Os segmentos com aneurisma são ressaltados na imagem com uma seta vermelha.

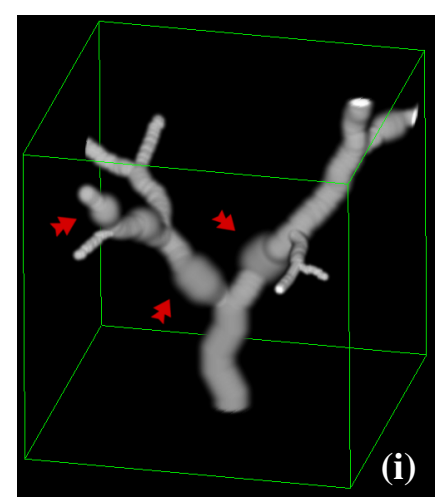

Variáveis modificadas: $\operatorname{prop} C D=4$; $\operatorname{margem} C D=2$.

Iterações: 5 .

Gramática:

$\mathrm{F}(\mathrm{d} 0) \rightarrow \mathrm{S}(\mathrm{d} 0)[+(\mathrm{th} 1) /(70) \mathrm{F}(\mathrm{d} 1)][-(\mathrm{th} 2) /(70) \mathrm{F}(\mathrm{d} 2)]$

$S(d 0): 0.5 \rightarrow G(d 0)-(25) G(d 0)+(25) D(d 0)+(25) G(d 0)-(25) G(d 0)$

$S(d 0): 0.5 \rightarrow G(d 0)+(25) G(d 0)-(25) D(d 0)-(25) G(d 0)+(25) G(d 0)$

$\mathrm{G}(\mathrm{d} 0) \rightarrow \mathrm{f}\left({ }^{\prime} \mathrm{CO} / 5^{\prime}, \mathrm{d} 0\right)$

$\mathrm{D}(\mathrm{d} 0): 0.3 \rightarrow \mathrm{f}\left({ }^{\prime} \mathrm{CO} / 25^{\prime}, \mathrm{d} 0\right) \mathrm{f}\left({ }^{\prime} 3 * \mathrm{co} / 25^{\prime},,^{\prime} \mathrm{d} 0 * 1.5^{\prime}\right) \mathrm{f}\left({ }^{\prime} \mathrm{Co} / 25^{\prime}, \mathrm{d} 0\right)$

$\mathrm{D}(\mathrm{d} 0): 0.7 \rightarrow \mathrm{f}\left({ }^{\prime} \mathrm{Co} / 5^{\prime}, \mathrm{d} 0\right)$

A RV seguinte contém estenose. Para criar esse efeito, a regra "D" contida na sua gramática têm $30 \%$ de probabilidade de simular a doença. Os segmentos com aneurisma são ressaltados na imagem com uma seta vermelha.

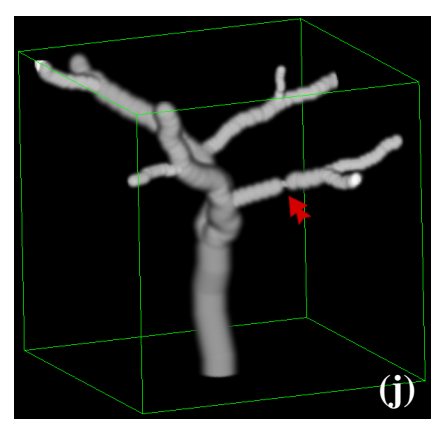

Variáveis modificadas: $\operatorname{prop} C D=4$; $\operatorname{margem} C D=2$.

Iterações: 5 .

Gramática:

$\mathrm{F}(\mathrm{d} 0) \rightarrow \mathrm{S}(\mathrm{d} 0)[+(\mathrm{th} 1) /(70) \mathrm{F}(\mathrm{d} 1)][-(\mathrm{th} 2) /(70) \mathrm{F}(\mathrm{d} 2)]$

$S(d 0): 0.5 \rightarrow G(d 0)-(25) G(d 0)+(25) D(d 0)+(25) G(d 0)-(25) G(d 0)$

$S(d 0): 0.5 \rightarrow G(d 0)+(25) G(d 0)-(25) D(d 0)-(25) G(d 0)+(25) G(d 0)$

$\mathrm{G}(\mathrm{d} 0) \rightarrow \mathrm{f}\left({ }^{\prime} \mathrm{Co} / 5^{\prime}, \mathrm{d} 0\right)$

$\mathrm{D}(\mathrm{do}): 0.3 \rightarrow \mathrm{f}\left({ }^{\prime} \mathrm{Co} / 25^{\prime}, \mathrm{d} 0\right) \mathrm{f}\left({ }^{\prime} 3 * \mathrm{co} / 25^{\prime},,^{\prime} \mathrm{do} / 2^{\prime}\right) \mathrm{f}\left({ }^{\prime} \mathrm{Co} / 25^{\prime}, \mathrm{d} 0\right)$

$\mathrm{D}(\mathrm{d} 0): 0.7 \rightarrow \mathrm{f}\left({ }^{\prime} \mathrm{Co} / 5^{\prime}, \mathrm{d} 0\right)$ 


\section{Capítulo 5}

\section{Conclusões}

Neste trabalho, descrevemos um método para a geração de redes vasculares sintéticas tridimensionais e a posterior geração de imagens de angiografia sintéticas que simulam as intensidades de imagens de angiografia reais. Esta tarefa de geração é realizada por meio de uma abordagem fractal, que utiliza sistemas de Lindenmayer como base para a geração.

O modelo de geração cria bifurcações e segmentos com características similares às encontradas em vasos reais e respeita restrições físicas de crescimento. As imagens finais simulam imagens de angiografia real como o perfil de intensidades, sendo possível a modificação do tamanho e espaçamento da imagem final.

Os atuais métodos de geração de vasos sintéticos por sistemas de Lindenmayer tratam apenas da geração em duas dimensões, dessa forma, consideramos que possibilitar a criação de vasos sintéticos em 3D é um grande avanço.

Devido à quantidade de variáveis iniciais, foi definido um padrão para os arquivos de entrada, e para simplificar o processo de criação desses arquivos e reduzir a possibilidade de ter arquivos com variáveis inválidas, foi desenvolvido um aplicativo de geração de arquivos de entrada.

Para tornar possível a geração a partir de regras gramaticais arbitrárias, foram desenvolvidos um analisador léxico e outro sintático, os quais realizam uma análise de uma gramática inicial dada no arquivo de entrada e a posterior produção de uma cadeia para uma determinada iteração. É importante salientar que não foi encontrado na literatura um gerador de cadeias para sistemas de Lindenmayer com regras arbitrárias.

A vantagem da metodologia descrita em relação a trabalhos similares, que utilizam sistemas de Lindenmayer e geram RVs sintéticas em duas dimensões [Liu et al., 2010; Zamir, 2001], é a possibilidade de adicionar regras estocásticas à gramática, a sua posterior criação em três dimensões, a adição de limitações físicas ao seu crescimento e a discretização da RV sintética criada em uma imagem volumétrica. O método é capaz de gerar imagens visualmente convincentes.

\subsection{Limitações e pesquisas futuras}

Uma imagem sintética de angiografia ideal é uma imagem que tem as mesmas características que uma imagem de angiografia real e os seus vasos ocupam aproximadamente o mesmo espaço 
e posição que os vasos reais. Assim, a principal limitação da nossa metodologia é que os vasos são criados apenas pelo que é pedido na gramática, sem considerar a fisiologia do corpo onde está crescendo, ou seja, não considera o caminho que um vaso real percorre, mas procura ir de acordo com a gramática dada.

A metodologia desenvolvida imita algumas características reais como ângulo provável de rotação nas bifurcações e comprimentos e respeita as restrições espaciais. No entanto, existem outras características que poderiam também ser utilizadas, como a análise da densidade dos tecidos por onde eles crescem, da necessidade de oxigênio para as artérias e do volume de $\mathrm{CO}_{2}$ que as veias requisitam.

Nos estudos mostrados em Hamarneh e Jassi [2010] e Szczerba e Székely [2002] foram realizados estudos levando em consideração a fisiologia das artérias e veias sem utilizar L-systems. Assim, poderia-se modificar o comportamento das funções de crescimento na nossa metodologia para utilizar um campo vetorial, no qual a possibilidade de crescimento em uma determinada posição é proporcional à quantidade de oxigênio requerida nessa posição. Dessa forma, os vasos que irrigam os tumores e cânceres poderiam ser melhor modelados devido ao fato de eles precisarem de uma fonte de sangue independente para se desenvolver [McGuire et al., 2012].

Neste trabalho, a gramática dada como entrada é criada manualmente. No entanto, obter a gramática de todos os órgãos e partes do corpo é um trabalho muito desgastante e repleto de imprecisões, o ideal neste caso, é automatizar a criação de gramáticas a partir de imagens volumétricas reais, com a finalidade de criar imagens sintéticas o mais similares possíveis às reais. Existem estudos, como o feito por Qu et al. [2008, 2009], que geram gramáticas de L-systems a partir de múltiplas imagens de plantas, para depois reconstruí-las em estruturas tridimensionais digitais. Estudos como esses podem ser utilizados como base para desenvolver métodos de extração de gramáticas a partir de segmentações de vasos e conseguir assim a automatização de geração das gramáticas. 


\section{Apêndice A}

\section{Tokens e definições do analisador sintático}

\section{A.1 Relação de tokens}

A relação completa de tokens válidos gerados pelo analisador léxico é:

DIAMETRO0: o texto “diametro0” e sua abreviação “d0”.

DIAMETRO1: o texto “diametro1” e sua abreviação “d1'.

DIAMETRO2: o texto “diametro2” e sua abreviação "d2'.

COMPRIMENTO: o texto "comprimento" e sua abreviação "co".

THETA1: o texto "theta1" e sua abreviação "th1'.

THETA2: o texto "theta2" e sua abreviação "th2'.

REMAP: o texto "remap" e sua abreviação "rm'.

NOME: os nomes das regras serão devolvidos como token "NOME" por exemplo na regra "F->f" o nome é F.

NUMERO: qualquer número inteiro ou real.

ASIGN: o símbolo de atribuição de nossas regras gramaticais “->”.

SIMBOLO: símbolos não terminais, como por exemplo "F" ou "X".

TERMINAL: símbolos terminais, como por exemplo "f" ou " $x$ ".

ESPECIAL: símbolos especiais como por exemplo: “+”, “-”, “[”, “"]”.

OPER: grupo de operações matemáticas que tem de ser calculadas com prioridade, por exemplo: "2+comprimento". Nesse caso, o símbolo "+” não é um símbolo especial, é a operação de adição. 
Os seguintes símbolos são tokens que tem o mesmo nome: “(”, “)” e “.”.

\section{A.2 Definições do analisador sintático}

O analisador sintático está baseado em gramáticas que definem seu comportamento. Para a definição dessas regras gramaticais internas do analisador sintático, utilizamos o seguinte padrão:

- As regras tem um nome que é seguido de “:” para depois continuar com a definição da regra.

- Os nomes das regras são definidos com letras minúsculas e os nomes dos tokens com letras maiúsculas.

- Se uma regra tem duas ou mais definições, essas podem ser escritas como: regra: definição1 | definição2

- Se dentro de uma definição são encontrados caracteres entre aspas, o caractere é utilizado literalmente. Por exemplo, a seguinte regra: parametro : "(" NUMERO ")", significa que um parametro é formado por um número entre parênteses. Assim, o texto (3.4) é considerado um parametro.

As gramáticas que definem o analisador sintático, no formato estabelecido pela biblioteca PLY, são:

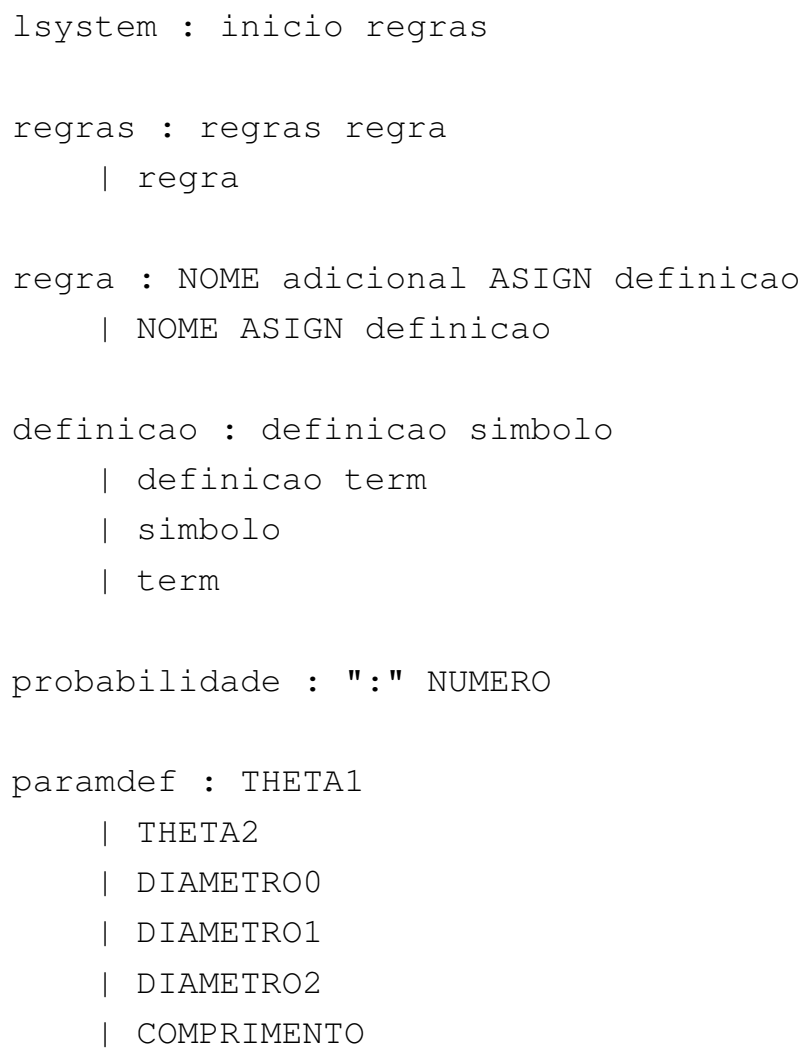




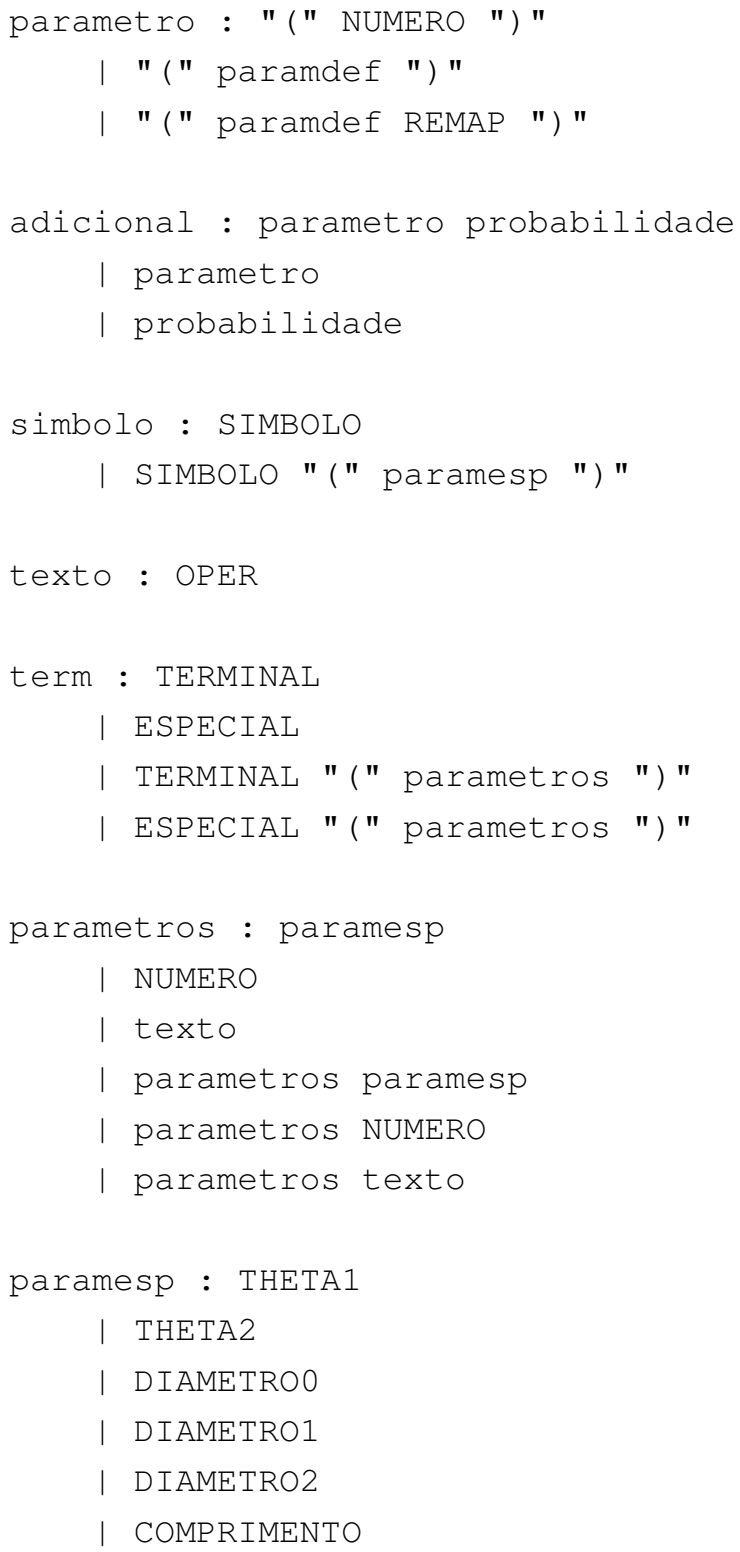





\section{Apêndice B}

\section{Algoritmos desenvolvidos}

Neste apêndice são apresentados os requisitos para executar os algoritmos desenvolvidos nesta metodologia, junto com fragmentos de código-fonte das funções principais implementadas.

As linguagens de programação e as bibliotecas utilizadas na implementação foram:

Linguagens: Python e C++.

Bibliotecas: Visualization Toolkit (VTK), Python, lex-yac (PLY), numpy, scipy, PIL (Python Image Library).

\section{B.1 Classe libGenerator}

A classe libGenerator é uma classe auxiliar dedicada a fazer os cálculos dos parâmetros e valores requeridos pelas palavras reservadas utilizadas na gramática.

Essa classe contém os valores por padrão dos parâmetros, assim como também, das funções para o cálculo dos diâmetros e ângulos de rotação numa bifurcação.

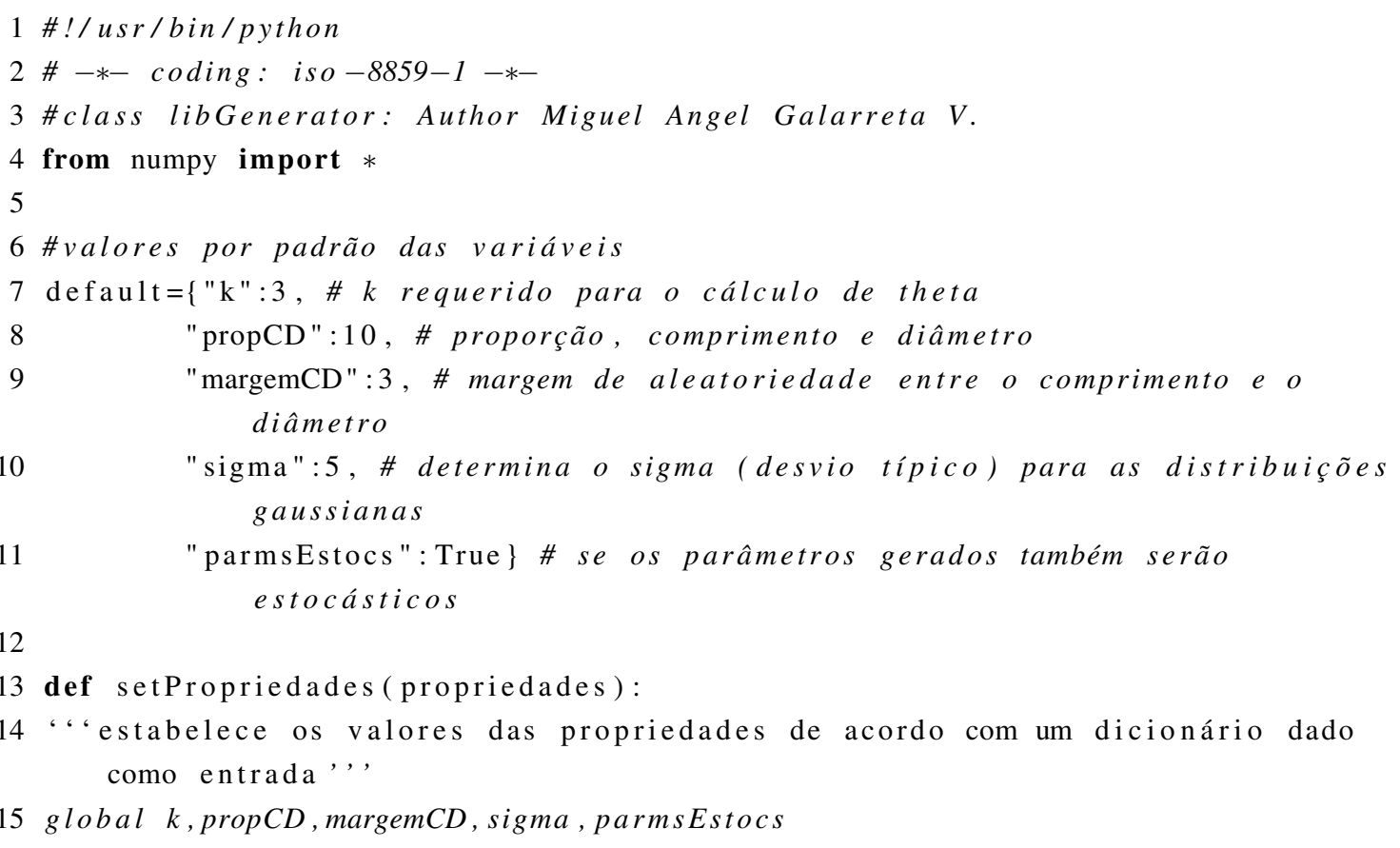


16

61

62

sp=lambda nam: default [nam] if propriedades==None or not nam in propriedades else propriedades [nam]

$$
k=\operatorname{sp}(" k ")
$$




\section{Apêndice C}

\section{Dados adicionais}

Neste apêndice é mostrado o código em Python gerado a partir de várias gramáticas e arquivos de entrada completos utilizados para a geração de alguns vasos sintéticos gerados nos resultados.

\section{C.1 Código intermediário gerado}

A continuação é mostrado o código em Python gerado a partir de varias gramáticas, utilizadas no Capítulo 4 de resultados.

Código em Python gerado a partir da gramática mostrada na Tabela 4.1:

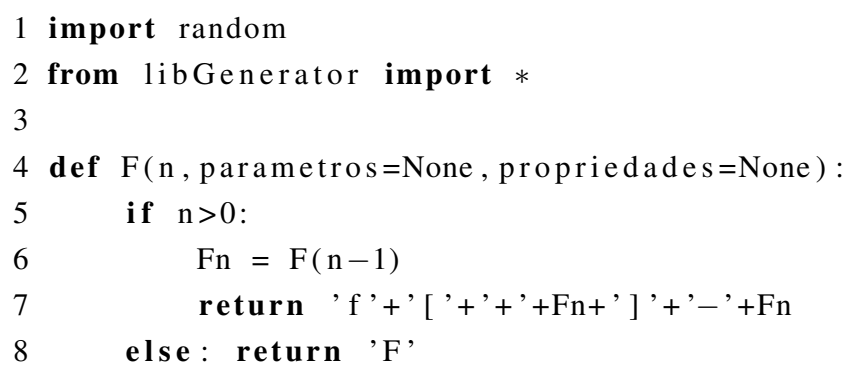

Código em Python gerado a partir da gramática mostrada na Tabela 4.2:

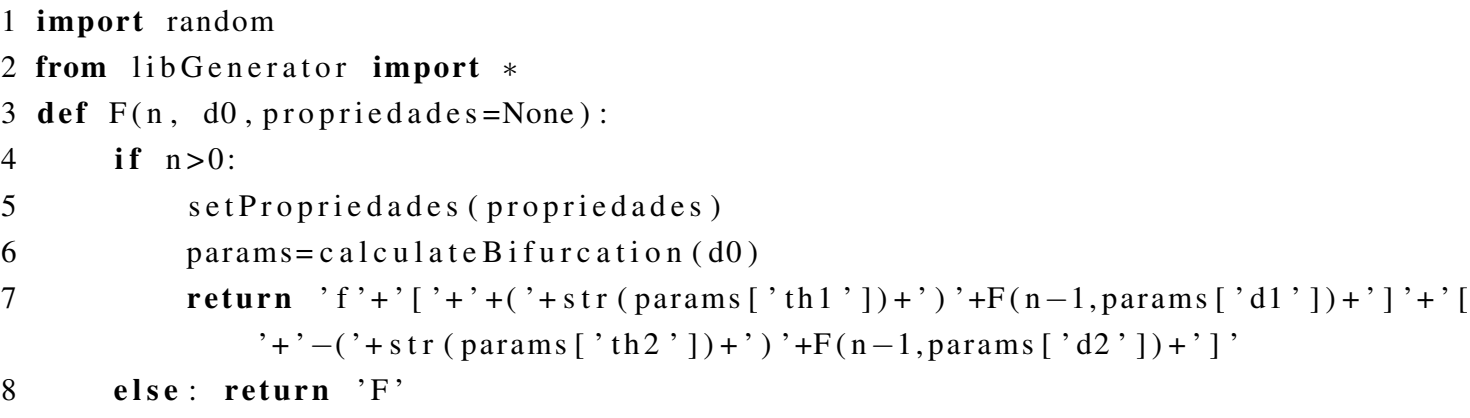

Código em Python gerado a partir da gramática mostrada na Tabela 4.3:

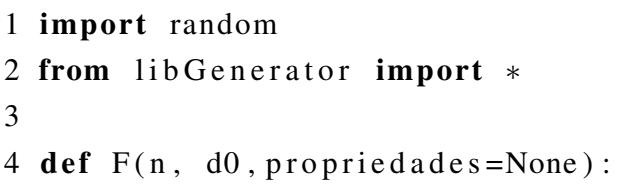




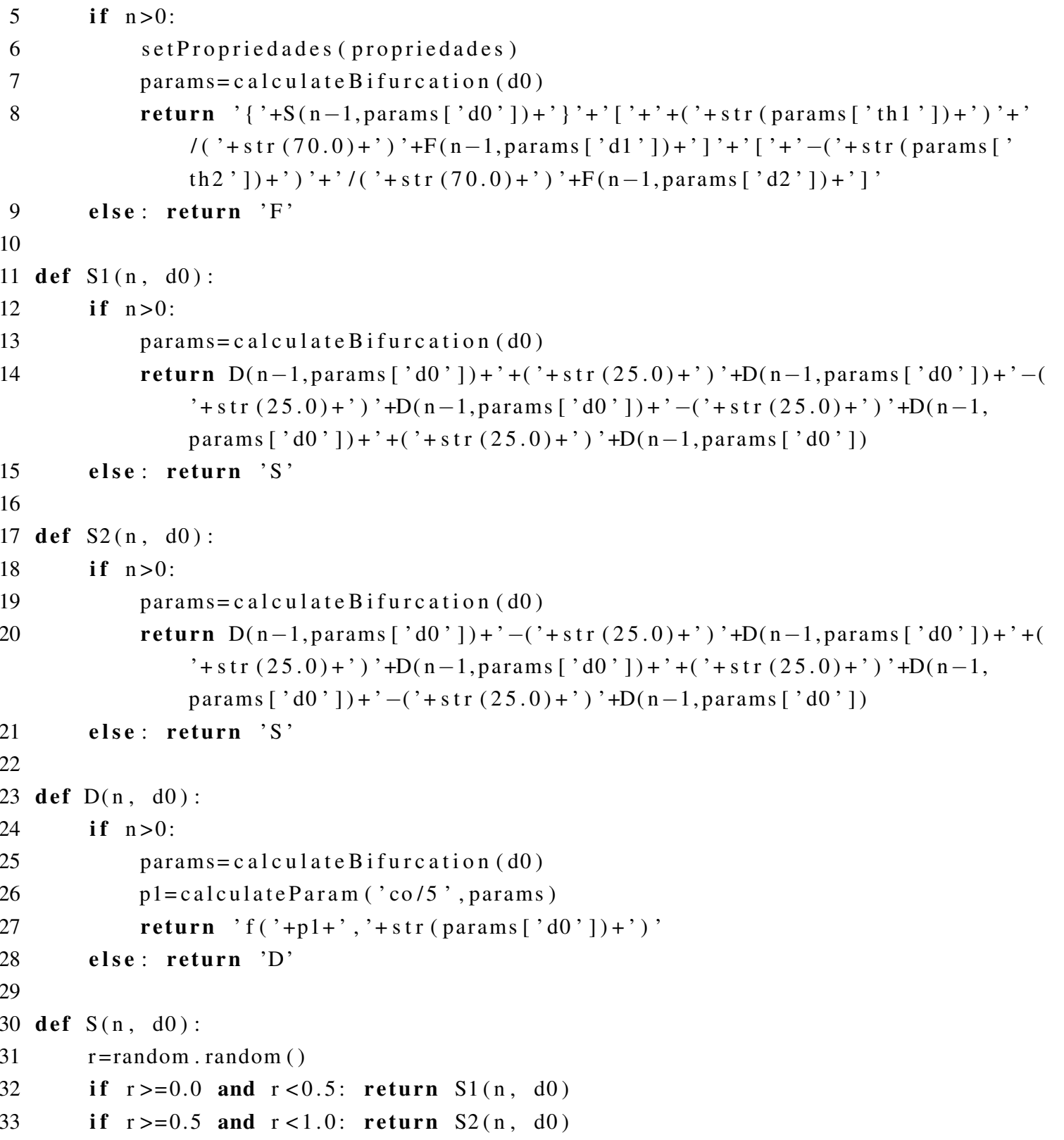

\section{C.2 Arquivos, gramáticas e valores de entrada utilizados}

\section{C.2.1 Arquivo de entrada para geração de vasos no fígado}

O texto seguinte pertence a um arquivo de entrada que foi utilizado para a criação da RV dentro de uma superfície definida no arquivo "figado.vtk". Nesse arquivo de entrada foi escolhido o ponto inicial $(131,190,138)$ devido ao fato de que esse ponto dentro da nossa superfície é aproximadamente o lugar de onde começa o crescimento das RVs em imagens reais de fígado.

$\mathrm{O}$ arquivo de entrada completo é: 


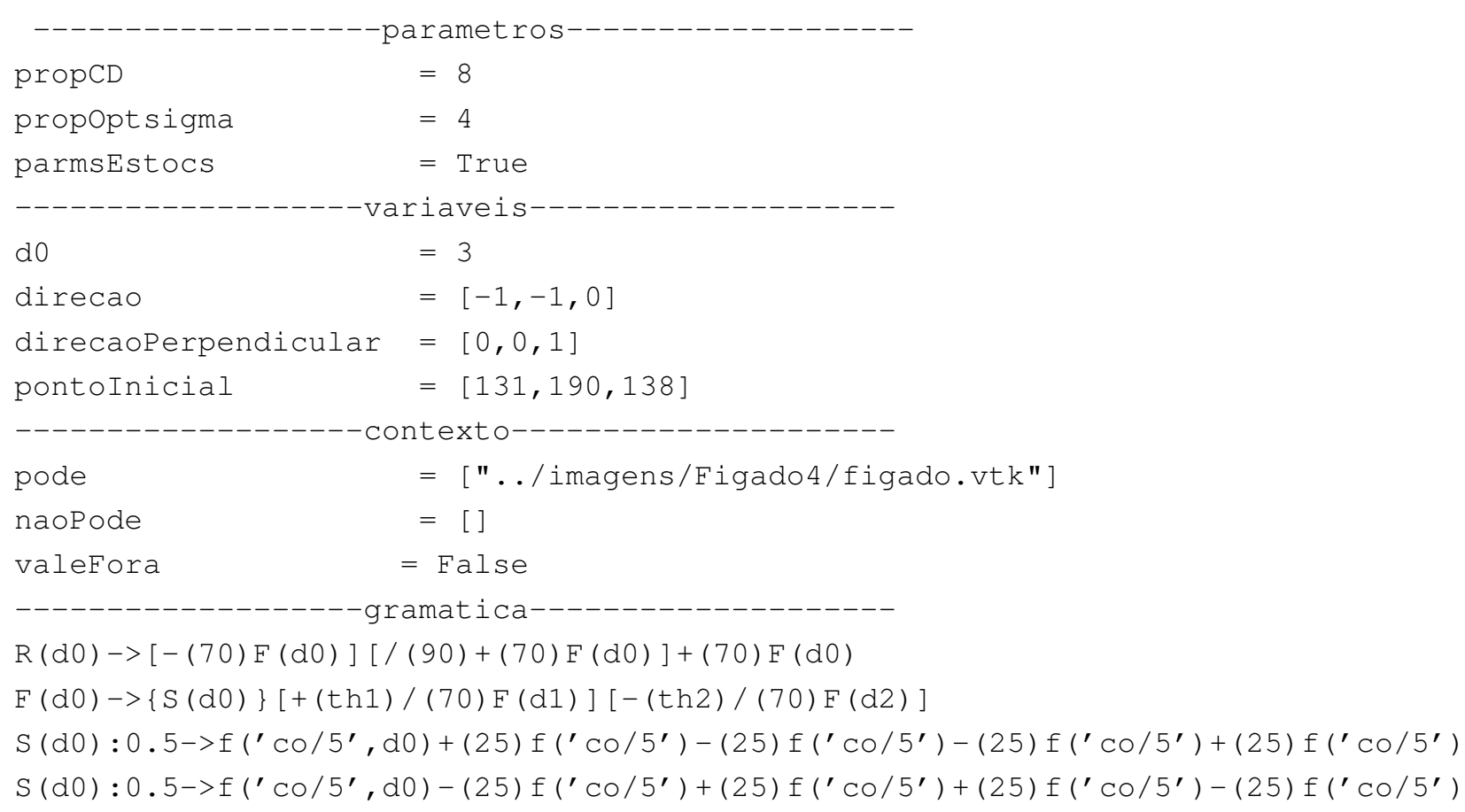

\section{C.2.2 Arquivo de entrada para geração de vasos na perna}

O seguinte texto pertence a um arquivo de entrada que foi utilizado para a criação da RV na perna. A RV foi limitada por duas superfícies: uma dos músculos da perna "perna.vtk" e outra apenas do fêmur chamada "osso.vtk". Ambas as superfícies foram obtidas a partir de uma imagem real de angio-TC da perna.

$\mathrm{O}$ arquivo de entrada completo é:

\begin{tabular}{|c|c|}
\hline propCD & $=13$ \\
\hline propoptSigma & $=6$ \\
\hline parmsEstocs & $=$ True \\
\hline \multicolumn{2}{|c|}{------------------- variaveis --------------------} \\
\hline do & $=2.5$ \\
\hline direcao & $=[0,0,-1]$ \\
\hline direcaoperpendicular & $=[0,1,0]$ \\
\hline pontoInicial & $=[112,76,180]$ \\
\hline \multicolumn{2}{|c|}{------------------- contexto ---------------------} \\
\hline pode & $=["$. /imagens/perna/perna.vtk" $]$ \\
\hline naopode & $=[" . . /$ imagens/perna/osso.vtk" $]$ \\
\hline valeFora & $=\mathrm{False}$ \\
\hline \multicolumn{2}{|c|}{$-------------------g r a m a t i c a--------------------$} \\
\hline \multicolumn{2}{|c|}{$\mathrm{F}(\mathrm{d} 0)->\{\mathrm{S}(\mathrm{d} 0)\}\left[+\left({ }^{\prime} \operatorname{th} 1-10^{\prime}\right) /(70) \mathrm{F}(\mathrm{d} 1)\right]\left[-\left({ }^{\prime} \operatorname{th} 2-10^{\prime}\right) /(70) \mathrm{F}(\mathrm{d} 2)\right]$} \\
\hline \multicolumn{2}{|c|}{$S(d i a m e t r o 0): 0.4->D(d 0)+(25) D(d 0)-(25) D(d 0)-(25) D(d 0) D(d 0)$} \\
\hline \multicolumn{2}{|c|}{$+(25) \mathrm{D}(\mathrm{d} 0)+(25) \mathrm{D}(\mathrm{d} 0)-(25) \mathrm{D}(\mathrm{d} 0)$} \\
\hline \multicolumn{2}{|c|}{$S($ diametro0):0.3->D $(\mathrm{d} 0)+(25) D(d 0)-(25) D(d 0)-(25) D(d 0)+(25) D(d 0)$} \\
\hline \multicolumn{2}{|c|}{$S(d i a m e t r o 0): 0.3->D(d 0)-(25) D(d 0)+(25) D(d 0)+(25) D(d 0)-(25) D(d 0)$} \\
\hline \multicolumn{2}{|l|}{$D(d 0)->f\left({ }^{\prime} \mathrm{CO} / 5^{\prime}, \mathrm{d} 0\right)$} \\
\hline
\end{tabular}


Devido ao fato de os vasos da perna serem mais longos que os vasos das outras partes do corpo, foi escolhido um valor de proporção comprimento/diâmetro (PropCD) igual a 13, o qual é maior que o valor padrão 10 .

Também procuramos um ponto ideal para começar o crescimento. Assim, foram escolhidas como coordenadas do ponto inicial $(112,76,180)$, devido ao fato de que nessa imagem real e nessas coordenadas está localizada a artéria femoral profunda. Optamos por direcionar o crescimento da rede em direção aos pés. Assim, o vetor inicial é $(0,0,-1)$.

Na gramática, o axioma $(F)$ gera bifurcações cujas rotações são de thet $a_{1}-10^{\circ}$ e thet $a_{2}-$ $10^{\circ}$. Isso, devido ao fato de que na perna os ângulos de bifurcação são menores que em outras partes do corpo. $\mathrm{O}$ valor de $10^{\circ}$ permitiu a geração de melhores resultados experimentais e foi obtido empiricamente.

A regra $(S)$ tem três possibilidades para sua execução. A primeira delas, a qual tem $40 \%$ de probabilidade de executar, cria segmentos com uma maior quantidade de sub-segmentos, criando por conseguinte um segmento com maior comprimento. As outras duas regras criam um segmento subdividido em 5 sub-segmentos com uma pequena tortuosidade. 


\section{Apêndice D}

\section{Publicações}

Durante o período de mestrado, foram redigidas, em co-autoria, os seguintes artigos:

- O artigo intitulado "Three-dimensional synthetic blood vessel generation using stochastic Lsystems", foi aceito para apresentação oral na conferência Medical Imaging do SPIE 2013 que será realizada em Florida, Estados Unidos da América [Galarreta-Valverde et al., 2013 in press].

- O artigo intitulado "A center-line based estimator of vessel bifurcations in angiography images" foi aceito para apresentação de pôster na conferência Medical Imaging do SPIE 2013 [Macedo et al., 2013 in press]. 



\section{Referências Bibliográficas}

Aho et al.(1998) A. V. Aho, R. Sethi e J. D. Ullman. Compiladores: principios, técnicas y herramientas. Addison-Wesley Iberoamericana. Citado na pág. 12, 22

Beazley(2009) D. Beazley. PLY (Python Lex-Yacc), 2009. Citado na pág. 20, 35

Bresenham et al.(1986) J. E. Bresenham, A. C. Gay e J. P. Richards. Graphics display system and method having improved clipping technique, Novembro 18 1986. US Patent 4,623,880. Citado na pág. 2,30

Bullitt et al.(2003) E. Bullitt, G. Gerig, S.M. Pizer, W. Lin e S.R. Aylward. Measuring tortuosity of the intracerebral vasculature from MRA images. Medical Imaging, IEEE Transactions on, 22(9): 1163-1171. Citado na pág. 45

Campbell e Abhyankar(1978) P. Campbell e S. Abhyankar. Fractals, form, chance and dimension. The Mathematical Intelligence, 1(1):35-37. Citado na pág. 2

Cemil Kirbas(2003) Francis K. H. Cemil Kirbas. A review of vessel extraction techniques and algorithms. Citado na pág. 1

Chagas et al.(2009) A. C. P. Chagas, E. C. Zilli, J. F. M. Ferreira, M. A. Moretti e R. F. Ramos. Saúde cardiovascular do homem brasileiro-visão da sociedade brasileira de cardiologia. Arq Bras Cardiol, 93(6):584-587. Citado na pág. 1

Elena e Manuela(2006) I. A. Elena e P. Manuela. The application of stochastic grammars for generation of fractals. Annals of the faculty of engineering Hunedoara. Citado na pág. 11

Friedl(2006) J. Friedl. Mastering regular expressions. O'Reilly Media, Inc. Citado na pág. 12

Galarreta-Valverde et al.(2013 in press) Miguel A. Galarreta-Valverde, Maysa M. G. Macedo, Choukri Mekkaoui e Macel P. Jackowski. Three-dimensional synthetic blood vessel generation using stochastic L-systems. SPIE Medical Imaging 2013. Citado na pág. 61

Hamarneh e Jassi(2010) G. Hamarneh e P. Jassi. Vascusynth: Simulating vascular trees for generating volumetric image data with ground-truth segmentation and tree analysis. Computerized Medical Imaging and Graphics, 34(8):605-616. Citado na pág. 7, 50

Heckbert(1994) P.S. Heckbert. Graphics gems IV, volume 4. Morgan Kaufmann. Citado na pág. 30

Heimann et al.(2009) T. Heimann, B. van Ginneken, M. Styner, Y. Arzhaeva, V. Aurich, C. Bauer, A. Beck, C. Becker, R. Beichel, G. Bekes, F. Bello, G. Binnig, H. Bischof, A. Bornik, P. M. M. Cashman, Y. Chi, A. Cordova, B. M. Dawant, M. Fidrich, J. Furst, D. Furukawa, L. Grenacher, J. Hornegger, D. Kainmueller, R.I. Kitney, H. Kobatake, H. Lamecker, Th. Lange, J. Lee, B. Lennon, R. Li, S. Li, H.-P. Meinzer, G. Nemeth, D. S. Raicu, A.-M. Rau, E. M. van Rikxoort, 
M. Rousson, L. Rusko, K. A. Saddi, G. Schmidt, D. Seghers, A. Shimizu, P. Slagmolen, E. Sorantin, G. Soza, R. Susomboon, J. M. Waite, A. Wimmer e I. Wolf. Comparison and Evaluation of Methods for Liver Segmentation from CT datasets. IEEE Transactions on Medical Imaging, 28 (8):1251-1265. Citado na pág. 39

Hopcroft et al.(1979) J. E. Hopcroft, R. Motwani e J. D. Ullman. Introduction to automata theory, languages, and computation, volume 2. Addison-wesley Reading, MA. Citado na pág. 9

Jacob(1995) C. Jacob. Genetic L-system programming: breeding and evolving artificial flowers with Mathematica. Em Proceedings of the First International Mathematica Symposium, páginas 215-222. Citeseer. Citado na pág. 2

Kirbas e Quek(2003) C. Kirbas e F. K. H. Quek. Vessel extraction in medical images by 3D wave propagation and traceback. Em Proceedings of the Third IEEE Symposium on Bioinformatics and Bioengineering., páginas 174-181. IEEE. Citado na pág. 31

Kókai et al.(1999a) G. Kókai, Z. Tóth e R. Ványi. Evolving artificial trees described by parametric L-systems. Em Electrical and Computer Engineering, 1999 IEEE Canadian Conference on, volume 3, páginas 1722-1727. IEEE. Citado na pág. 2

Kókai et al.(1999b) G. Kókai, Z. Tóth e R. Ványi. Modelling blood vessels of the eye with parametric L-systems using evolutionary algorithms. Artificial Intelligence in Medicine, páginas 433-442. Citado na pág. 9

Lindenmayer(1968) A. Lindenmayer. Mathematical models for cellular interactions in development I. filaments with one-sided inputs. Journal of Theoretical Biology, 18(3):280-299. Citado na pág. 9

Lindenmayer(1974) A. Lindenmayer. Adding continuous components to L-systems. L Systems, conference in Aarhus, Denmark, páginas 53-68. Citado na pág. 11

Linz(2011) P. Linz. An introduction to formal languages and automatas. Jones \& Bartlett Publishers. Citado na pág. 9

Liu et al.(2010) X. Liu, H. Liu, A. Hao e Q. Zhao. Simulation of blood vessels for surgery simulators. Em 2010 International Conference on Machine Vision and Human-machine Interface, páginas 377-380. IEEE. Citado na pág. 2, 24, 49

Macedo et al.(2013 in press) Maysa M. G. Macedo, Miguel A. Galarreta-Valverde, Choukri Mekkaoui e Macel P. Jackowski. A center-line based estimator of vessel bifurcations in angiography images. SPIE Medical Imaging 2013. Citado na pág. 61

Mandelbrot e Aizenman(1979) B.B. Mandelbrot e M. Aizenman. Fractals: form, chance, and dimension. Physics Today, 32:65. Citado na pág. 2

McCormack et al.(1993) J. McCormack et al. Interactive evolution of L-system grammars for computer graphics modelling. ISO Press, Amsterdam. Citado na pág. 11

McGuire et al.(2012) T. F. McGuire, G. B. Sajithlal, J. Lu, R. D. Nicholls e E. V. Prochownik. In vivo evolution of tumor-derived endothelial cells. PloS one, 7(5):e37138. Citado na pág. 50

Murray(1926) C. D. Murray. The physiological principle of minimum work applied to the angle of branching of arteries. The Journal of General Physiology, 9(6):835. Citado na pág. 2, 25

Piegl(1989) L. Piegl. Modifying the shape of rational B-splines. Part 1: Curves. Computer-Aided Design, 21(8):509-518. Citado na pág. 2 
Polzehl e Tabelow(2007) J. Polzehl e K. Tabelow. FMRI: A package for analyzing FMRI data. $R$ News, 7:13-17. Citado na pág. 28

Prezemyslaw e Lindenmayer(1996) P. Prezemyslaw e A. Lindenmayer. The algorithmic beauty of plants, 1996. Citado na pág. 9

Qi et al.(2011) H. Qi, R. Qiu e J. Jia. L-system based interactive and lightweight web 3D tree modeling. Em Proceedings of the 10th International Conference on Virtual Reality Continuum and Its Applications in Industry, páginas 589-592. ACM. Citado na pág. 2

Qu et al.(2008) Hongchun Qu, Q. Zhu, L. Zeng, M. Guo e Z. Lu. Automata-based L-grammar extraction from multiple images for virtual plants. Em Bio-Inspired Computing: Theories and Applications, 2008. BICTA 2008. 3rd International Conference on, páginas 89-96. IEEE. Citado na pág. 50

Qu et al.(2009) Hongchun Qu, Q. Zhu, M. Guo e Z. Lu. An intelligent learning approach to Lgrammar extraction from image sequences of real plants. International Journal On Artificial Intelligence Tools: Architectures, Languages, Algorithms, 18(6):905. Citado na pág. 50

Rozenberg(1980) Grzegorz Rozenberg. The Mathematical Theory of L-Systems. Academic Press, primeira edição. Citado na pág. 8,9

Schroeder et al.(2003) W. Schroeder, K. Martin e B. Lorensen. The Visualization Toolkit: An Object Oriented Approach to 3D Graphics 3rd Edition, Kitware. Inc. Publisher. Citado na pág. 14

Suetens(2009) Paul Suetens. Fundamental of Medical Imaging. Cambridge University Press, segunda edição. Citado na pág. 5, 6

Szczerba e Székely(2002) D. Szczerba e G. Székely. Macroscopic modeling of vascular systems. Medical Image Computing and Computer-Assisted Intervention-MICCAI 2002, páginas 284-292. Citado na pág. 7, 50

Vinoy et al.(2003) K. J. Vinoy, J. K. Abraham e V. K. Varadan. On the relationship between fractal dimension and the performance of multi-resonant dipole antennas using Koch curves. IEEE Transactions on Antennas and Propagation, 51(9):2296-2303. Citado na pág. 8

Von Koch (1993) H. Von Koch. On a continuous curve without tangent constructible from elementary geometry. Classics on Fractals (Westview Press, 2004) pp, 25:45. Citado na pág. 10

Wood et al.(2006) N. B. Wood, S. Z. Zhao, A. Zambanini, M. Jackson, W. Gedroyc, S. A. Thom, A. D. Hughes e X. Y. Xu. Curvature and tortuosity of the superficial femoral artery: a possible risk factor for peripheral arterial disease. Journal of applied physiology, 101(5):1412-1418. Citado na pág. 45

Xiao e Xu(2011) X. Xiao e Y. Xu. The design and implementation of C-like language interpreter. Em 2nd International Symposium on Intelligence Information Processing and Trusted Computing (IPTC), 2011, páginas 104-107. IEEE. Citado na pág. 12, 20, 22

Zamir(1976) M. Zamir. Optimality principles in arterial branching. Journal of Theoretical Biology, 62(1):227-251. Citado na pág. 2

Zamir(1988) M. Zamir. Distributing and delivering vessels of the human heart. The Journal of general physiology, 91(5):725. Citado na pág. 24, 25 
Zamir(1999) M. Zamir. On fractal properties of arterial trees. Journal of theoretical biology, 197 (4):517-526. Citado na pág. 2

Zamir(2001) M. Zamir. Arterial branching within the confines of fractal L-system formalism. The Journal of general physiology, 118(3):267. Citado na pág. 2, 7, 24, 49

Zana e Klein(2001) F. Zana e J. C. Klein. Segmentation of vessel-like patterns using mathematical morphology and curvature evaluation. Image Processing, IEEE Transactions on, 10(7):10101019. Citado na pág. 30

Histograma de referências bibliográficas

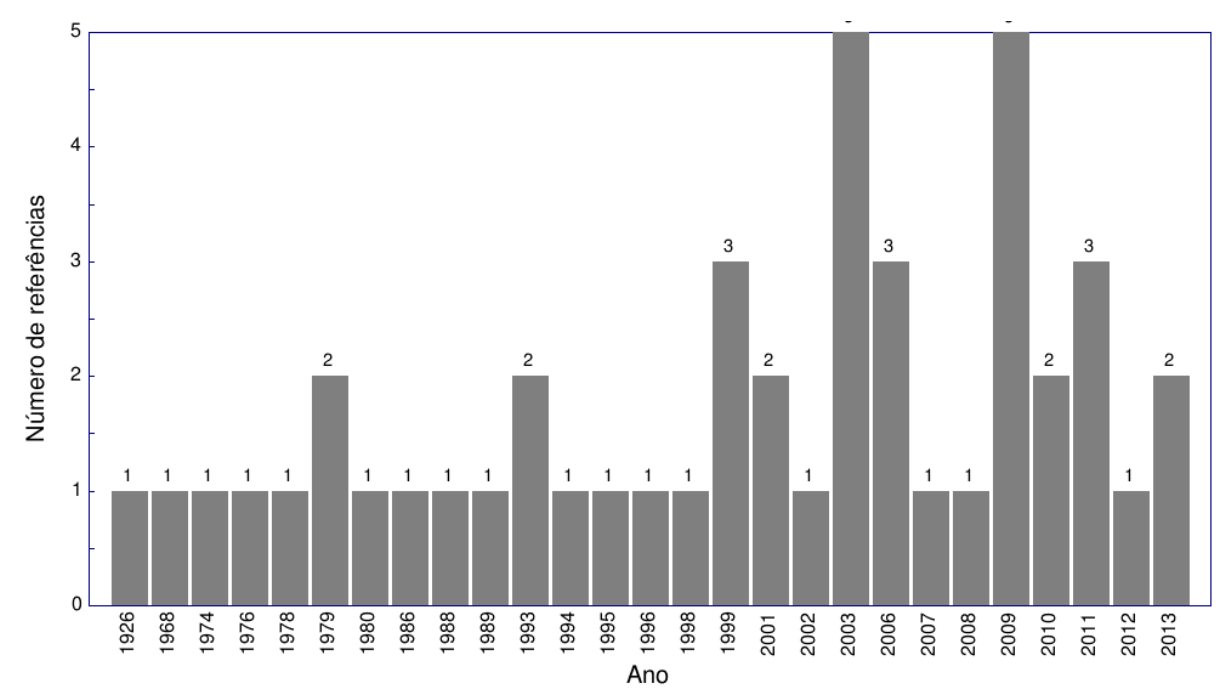




\section{Índice Remissivo}

área do trabalho

fundamentos, 5

ângulos de bifurcação, 24

adição de volume, 30

alfabeto, 8, 15

analisador léxico, 12, 20

analisador sintático, 12, 22

angio-RM, 6

angio-TC, 5

aplicação da distribuição, 33

autômatos, 8

banco de imagens sintéticas, 45

bifurcação, 7

cálculo das palavras reservadas, 24

cadeia final, 19

complexidade computacional, 33

comprimento, 24

conceitos matemáticos, 8

controle de restrições, 37

criação de redes vasculares sintéticas, 7

curvas de Koch, 10

definição da gramática e parâmetros, 13

definições do analisador sintático, 52

diâmetros, 25

discretização, 28, 41

esqueleto de redes vasculares, 8

esqueleto de RV, 29

exemplos de gramáticas, 35

fluxo sanguíneo, 7

formato do arquivo de entrada, 17

fractais, 8

função gaussiana, 31

função sigmoide, 31

geração, 19

geração da rede vascular, 25 geração de cadeias, 35

geração de RV, 36

gerador de funções Python, 22

gramática, 8, 16

instrução avançar, 26

instrução de rotação de direção, 27

instrução de rotação do plano, 27

instrução empilhar e desempilhar, 28

instruções e seus parâmetros, 25

interpolação de pontos, 42

L-System, veja sistema de Lindermayer

modelo fisiológico, 7

normalização, 29

parâmetros, 29

ramificação, 7

rede vascular sintética, 6

relação de tokens, 51

ressonância magnética, 6

simulação de anomalias, 27

sistema de Lindenmayer, 9

tokens, 51

tomografia computadorizada, 5

tortuosidade, 44

variáveis iniciais, 14 